\title{
MONTANA PALLADIUM RESEARCH INITIATIVE
}

\section{Final Technical Report}

John W. Peters (Principle Investigator)

TASK 1 - PALLADIUM MEMBRANE DEVELOPMENT FOR GAS PURIFICATION Jay McCloskey (Lead Investigator)

TASK 2 - COMPOSITE HYDROGEN-PRODUCING MATERIALS John W. Peters (Lead Investigator) - Trevor Douglas and Mark Young (Co Investigators)

TASK 3 - CHARACTERIZATIOJ OF PLATINUM-GROUP ELEMENT NANOPARTICALS USING LASER-INDUCED BREAKDOWN SPECTROSCOPY David McGinnis (Lead Investigator) - Stuart Snyder (Co Investigator)

TASK 4 - PROTON EXCHANGE MEMBRANE FUEL CELL FIELD TRIALS David McGinnis (Lead Investigator) - Brian Gurney (Co Investigator)

DOE Project Manager-Jim Alkire, (303) 275-4795, Fax (303) 275-4753, James.Alkire@go.doe.gov

DOE HQ Technology Manager: Roxanne Garland (202) 586-7260 Rxoanne.Garland@ee.doe.gov

DOE Field Project Officer: Katie Randolph (303) 275-4901 katie.randolph@go.doe.gov

Contract Number: DE-FC36-06G086060

Start Date: Aug 1, 2006

End Date: June 1, 2010 


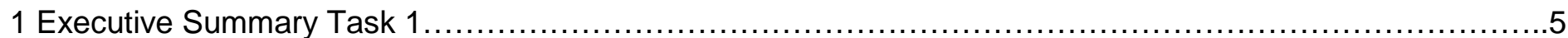

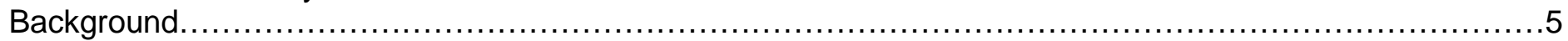

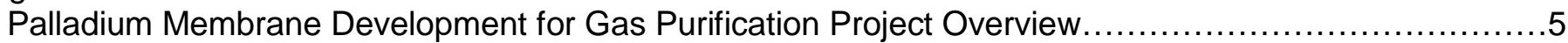

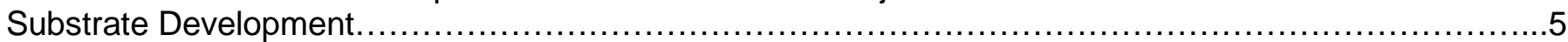

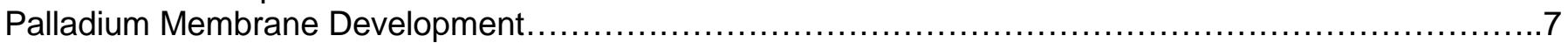

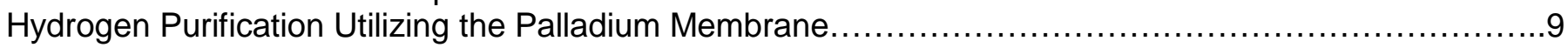

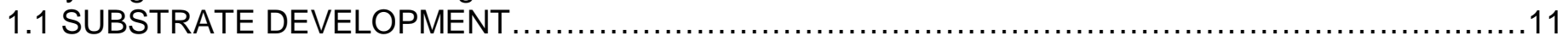

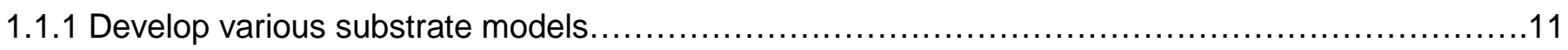

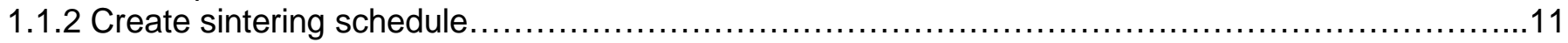

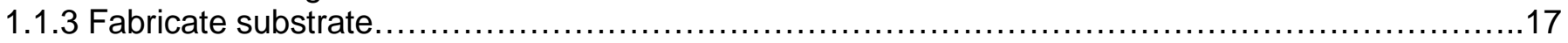

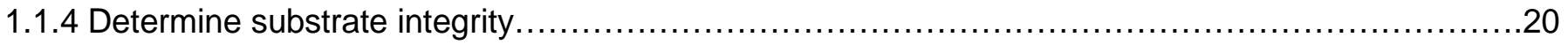

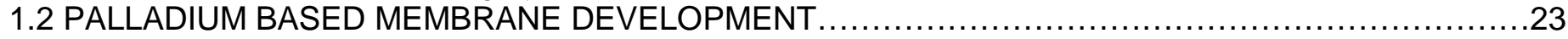

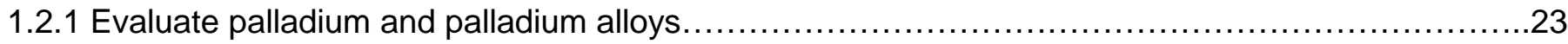

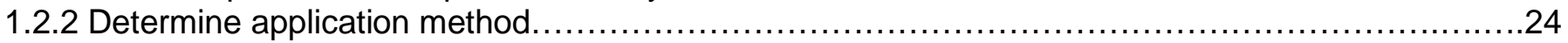

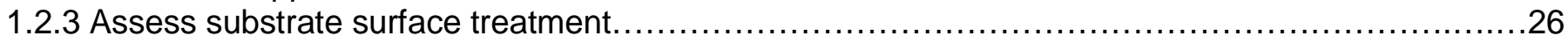

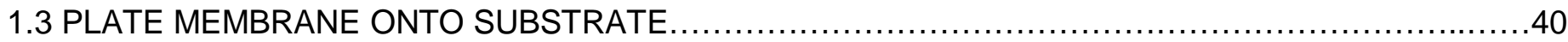

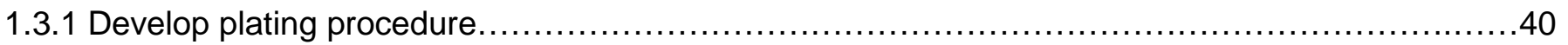

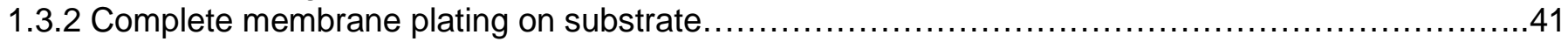

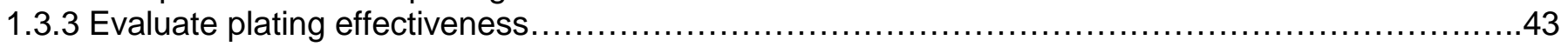

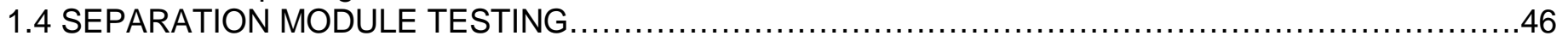

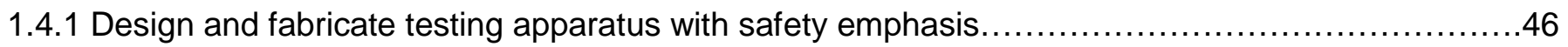

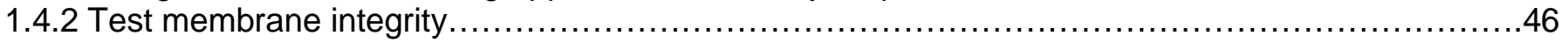

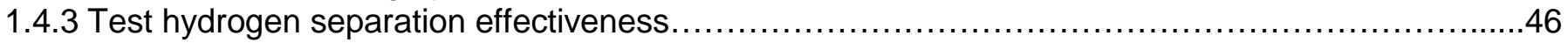

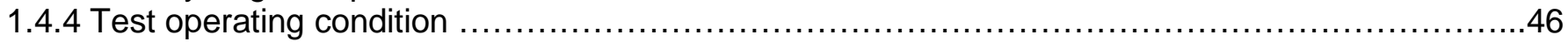

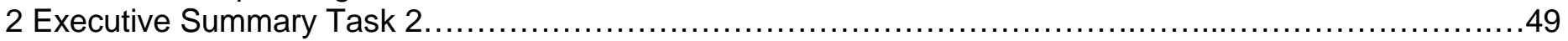

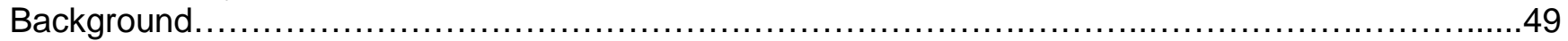

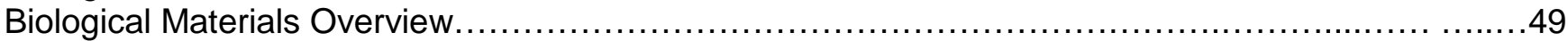

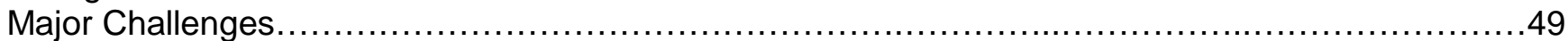

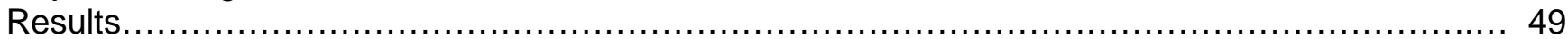

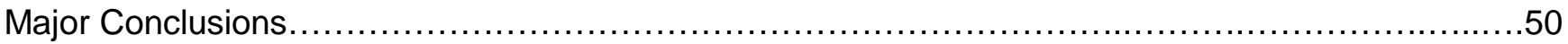

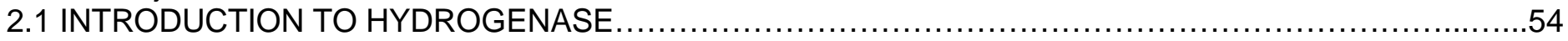

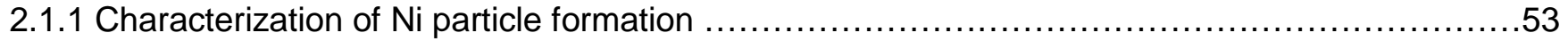

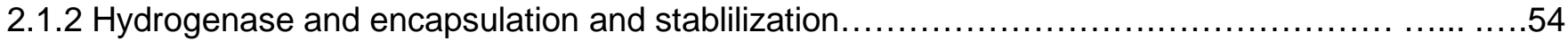

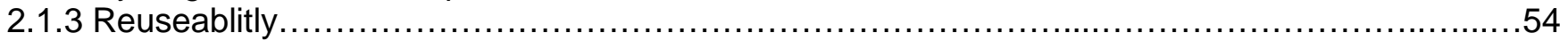

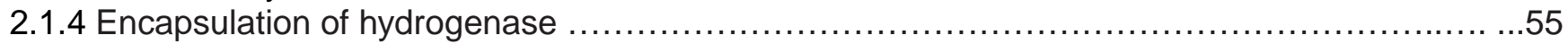

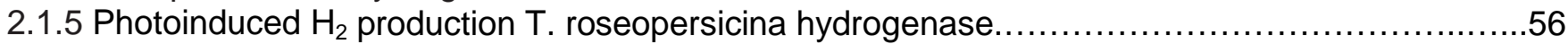

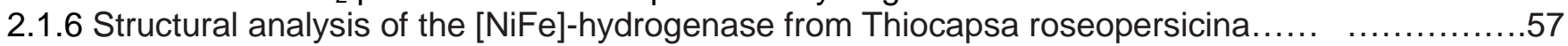

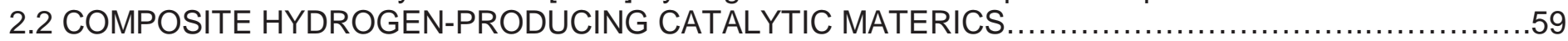

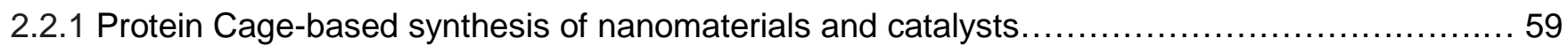

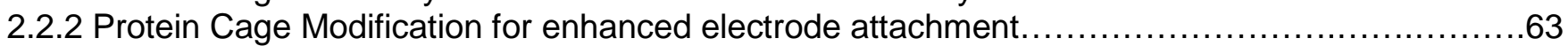

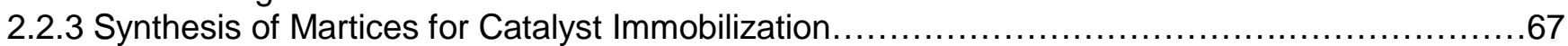

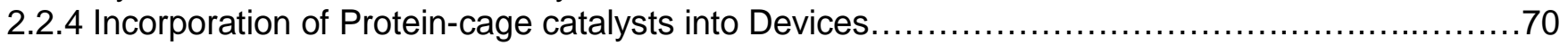

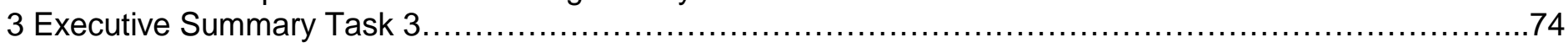

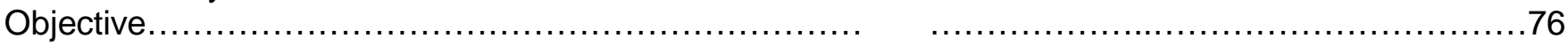

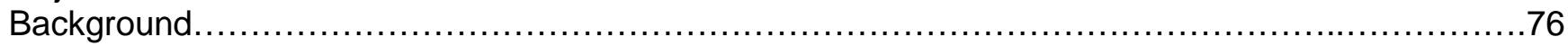

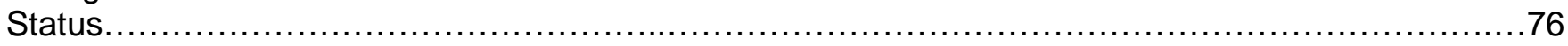

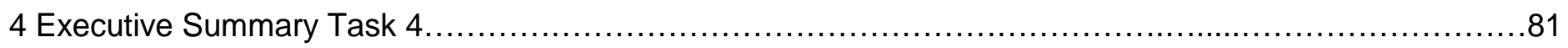

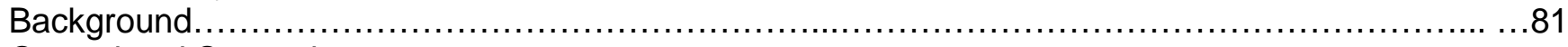

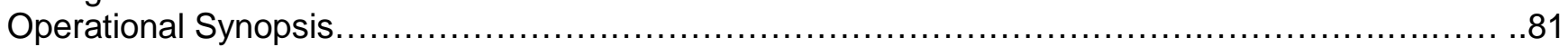

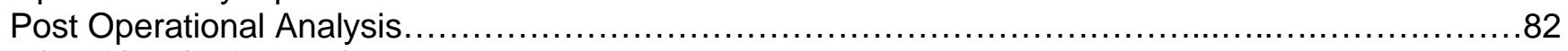

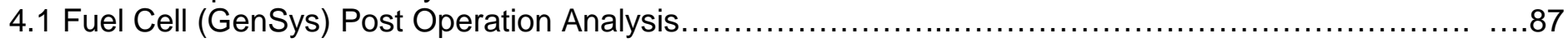

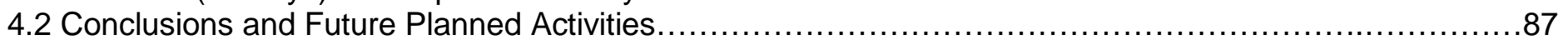

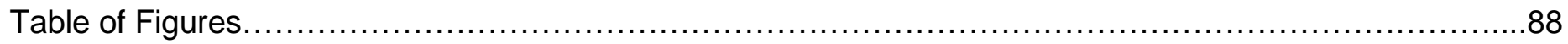

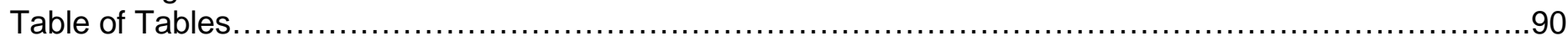




\section{DE-FC36-06G086060}

\section{MPRI OVERVIEW}

Project Objective: The overarching objective of the Montana Palladium Research Initiative ("Initiative") is to perform scientific research on the properties and uses of palladium in the context of the U.S. Department of Energy's Hydrogen, Fuel Cells and Infrastructure Technologies Program. The purpose of the research will be to explore possible palladium as an alternative to platinum in hydrogen-economy applications. To achieve this objective, the Initiative's activities will focus on several cutting-edge research approaches across a range of disciplines, including metallurgy, biomimetics, instrumentation development, and systems analysis.

Background: Platinum-group elements (PGEs) play significant roles in processing hydrogen, an element that shows high potential to address this need in the U.S. and the world for inexpensive, reliable, clean energy. Platinum, however, is a very expensive component of current and planned systems, so less-expensive alternatives that have similar physical properties are being sought. To this end, several tasks have been defined under the rubric of the Montana Palladium Research Iniative. This broad swath of activities will allow progress on several fronts. The membrane-related activities of Task 1 employs state-of-the-art and leading-edge technologies to develop new, ceramic-substrate metallic membranes for the production of high-purity hydrogen, and develop techniques for the production of thin, defect-free platinum group element catalytic membranes for energy production and pollution control. The biomimetic work in Task 2 explores the use of substrate-attached hydrogen-producing enzymes and the encapsulation of palladium in virion-based protein coats to determine their utility for distributed hydrogen production. Task 3 work involves developing laser-induced breakdown spectroscopy (LIBS) as a real-time, in situ diagnostic technique to characterize PGEs nanoparticles for process monitoring and control. The systems engineering work in task 4 will determine how fuel cells-taken as systems-behave over periods of time that should show how their reformers and other subsystems deteriorate with time. 
TASK 1

Project Title: PALLADIUM MEMBRANE DEVELOPMENT FOR GAS PURIFICATION

Project Period: August 1, 2006-June 1, 2010

Prime Award Number: DE-FC36-06G086060

Subaward Number: G211-07-W1477

CFDA Number: 81.087

Recipient: Montana Tech of the University of Montana

The Center for Advanced Mineral and Metallurgical Processing (CAMP)

Jay McCloskey (Project Director \& Primary Contact)

Montana Tech/CAMP

1300 West Park Street

Butte, Montana 59701

Phone: (406) 496-4875, Fax: (406) 496-4512

imccloskey@mtech.edu

Dr. William Gleason (Co-Investigator, Technical Manager)

Dr. Larry Twidwell (Co-Investigator, Technical Support)

Joe Figueira, Carleen Cassidy, Corby Anderson, John Krstulich, Stacy Davis, Ryan Christianson, Tyler Salisbury, Steve McGrath

Awarding Agency: U.S. Department of Energy

Arlene Anderson (Development Manager)

Phone: (202) 586-3818, Fax: (202) 586-9811

Arlene.Anderson@ee.doe.gov

Jim Alkire (DOE Project Officer)

Phone: (303) 275-4795, Fax: (303) 275-4753

James.Alkire@go.doe.gov

Prime Award: Montana State University

John Peters (Principal Investigator)

MSU-Chemistry

P.O. Box 173400

Bozeman, MT 59717

Phone: (406) 994-7211, Fax: (406) 994-7951

John.peters@chemistry.montana.edu

Teri Thayer, Barbara Bunge, Sandy Sward 


\section{Palladium Membrane Development for Gas Purification}

\section{Executive Summary}

\section{Background}

Because hydrogen is uniquely soluble in bulk palladium and will readily pass through metal where other gases will not, a structurally-sound palladium-based membrane can be used to separate pure hydrogen from other gases. However, the excessive cost and difficulty in dealing with high purity hydrogen in compressed gas form has led to considerable interest in purifying an in-process hydrogen stream from conventional reformers.

Currently, a number of different purification methods for hydrogen are in use to produce hydrogen with purity in the range of 99.999 mol\%. Methods include pressure swing adsorption, polymer membrane permeation, liquid absorption, and cryogenic systems. Higher purity hydrogen in the range 99.9999 or greater mol\% is typically created by using palladium alloy membranes on porous stainless steel tubes. Here, most of the membranes are porous stainless steel tube-in-tube assemblies with the palladium being deposited on the substrate by means of chemical vapor deposition, electroless plating, sputtering deposition, or by spray pyrolysis.

In most of these systems, the thinner the membrane, the greater the hydrogen flux across the membrane and the smaller the area required for the purification unit; however, the membrane must also be sufficiently robust to withstand mechanical, chemical, and material degradation due to differences in thermal expansion, á- $\beta$ phase transitions, and in hydrogen embrittlement.

Palladium Membrane Development for Gas Purification Project Overview

Over the past three years, the Department of Energy (DOE) has funded palladium membrane research for the purification of hydrogen through the Palladium Membrane Development for Gas Purification Program. The Center for Advanced Mineral and Metallurgical Processing (CAMP) is located on the campus of Montana Tech of the University of Montana (Tech) in Butte, Montana. CAMP was tasked under the Montana Palladium Research Initiative - Palladium-Based Membrane on a Porous Stainless Steel Substrate with investigating an innovative palladium membrane concept on a porous stainless steel substrate. Improving the palladium membrane is dependent on the means of deposition, and the underlying substrate itself is produced in a novel way that greatly improves its abilities.

\section{Substrate Development}

An exhaustive effort was carried out to develop a viable substrate along with standard operating procedures (SOP) which would satisfy safety and repeatability of parts. The resulting substrate is manufactured onsite by using the ProMetal/ExOne rapid prototyping machine referred to as the ProMetal R2 3D printer. The substrate is composed of 20-70 micron 316 or 420 stainless steel powders that use the ExOne binder JP05-3 1B with an additive of ammonium molybdate. Conventionally used in the 
sand-casting industry, the ProMetal R2 printer had to be redesigned to meet the project needs. The substrates are designed by using 3-dimensional CAD programs which are then printed layer-bylayer to allow production of substrates custommade for discreet processes. Based on the binder and the work completed by the ExOne Company, a recommended debinding and presintering profile was

De-binding and Sintering Profile for SS Substrate

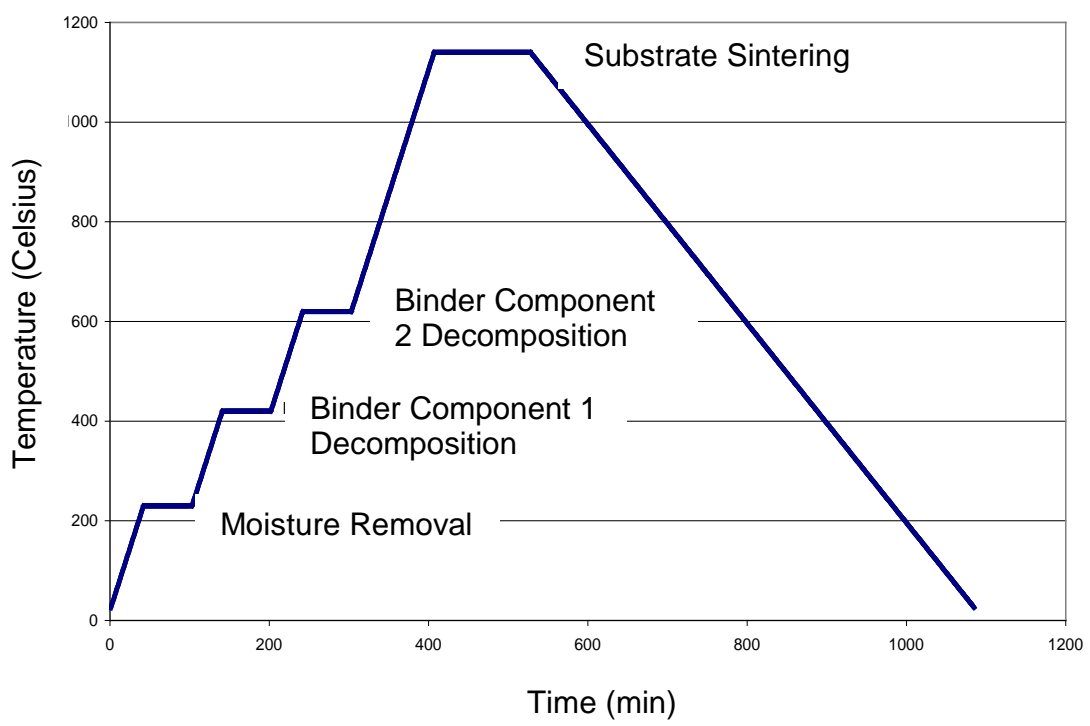

Figure 1. De-binding and sintering profile developed. A sintering regimen was designed to maximize the substrate porosity but still provide acceptable strength, because the product being designed will benefit from porosity more than from strength. Sintering allows mechanical properties and porosity to be manipulated to match the requirements of the discreet designs. The sintering profile developed is shown in the Figure 1. This profile is now used for substrate development.

Initial analysis was relatively simple and consisted of compression tests to determine load to failure. The compressive strengths for the partial sintering profile shown above are presented in Table I. Although the density change is minimal here and reflects the partial sintering regimen,

\begin{tabular}{|l|l|l|}
\hline & $\begin{array}{l}\text { Density } \\
\text { (g/cm2) }\end{array}$ & $\begin{array}{l}\text { Compression } \\
\text { Stress }\end{array}$ \\
\hline Cast & NA & 465 \\
\hline Cured & 3.97 & 493 \\
\hline Sintered & 4.12 & 22055 \\
\hline
\end{tabular}

Table 1. Preliminary strength measurements for cube the increase in strength is substantial.

Further tests were done on titanium substrates to evaluate methods applicable to the product. One of the concerns with this type of fabrication is whether the fabricated piece will exhibit preferred mechanical properties that depend on the orientation of the print layers. To determine if this occurs, a number of CAD drawings were produced of the same square bar stock printed in various orientations. Bars were produced with the layers printed at $45^{\circ}$ in the $X-Y$ plane and $45^{\circ}$ in the Z-axis. Additional bars were produced with the layers parallel to the long axis of the bar (horizontal orientation) and with the layers parallel to the short axis of the bar (vertical orientation). 
Eight tests were performed on four sintered titanium specimens, all of which were sintered at $1127^{\circ} \mathrm{C}$ in the retort furnace. Each specimen was tested with the printed layers parallel to the testing surface (horizontal orientation), and then they were tested with these layers perpendicular to the testing surface (vertical orientation). Table 2 below summarizes the test results.

\begin{tabular}{|c|c|c|c|c|c|c|c|c|c|}
\hline $\begin{array}{c}\text { Specimen } \\
\text { Descriptio } \\
\mathrm{n}\end{array}$ & \begin{tabular}{|c|}
$\begin{array}{c}\text { Length } \\
\text { (in) }\end{array}$ \\
\end{tabular} & $\begin{array}{l}\text { Width } \\
\text { (in) }\end{array}$ & $\begin{array}{l}\text { Thickne } \\
\text { ss (in) }\end{array}$ & $\begin{array}{l}\text { Mass } \\
\text { (g) }\end{array}$ & \begin{tabular}{|c|} 
Measured \\
Flexural \\
$(\mathrm{kHz})$ \\
\end{tabular} & $\begin{array}{c}\text { Young's } \\
\text { Modulus } \\
\text { (GPa) }\end{array}$ & \begin{tabular}{|c|}
$\begin{array}{c}\text { Poisson' } \\
\text { s Ratio }\end{array}$ \\
\end{tabular} & $\begin{array}{c}\text { Poisson's } \\
\text { Ratio } \\
\text { Required } \\
\end{array}$ & $\begin{array}{c}\text { Layer } \\
\text { Orientation }\end{array}$ \\
\hline Ti \# 20p & 1.187 & 0.241 & 0.228 & 3.37 & 33.857 & 106.20 & 0.340 & & Parallel \\
\hline Ti \# 20p & 187 & 0.228 & 0.241 & 3.37 & 33.860 & 97.10 & 0.340 & 0.812 & $\begin{array}{l}\text { Perpendicula } \\
\text { r }\end{array}$ \\
\hline $\mathrm{Ti} \#$ 22p & 1.169 & 0.236 & 0.230 & 3.29 & 35.177 & 107.30 & 0.340 & & Parallel \\
\hline & 669 & 0.230 & 0.236 & 3.29 & 35.200 & 103.20 & 0.340 & 0.590 & $\begin{array}{l}\text { Perpendicula } \\
\mathrm{r}\end{array}$ \\
\hline $\mathrm{Ti} \# 21 \mathrm{p}$ & 1.185 & 0.239 & 0.230 & 3.21 & 32.823 & 93.24 & 0.340 & & Parallel \\
\hline Ti \# 21p & L85 & 0.230 & 0.239 & 3.21 & 32.934 & 88.32 & 0.340 & 0.665 & $\begin{array}{l}\text { Perpendicula } \\
r\end{array}$ \\
\hline Ti \# 23p & 1.188 & 0.237 & 0.231 & 3.29 & 32.644 & 95.41 & 0.340 & & Parallel \\
\hline Ti \# 23p & 1.188 & 0.231 & 0.237 & 3.29 & 32.707 & 91.63 & 0.340 & 0.601 & $\begin{array}{l}\text { Perpendi } \\
\mathrm{r}\end{array}$ \\
\hline
\end{tabular}

Table 2. Influence of layer orientation of Young's modulus

Because this analysis was strictly qualitative, the value used for Poisson's ratio (which was required to calculate Young's modulus) was held constant at 0.340 for all tests. Please note that the elastic moduli are smaller than that for solid titanium (110 GPa) as a result of residual porosity. All equations which were used accounted for the specimen's dimensions but not for the layer orientation; therefore, any changes seen in Young's modulus would be due to layer orientation. As can be seen, each specimen exhibited similar differences. However, the column labeled "Poisson's Ratio Required" gives what the Poisson's ratio of the perpendicular layer orientation measurement needs to be in order to make the Young's modulus of that measurement the same as that of the measurements taken with parallel layer orientation. As seen, the value is unreasonably large for all specimens.

The examination thus shows that layer orientation does influence the elastic modulus properties of titanium parts. It is further assumed that all metal parts will exhibit the same properties.

\section{Palladium Membrane Development}

Palladium membrane/coating was developed by using a known process called electroless plating. This method-when combined with the surface area and porosity control inherent in the substrate manufacturing technique-allows for an optimized system specifically targeted to purifying hydrogen. Important variables for forming a stable, coherent palladium membrane on the stainless steel substrate were also identified. These variables included: particle size of the oxide infiltrant, sensitization/activation solution phase concentrations and time of exposure, and 
solution palladium concentration and time of reduction. The four principal parts for applying the palladium membrane coating to the stainless steel substrate are: infiltration with oxide particles; tin sensitization of the substrate; palladium activation of the substrate; and the palladium reduction reaction.

Project efforts were focused on reducing the membrane thickness on the stainless steel substrate both to improve hydrogen permeability rate and to decrease the cost, given the cost of palladium. Most of the reductions make use of palladium in the chloride form, and that method was chosen for the initial work with the following deposition reaction:

$$
2 \mathrm{Pd}\left(\mathrm{NH}_{3}\right)_{4}{ }^{2+}+\mathrm{N}_{2} \mathrm{H}_{4}+4 \mathrm{OH}^{-} \rightarrow 2 \mathrm{Pd}^{0}+8 \mathrm{NH}_{3}+\mathrm{N}_{2}+4 \mathrm{H}_{2} \mathrm{O} \text {. }
$$

The Chemistry Department at the University of Montana is also performing support work to investigate different electroless plating techniques. In particular, this work on polymer reactions and silica gels suggests that palladium acetate is an excellent candidate for the reaction, having given stable deposits in other work. A general reaction scheme of the palladium reduction and deposition using the acetate form is shown below:

$$
\begin{gathered}
\mathrm{Pd}(\mathrm{OAC})_{2} \rightarrow 2 \mathrm{Pd}^{2+}+\mathrm{N}_{2} \mathrm{H}_{4}+4 \mathrm{OH}^{-1} \rightarrow \\
2 \mathrm{Pd}^{0}+\mathrm{N}_{2}+4 \mathrm{H}_{2} \mathrm{O}+8 \mathrm{NH}_{3} .
\end{gathered}
$$

Other palladium compounds were also identified, such as $\mathrm{K}_{2} \mathrm{PdCl}_{4}$ and $\mathrm{Pd}\left(\mathrm{NH}_{3}\right)_{4} \mathrm{Cl}_{2}$. Investigations into different reducing agents such as $\mathrm{H}_{3} \mathrm{PO}_{2}$ and $\mathrm{NaH}_{2} \mathrm{PO}_{2}$ compared to hydrazine were investigated, as was the use of moderators such as $\mathrm{NH}_{4} \mathrm{OH}, \mathrm{NaOH}$, EDTA, and PVA to modify both the viscosity and the $\mathrm{pH}$ of the plating solution to improve the quality of the layer.

A series of scoping tests were conducted to provide background data so that important variables could be identified and a detailed optimization study planned and conducted.

The results of the baseline test reduced palladium onto the substrate without infiltrating an oxide, sensitizing the surface, or activating the stainless steel particle surface is provided in photomicrographs of the substrate shown in Figure 2. This figures shows that the palladium is not bonding to the surface.

Figure 3 is a photomicrograph of a fully treated stainless steel substrate. This

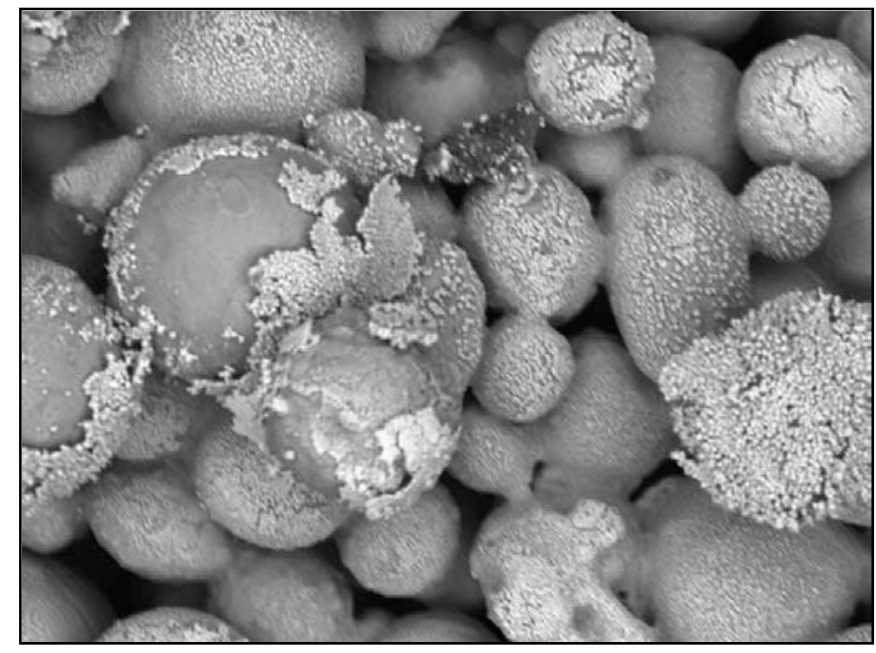

Figure 2. Baseline only-Pd reduction - surface view

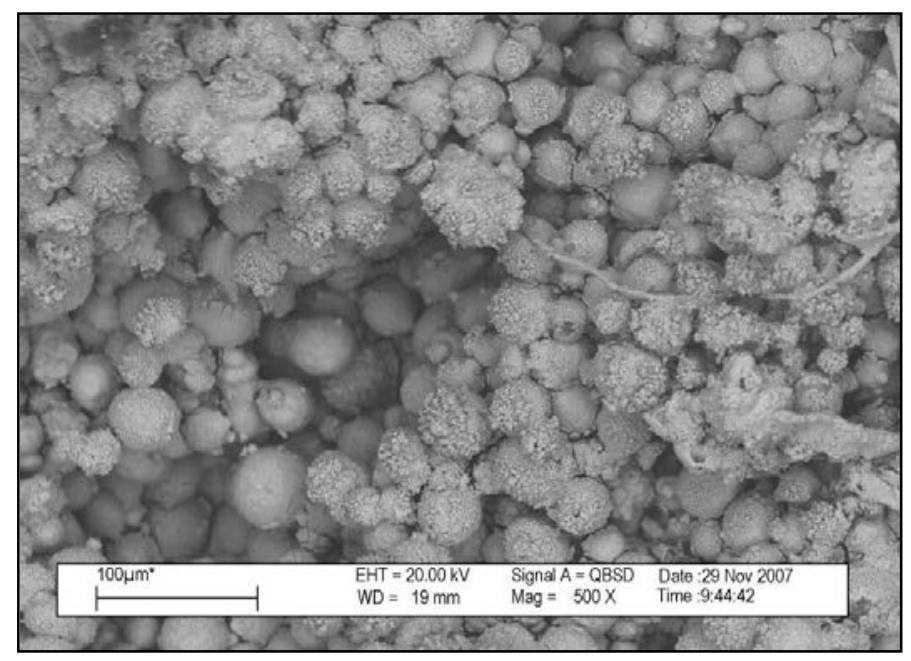

Figure 3. Photomicrograph of the baseline infiltration/sensitization/activation/Pd reduction 
included infiltration done with a 0.1 micrometer zirconium dioxide $\left(\mathrm{ZrO}_{2}\right)$ particulate slurry, the stainless steel particulate was sensitized and activated, and finally palladium was reduced into the substrate. Palladium reduction occurred over a 1.25-hour period. Figure 4 shows the SEM/EDX spectra of this baseline test, again indicating palladium reduction occurs on the surface. In this case, the contributory peaks from the stainless steel substrate are suppressed almost completely, indicating a uniform, coherent layer over the scan area and by extension the entire surface.

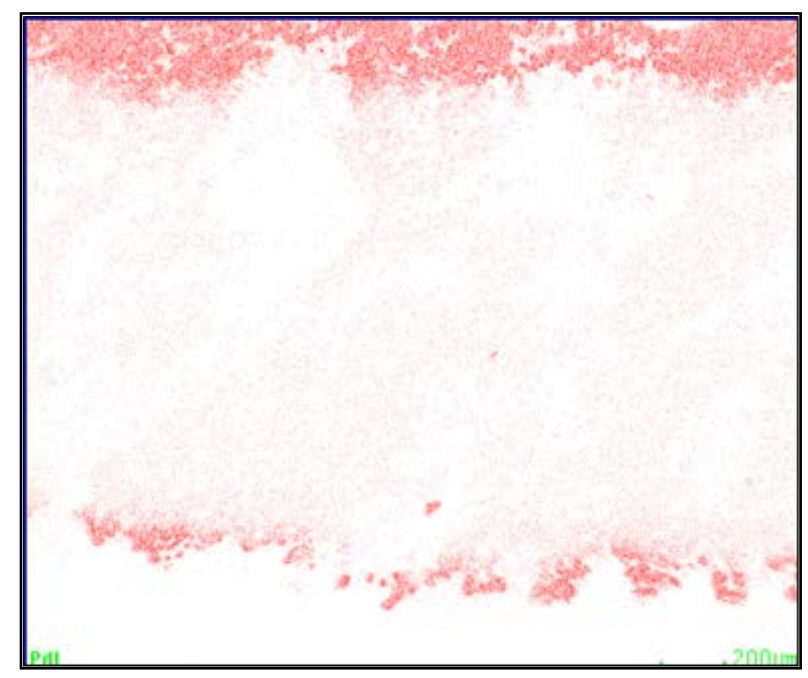

Fiqure 5. Palladium coating on substrate

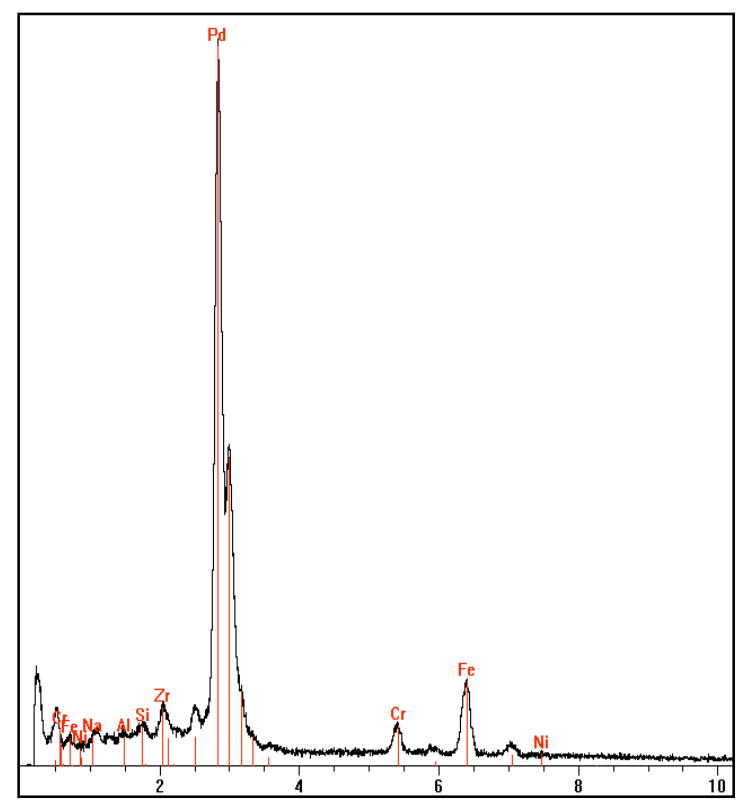

Figure 4. SEM/EDX spectra of the baseline infiltration/sensitization/activation/Pd reduction

Figure 5 is an $x$-ray digital map of the palladium on the fractured surface of the infiltration/sensitization/activation/reduction baseline. This image shows the viable $\mathrm{Pd}$ profile on the exposed surface utilizing various process parameters. Note also the different thicknesses and layer coherence on both the top and the bottom. The substrates were immersed in stirred bath with the direction of stirring from top to bottom.

Hydrogen Purification Utilizing the Palladium Membrane

Hydrogen purification was achieved utilizing a fully treated stainless steel substrate. Figure 6 shows the proof-of-concept test bed for the preliminary work completed. The palladium coated stainless steel substrate measuring $3 / 8$ inch diameter by $1 / 4$ inch thick was mounted and sealed within the brass fitting as a reactor. This assembly can also be mounted in the stainless steel pipe and suspended within a tube furnace for elevated temperature experiments. Mixed gas was used in this stage, being fed into the reactor under controlled pressures. The exiting gas is fed through the coils suspended in a water bath to cool the mix, and then through the drier tube. Analysis of the purified gas was done with an Agilent four-channel gas chromatograph.

Three substrates tested and coated as per the current method, one with a final palladium reduction reaction of 15 minutes, one of 30 minutes, and one of 60 minute. 
The gas used was 2 molar \% hydrogen and the balance air. Results of the initial tests are shown in Table 3.

In follow-up tests, the same three substrates were retested with a non-coated substrate. A line purge was included, done for 15 seconds, and then purification begun with the purge maintained until the $\mathrm{GC}$ began to pull the sample. The gas used was 4 molar \% hydrogen and the balance air. Table 4 shows the results of the follow-up testing. Results in both tests are encouraging, showing a definite increase in molar $\%$ hydrogen.

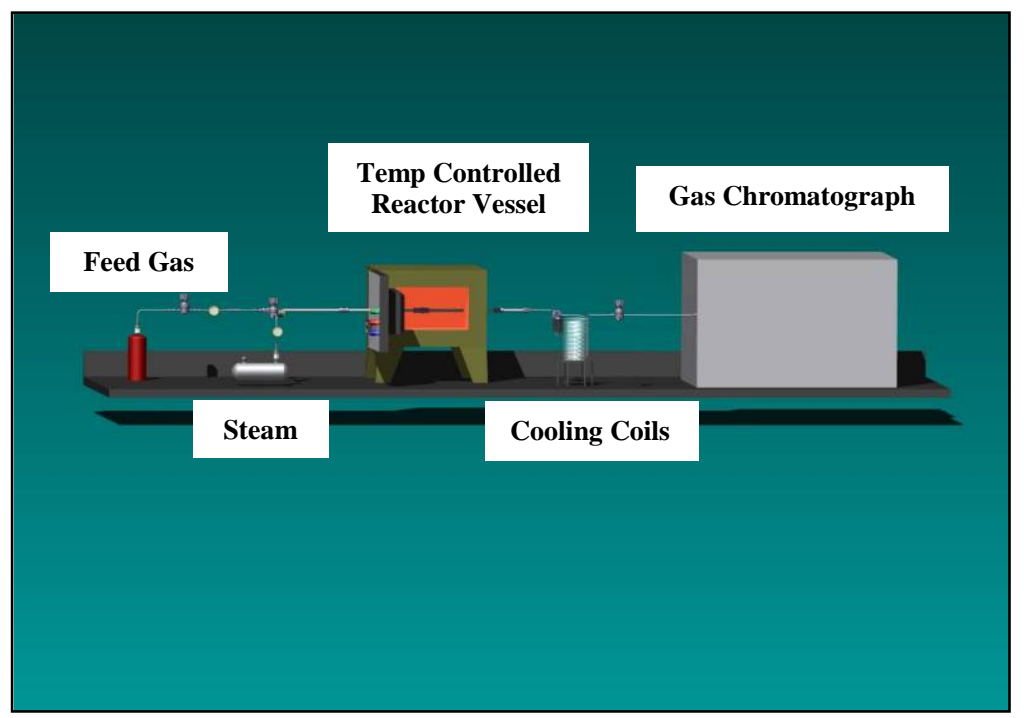

Figure6 . Proof-of-concept test bed for hydrogen production

\begin{tabular}{|l|l|l|l|l|}
\hline $\begin{array}{l}\text { No } \\
\text { Substrate }\end{array}$ & $\begin{array}{l}\text { 15-min } \\
\text { Coating }\end{array}$ & $\begin{array}{l}\text { 30-min } \\
\text { Coating }\end{array}$ & $\begin{array}{l}\mathbf{6 0 - m i n} \\
\text { Coating }\end{array}$ & $\begin{array}{l}\text { \% } \\
\text { Difference } \\
\text { 60-min }\end{array}$ \\
\hline 1.824 & 1.936 & 2.046 & 2.355 & $29.11 \%$ \\
\hline 2.076 & & 1.813 & 3.042 & $46.53 \%$ \\
\hline 1.818 & & & 2.207 & $21.40 \%$ \\
\hline
\end{tabular}

However, one issue did arise

Table 3. Initial hydrogen purification tests (molar \% $\mathrm{H}$ ) that caused concern with powder. Dust can be generated in the chamber beneath the working chamber where the lifting mechanisms for the boxes are located and where the reclamation buckets are located (see Figure 7). Note the small grey piles to the left and

\begin{tabular}{l|l|l|}
\hline No Coating & 60-min Coating & \% Difference \\
\hline 4.041 & 5.483 & $35.68 \%$ \\
\hline 4.076 & 5.673 & $39.18 \%$ \\
\hline 4.036 & 5.628 & $39.44 \%$ \\
\hline
\end{tabular}

Table 4. Follow-up hydrogen purification tests (molar \% $\mathrm{H}$ ) behind the sealed bucket. When either the build box or the feed box moves, powder can be trapped between the moving platform and the sides of the boxes. As the platforms move, this trapped powder then falls to the floor of the lower chamber. Although only a small amount of powder, about a milligram per platform movement range, is thus lost, substantial amounts can build up on the floor of the lower platform if a regular cleaning schedule is not followed. For this reason, caution must be exercised whenever the lower chamber is accessed. The vacuum seal between the boxes and the lifting mechanism must also be regularly maintained to minimize the possibility of dust lost to the lower chamber. During the initial titanium runs using the $\mathrm{R} 2 \mathrm{R}$, this dust was

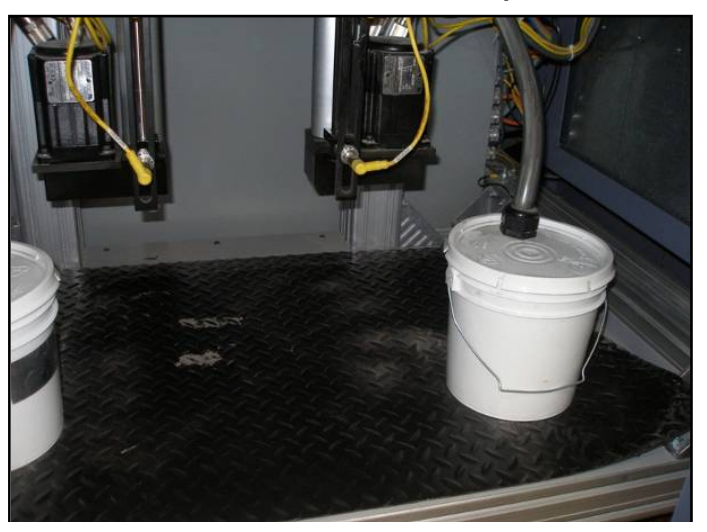

Figure 7. Titanium Dust in Lower Chamber 
evaluated after each production run. During a two hour, seventeen minute run of 147 layers, only 0.3 grams of powder was lost. Given the size of the chamber and the length of time involved, this amount was not considered dangerous.

Once a safe working environment was assured, SOPs were produced in conjunction with ExOne detailing the operation of the R2R. These strict procedures not only dealt with both basic machine operations such as start-up and shut-down sequences but also dealt with upset conditions such as printhead plugging or build-box malfunctions. As a representative example of the complexity of operations, much of the initial work focused on producing a hollow shape with a thin wall, varying diameters, and substantial curvature. Because the printing jobs can take up to thirty hours depending on the number of layers, consistency of operations was paramount. In the initial development work, sustained printing could not be done because the R2R experienced a shut-down failure at around midnight every night, partially due to transient problems in the electrical service. Whenever the R2R pauses for any reason during the cycle and printing is not resumed within the time it takes for the binder set in place, a layer fault occurs. Because the powder beds are heated, the binder tends to spread downward through the shape and assist in maintaining the shape. Any lengthy interruption then creates a dried layer. When printing is resumed, the binder sprayed on the subsequent layers does not fully bind the dried layer.

Figure 8 shows such a fault layer. To overcome this problem, the software had to be altered and procedures set into place to monitor for such failures. Over the course of several months, approximately 50 SOPs were produced.

\subsection{SUBSTRATE DEVELOPMENT}

\subsubsection{Develop various substrate models}

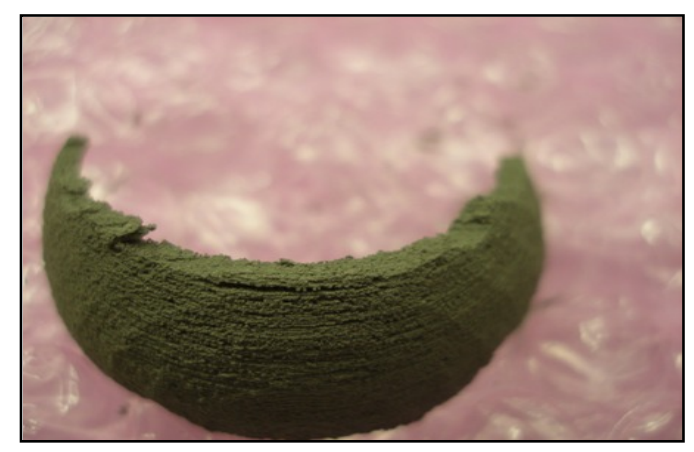

Figure 8. Layer fault due to interrupted printing

A number of substrates were developed in order to meet the various needs of the project. These ranged from simple chips used in the palladium coating tests all the way up to a maximized surface area design suitable for industrial use. Many of the substrates were developed to allow multiple uses so that mechanical testing, chemical testing, image analysis, and sintering could all use the same pieces. Particular designs were also created to allow for specific measurements to be taken, such as the shields used to evaluate distortion.

\subsubsection{Create sintering schedule}

Once sufficient experience had been gained with the methods and equipment, substrate development began. Drawings existed in sufficient number to allow the initial investigations into green strength and sintering. 
Variables were optimized to maximize green strength and included the amount of binder used, droplet size, waveform, powder spreading speed and drying time between binder spray passes, print-head cleaning routine and most importantly, clogging of the printhead. Green strength was evaluated by simply removing the pieces from the R2R and evaluating their cohesiveness during the transfer process. Initially, the printed pieces were removed and cured in an oven, but this approach proved problematical and the parts were then cured in-situ with the build box set on a hot plate and the curing temperature carefully controlled.

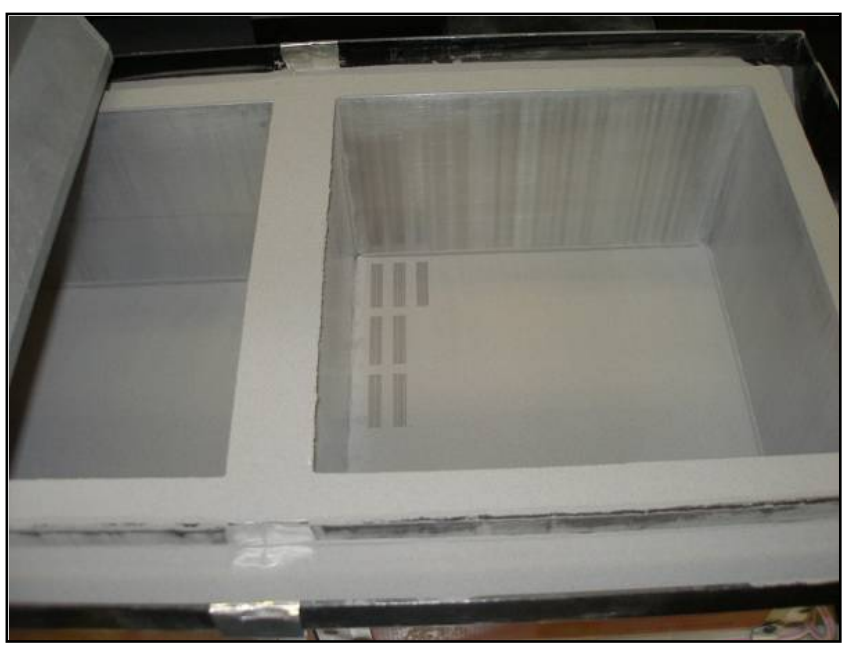

Figure 9. Feed box (left) and build box (right) at the end of a print job Figure 9 shows the two boxes used on the process. To the left, the feed box (shown in its lowest position), and to the right is the build box (shown with seven pieces in the finished print position).

The parts are relatively sturdy if they are solid. However, they become increasingly delicate as thicknesses decrease, complexity increases, or thin walled structures are produced. During the print cycle, the binder is partially cured when infrared heating elements move over each printed layer; but the amount of binder holding the spherical powders together is minimized in order to limit the amount of binder in the product. Figure 10 shows a binder bridge between two particles. Use of a minimized

binder requires careful handling

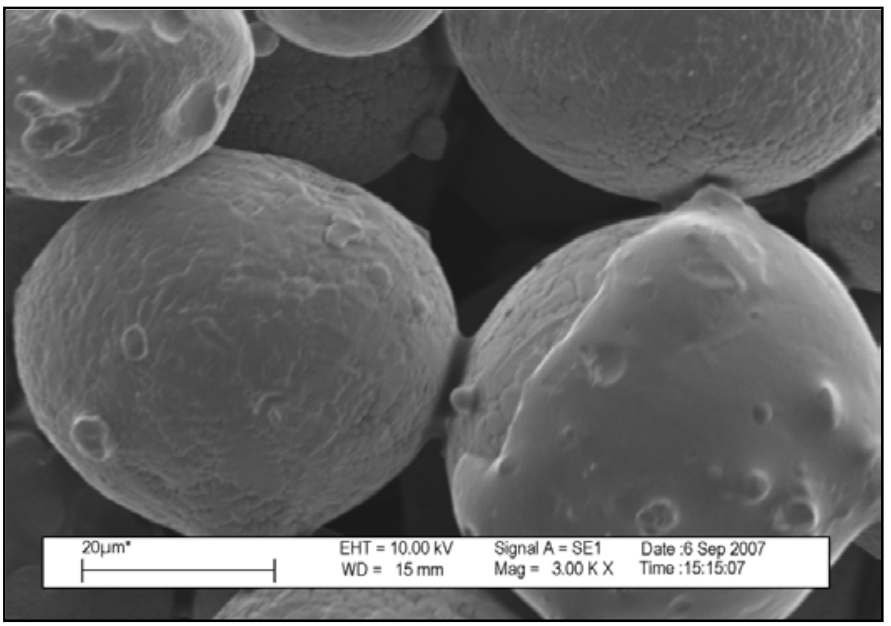

Figure 10. Binder adhesion after curing between the curing and sintering stages.

Once the parts are cured, de-binding and sintering is done. Multiple steps are required here because the binder must be removed and sintering done. The initial work was done by using a recommended profile, which was shown in Figure 1.

This profile was used for all initial work. Sintering profiles were explored to take advantage of the loosely packed powder performs produced by the R2R printing process. The capability to manipulate density by manipulating powder characteristics and sintering allows a great deal of versatility in designing parts. For instance, parts can 
be coated and combined with a porous substrate infiltration can be done to impart particular characteristics to a piece, or mechanical properties can be manipulated according to the degree of sintering employed. Initial work clearly showed that sintering can range from fully sintered pieces to only incidentally sintered pieces. Figure 11 shows a stainless steel powder that has been partially sintered and that thus preserves much of the porous structure of the printed piece.

The sintering plan must also deal with the cleaning and binding fluids used in the printing process. A burnout cycle is required during sintering to remove these constituents. The development work done by Ex-one had demonstrated that the burnout

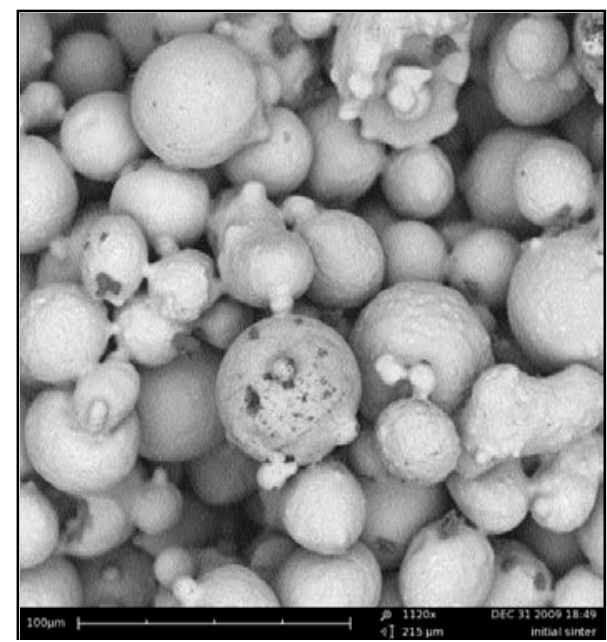

Figure 11. Partially sintered stainless steel powder cycle was going to be problematic. Coincident with the substrate development, titanium sintering trials were performed for a different grant. Here, samples were run through a burnout cycle, and others were run through a complete burnout-sintering cycle to determine the effect of the burnout cycle on pore structure and on the resulting density of the final part.

Two furnaces were used for sintering: a vacuum furnace and an ambient pressure retort furnace. The vacuum furnace is a Centorr series LF furnace, with a tungsten hot zone and is capable of operation to $2000^{\circ} \mathrm{C}$ in high vacuum. The system can also run with process gases, but the temperatures are restricted by the materials involved. The furnace is top loading with a cylindrical hot zone about 3 inches in diameter and 3 inches high.

The sintering profile used in the Centorr vacuum furnace is as shown above, based on the proprietary formulation of the binder. The burnout cycle for the titanium sintering tests followed this basic procedure, under a flow of argon- $5 \%$ hydrogen gas at a flow rate of $2 \mathrm{~L} / \mathrm{min}$, with one exception: once the furnace had soaked at $850^{\circ} \mathrm{C}$ for about 15 min, the operation was switched over to vacuum operation on the roughing pump only. Here, the samples were ramped to $1450^{\circ} \mathrm{C}$ at $10^{\circ} \mathrm{C} / \mathrm{min}$, soaked at $1450^{\circ} \mathrm{C}$ for $90 \mathrm{~min}$, and then given a controlled cooling at $-25^{\circ} \mathrm{C} / \mathrm{min}$ to $650^{\circ} \mathrm{C}$, where the furnace power was turned off. Finally, all sample bars were processed in a bed of zirconia powder.

These bars were then removed and examined microscopically. Bar surfaces showed a bright metallic luster with some light yellow discoloration in some places, and the bar was placed into an x-ray diffractometer in order to determine the surface structure and probable composition. Figure 12 shows a pattern that reveals the presence of titanium metal and a second crystalline phase thought to be a titanium carbo-nitride. From the nitrogen-titanium phase diagram, the solubility of carbon is only $0.15 \%(0.6$ at $\%)$ in $\beta-\mathrm{Ti}$, above which $\mathrm{Ti}_{2} \mathrm{C}$ precipitates. The solubility of nitrogen and oxygen in $\beta-\mathrm{Ti}$ is much higher, about $2 \%$ and $2.5 \%$ respectively. With the precipitation of any carbide, the 
system becomes

very complex because carbon and oxygen can form a series of several possible compounds, depending on the partial pressure of oxygen and hydrogen.

The sintered density of the titanium bars is about $80 \%$ as measured by ASTM B328-96 and shows the versatility of the process in manipulating density. Bar porosity is largely interconnected and Figure 13 shows the microstructure of the piece. There are round precipitates about $5 \mu \mathrm{m}$ in diameter and long precipitates that appear to be along grain boundaries.

It is likely that one or both precipitates are phases that originate in the residue from the burnout cycle. It is known that the binder has an organic constituent. Titanium will start to absorb interstitial elements at temperatures as low as $200^{\circ} \mathrm{C}$.

The sample was further evaluated by SEM, and an image is shown in Figure 14. The globular and grain boundary phases are sulphides and/or phosphides of titanium, which appear at the boundaries because neither sulphur nor phosphorus is soluble in titanium.

Some titanium nitride has also precipitated and appears as an etch step in the center left of the image. The sulphur and phosphorus originate in the binder.

Under reducing conditions, such as

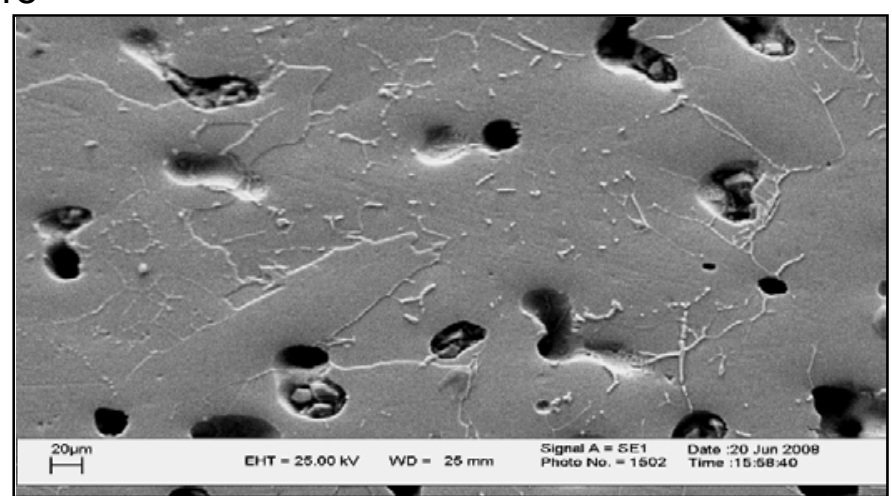

Figure 14. SEM image of titanium bar with sulphidephosphides inclusions

with the sweep gas, it is thought that the sulphur and phosphorus do not form oxides but 
instead form these precipitates. However, it is not known what effect these inclusions would have on the mechanical properties of the material.

This sintering investigation showed that the binder was one potential problem with the manufacturing process. Another potential problem showed up during subsequent sintering tests when substantial discoloring of the pieces appeared, as shown in Figure 15. The bar on the left has been discolored throughout what would be the entire substrate thickness, and the bar on the right is the natural color of the stainless steel powder and represents a successful sintering.

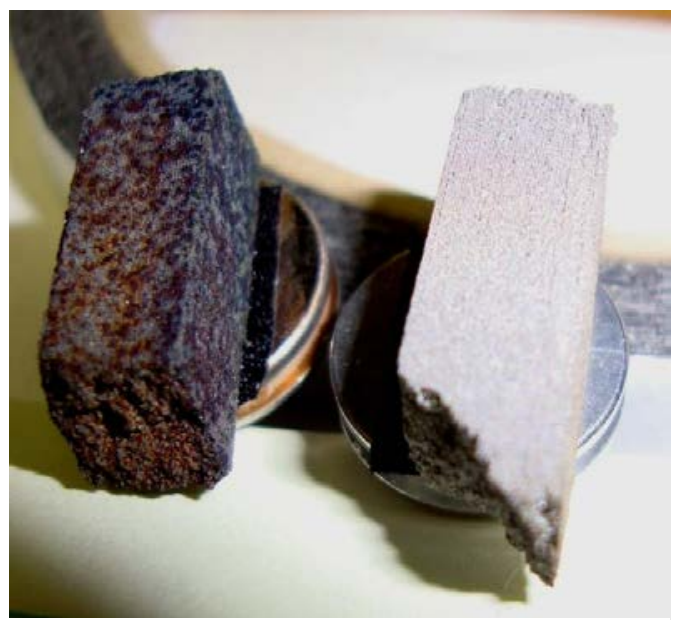

Fiqure 15. Sintering discoloration

Further examination both of the piece and of the process showed that the Argon covering gas was contaminated, probably by trace amounts of water used in the compression cycle for the tanks. Given the small size of the furnaces used for sintering, even trace amounts of gases are unacceptable. Not only was discoloration substantial, but mechanical strength was also severely compromised. Here, the pieces could easily be broken by hand, but the non-contaminated pieces could not be broken without the use of fixturing. Follow-up examination of the piece such as shown in Figure16 revealed only occasional clumps of secondary phases on the spheres. The streaking aspect of the contamination can also be seen in the macroviews. This result clearly indicates that minute contamination can severely compromise the substrate.

Dilatometer testing for the coefficient of thermal expansion also showed substantial differences in the pieces. In particular around $800 \mathrm{C}$, expansion of the oxidized substrate abruptly

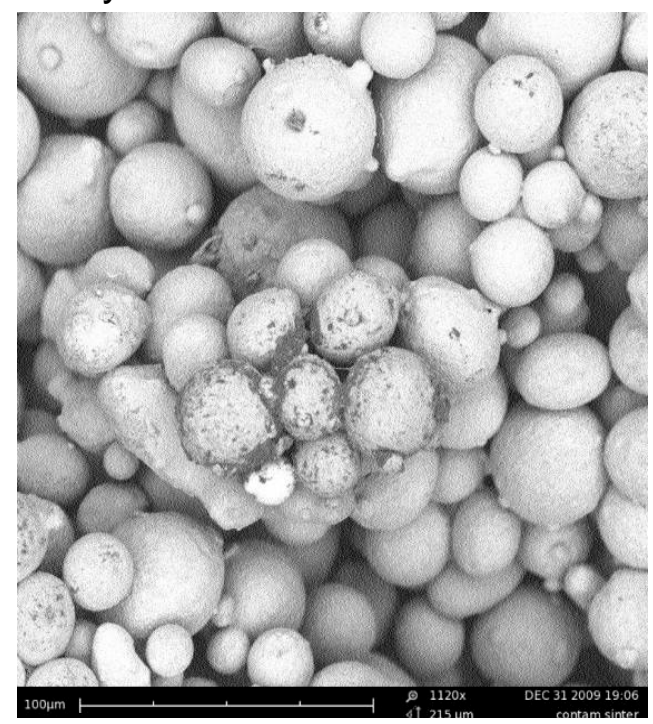

Figure 16. Sintering discoloration close up diminishes, almost ending; but the non-oxidized substrate resumes expansion, as is to be expected for a 420 stainless steel alloy. These results indicate that minute contamination during sintering can severely compromise the substrate.

Following the initial work, several changes were made to accommodate improved knowledge both of the system and of the materials. Re-evaluation and redesign necessitated high-purity argon covering gas and an improved binder. ExOne, the company producing both the R2R Printer and binder, developed the new binder. Followup tests with the new binder resulted in significant problems. Figure 17 shows printed 
test bars using the new binder and cured for different times. A minimum of 6 hours was needed to cure the pieces, and even then only one part in ten was recovered in whole. This finding clearly indicates that careful control of process variables

must be maintained throughout all phases of substrate production if a consistent, reproducible part is to be produced. ExOne personnel recalibrated the R2R specifically for the new binder, and results are now outstanding. The improved binder

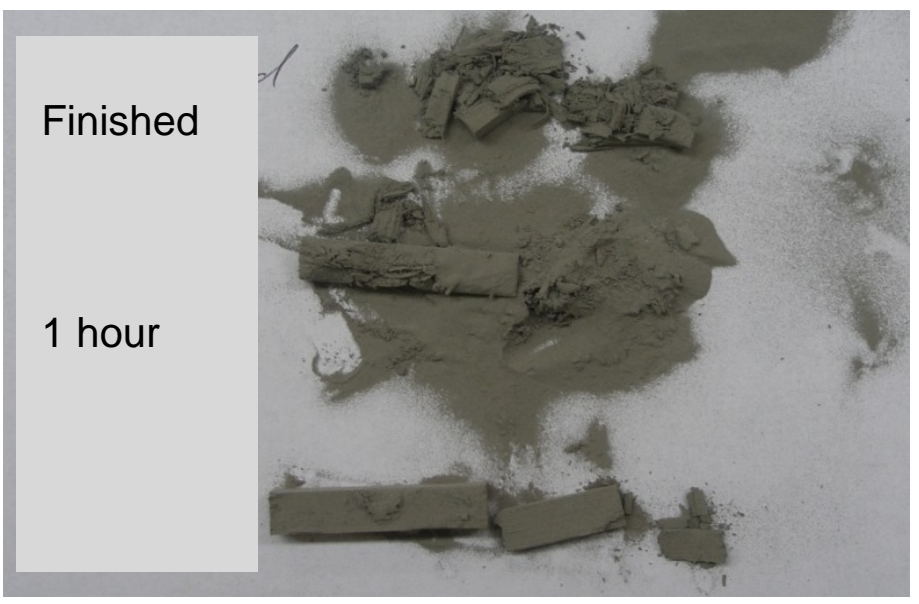

Figure 17. Binder failure coincided with the addition of new equipment that allowed binder evaluation by using thermo-gravimetric analysis over a temperature range of $25-1000^{\circ} \mathrm{C}$, a ramp speed of $20^{\circ} \mathrm{C} /$ minute, and a 5 minute isotherm at $1000^{\circ} \mathrm{C}$ with a Nitrogen purge. The printed and cured pieces were evaluated at curing times with 15 minute intervals. Figure18 (which is a screen shot from the TGA) shows the results for the powder/binder compact, cured for 240 minutes in-situ.

The recommended sintering profile somewhat corresponds with TGA analysis, showing the water loss at $\sim 200^{\circ} \mathrm{C}$, the phase 1 decomposition at $\sim 400^{\circ} \mathrm{C}$, and the phase 2 decomposition at $\sim 600^{\circ} \mathrm{C}$. Phase 1 decomposition is substantially more than the water and phase 2 losses but happens very quickly, as indicated by the steep slope of the weight loss. Phase 2 decomposition
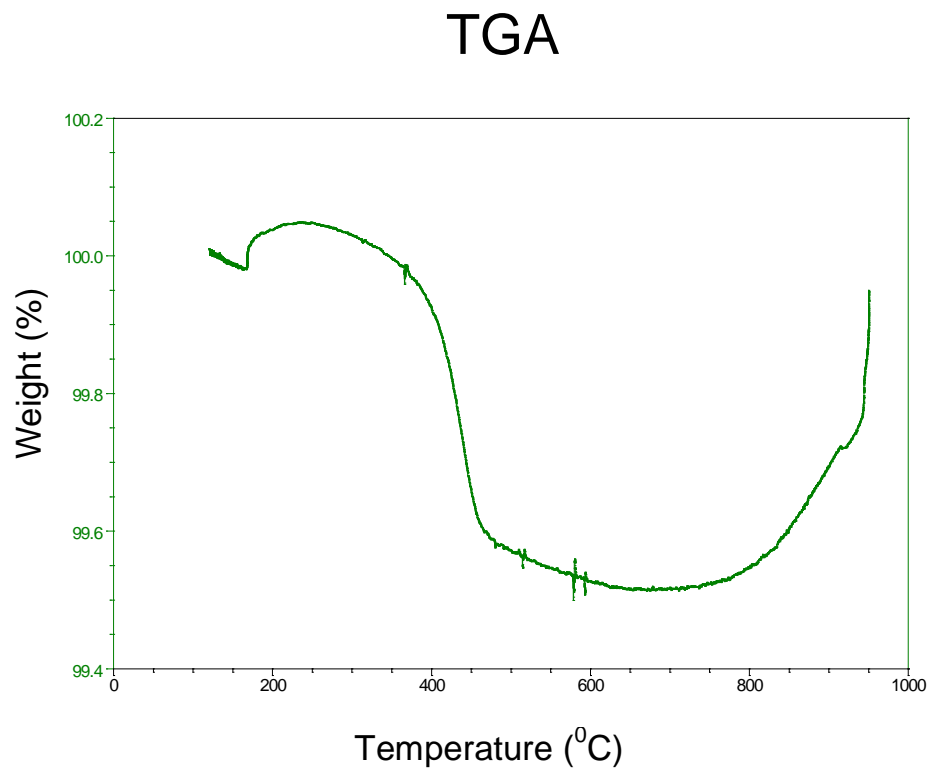

Figure 18. Binder burnout for a 240-minute cure begins at $>450^{\circ} \mathrm{C}$ and runs until $\sim 600^{\circ} \mathrm{C}$, indicating that the time and temperature of phase 2 decomposition requires adjustment to accommodate the broad range over which the second phase (polymer binder) is lost. Unfortunately, the driving force for densification is the reduction of surface area. More accurately, it is the reduction of surface curvature by the diffusion of atoms within the crystal lattice to minimize energy. At lower temperatures, the predominant mechanism is surface diffusion where metal atoms move along the surface of the particles. Although, there is no change in the density, the inter-spherical pores become rounded with the effect of reducing the driving force available for densification during sintering (bridging). Thus, it is important to 
reduce the time at lower temperatures to minimize diffusion prior to sintering, not to increase it in order to more effectively eliminate residual binder. In order to determine the proper balance between these two issues, further sintering must be carried out.

\subsubsection{Fabricate substrate \\ This sintering regimen is designed to maximize porosity and to still provide acceptable strength, because the product being designed will benefit from porosity more than strength. Figure 19 shows, the spheres are joining, in some cases by a substantial percentage of the particle diameter as seen in the two particles in the center of the figure.}

Figure 20 shows a macro-view of the cured and sintered piece along a fracture edge. Notice both the packing structure of the spheres and the clearly evident layer lines.

The initial substrate development runs involved printing a complex part that allowed us to evaluate several aspects of fabrication. These included fineness of detail possible, distortion, dimensional stability, and greenware strength and durability; also included were binder consumption, sintering requirements, and shelf life. Figure 21 shows the test pieces in the build box after printing is complete. In this picture, notice that the build box is near the top of its cycle and that a line is visible in the right hand shields below the letters spelling Montana Tech. This line is the result of one clogged channel in the printhead.

Figure 21. Test shields used to evaluate both the process and the parts 
Figure 22 shows the shields after sintering. To evaluate maximum distortion, titanium was again used; here, the three shields at the top of the picture are sintered at $1450^{\circ} \mathrm{C}$ and the bottom shield is only sintered at $1127^{\circ} \mathrm{C}$. Notice the crisp edges of the partially sintered piece, the detail of the lettering, and the fineness of detail in the lower section.

A CAD drawing of the shield is also included to illustrate the parts development method. Figure 23 shows this drawing, which is then converted to a "sliced"

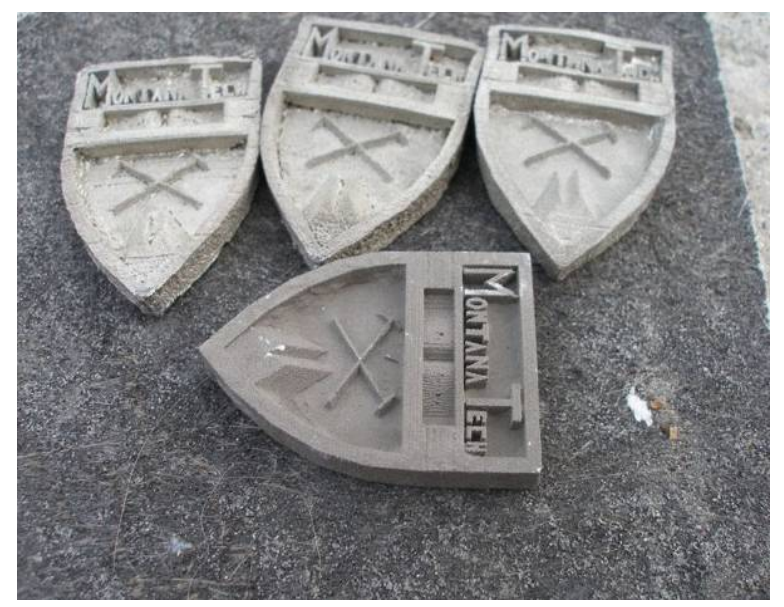

Figure 22. Sintered shields drawing to enable the R2R to print the piece in stacked layers, with each layer bonded to the layer below. Comparisons to this CAD drawing of the partially sintered piece are difficult to accomplish with conventional measuring devices. CAMP is

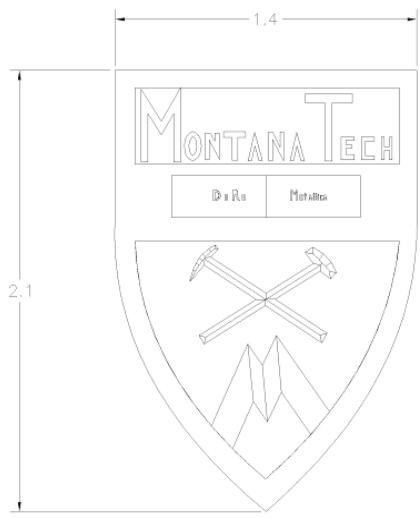

Figure 23. CAD drawing and dimensions of Montana Tech shield

Distortion in this shield represents what is currently our best effort at distortion control of a complex piece and ranges from a few thousandths of an inch to approximately twelve thousandths. This is considered acceptable distortion in that the piece was designed to maximize the potential for distortion, having thick and thin sections, a large strong-back, and thin lettering. currently evaluating a laser scanning device that will allow such comparisons between the intended piece-as indicated by the CAD drawings-and the final piece. A sample of this comparison is shown in Figure 33 with stainless steel being used this time to evaluate substrate distortion control. The colors represent the deviation between the drawing and the sintered piece. Keep in mind this piece is not fully sintered, so that fine detail is possible as in the bottom figure of Figure 24. 
Once proper operating procedures were in place and the process was in control, the initial substrates were produced.

Figure 25 shows the initial design was a bulb, meant to maximize surface area. Notice the multiple images. The R2R can print as many pieces as can fit in the build box. Nine pieces were used in the initial run, not because that is what would fit, but because at 690 layers for a bulb, this represented a 30 hour printing job. This approach allowed evaluation of both multiple-part printing and long-term processing. Figure 26 shows the nine pieces after removal from the build box. Because they are hollow, the bulbs are filled with loose powder that must be removed prior to

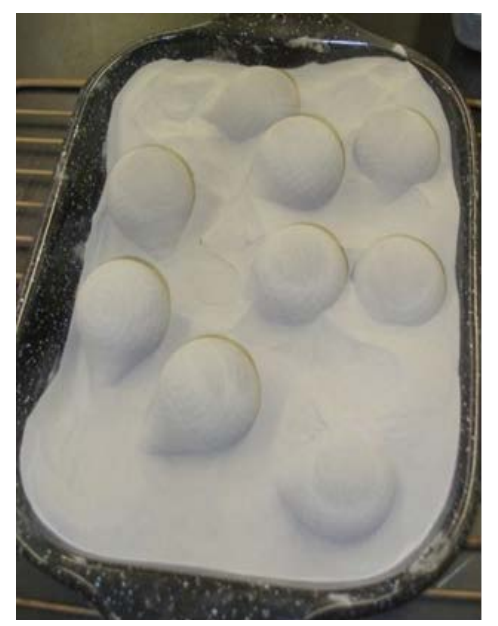

Figure 26. Photograph of nine bulb recovered from print job.

Figure 27 shows a comparison between cured and sintered substrates. Notice the line fault in the left, sintering. Here, wall thickness is such that considerable care must be exercised in sintering preparation. Each bulb is emptied of metal powder, sprayed to remove excess powder, partially refilled with aluminum oxide, packed in a bed of aluminum oxide, and then transferred to the sintering furnace. cured bulb.Size analysis of a cured and sintered bulb was also done and is shown in Figure 28. This analysis shows that on one of the critical areas, the stem diameter, distortion is minimal $(2.7 \%$ on the outer diameter and $3.0 \%$ on the inner diameter). This indicates that sintering stresses induced by shrinkage would be reasonably balanced between the inner surface of hollow substrates and the outer surfaces of the hollow substrates. This issue is critical here, because the substrate design, as with many coated filtering designs, consists of a thin walled, modified tube-in-tube. Substantial residual stress within the structure would greatly shorten the service life of the design. Notice, too, that the distortion of the outer 
curvature is small (in the green range) but that it transitions from an expansion distortion in the lower concave section to a shrinkage distortion in the upper convex section.

Thermal expansion testing of non-sintered constructs was also done to evaluate possible distortion issues. As the powder is heated, it should expand at a constant rate until solid phase sintering starts, and then the expansion rate should decrease. Once liquid phase sintering is reached, the part should start densification and the expansion rate

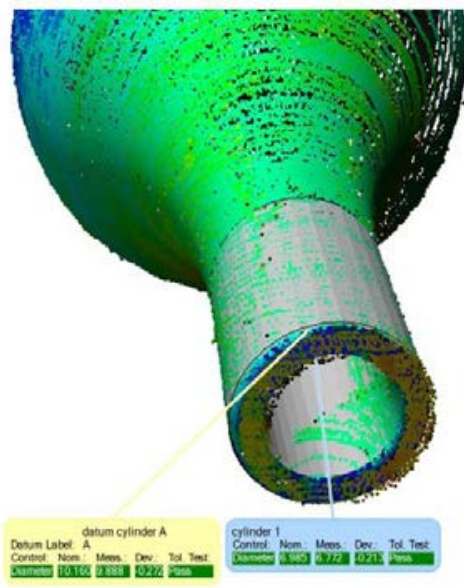

Figure 28. Bulb distortion analysis should decrease significantly. If this does not happen, the testing is stopped completely.

There is transient loss of expansion at $\sim 400^{\circ} \mathrm{C}$, and coinciding with the middle of the mass loss shown in the TGA analysis of Figure 18. These results agree with size analysis done on sintered parts. It appears that expansion is consistent in threedimensions, minimizing the risk of residual stress building in complex pieces.

However, considerable work remains to be done in evaluating thermal expansion of the printed constructs because significantly less thermal expansion occurs. In part, this takes place because packing of the spheres is transitory in raw powder but not so in layered and bound constructs and also because evolved gas is present in bound constructs. But, the presence of binder appears to affect the sintering behavior enough to require additional testing. Several other forms were also produced in order to evaluate the effect of different variables. In all, over one thousand different constructs were printed, with over four hundred sintered.

\subsubsection{Determine substrate integrity}

Substrate integrity is determined by sintering. Distortion analysis showed substrates with minimal distortion can be produced with this method, but they lack corresponding strength and are of limited use. The substrates must be of sufficient strength not only to withstand production methods but also to withstand follow-on fabrication, installation and repair techniques, and operational stress.

Initial analysis was relatively simple, consisting of compression tests to determine load to failure. The compressive strengths for the partial sintering profile shown in Figure 11 (previously) are presented in Table 5. As can be seen, the density change is minimal and reflects the partial sintering regimen, but the increase in strength is substantial.

Further tests were done on titanium

\begin{tabular}{|l|l|l|}
\hline & $\begin{array}{l}\text { Density } \\
\left(\mathbf{g} / \mathbf{c m}^{2} \text { ) }\right.\end{array}$ & $\begin{array}{l}\text { Compression } \\
\text { Strength (psi) }\end{array}$ \\
\hline Cast & NA & 465 \\
\hline Cured & 3.97 & 493 \\
\hline Sintered & 4.12 & 22055 \\
\hline
\end{tabular}

Table 5. Preliminary strength measurements for printed cube 
substrates to evaluate methods applicable to the product. A major concern with this type of fabrication is whether the fabricated piece

will exhibit preferred mechanical properties depending on the orientation of the print layers. To determine if this occurs, a number of CAD drawings were produced of the same square bar stock printed in various orientations.

Figure 29shows an isometric view of the bars sliced $45^{\circ}$ in the $X-Y$ plane and $45^{\circ}$ in the $Z$ axis. Additional bars were produced with the layers parallel to the long axis of the bar (horizontal orientation) and

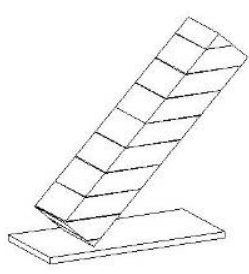

Figure 29. $C A D$ drawing of a $45^{\circ}$ print, showing layer orientation

layers parallel to the short axis of the bar (vertical orientation).

The initial work examined the elastic modulus of the material using an excitation technique outlined in ASTM Standard E 1876-01. The schematic of the equipment is shown in Figure 30. To test the concept, aluminum alloy 2024-T6 was first tested. This approach was taken because the elastic properties of interest (Young's modulus, Poisson's ratio, and the shear modulus) are well known. With these properties and the specimen's mass and dimensions, the calculations found in ASTM E 1876-01 for rectangular bars were solved to determine both the flexural and the torsional frequencies of the first modes of vibration for the bar. Resonant frequencies of the known material were measured, and analysis conducted between the calculated frequencies and the measured frequencies. Modifying the test apparatus and measurement techniques minimized these errors to less than $1 \%$, proving the concept for the preliminary testing.

Eight tests were performed on four sintered titanium specimens, all of which were sintered at $1127^{\circ} \mathrm{C}$ in the retort furnace. Each specimen was tested with the printed layers parallel to the testing surface (horizontal orientation) and then tested with these layers perpendicular to the testing surface (vertical orientation). Table 6 below summarizes the test results.

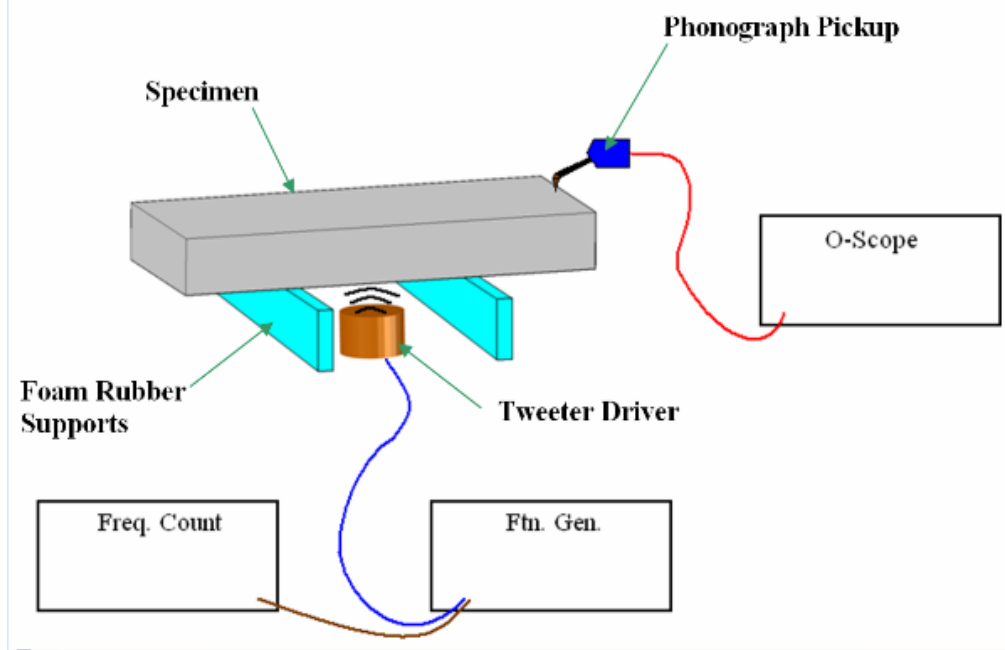

Figure 30. Concept test setup for measuring flexural frequency of specimen 


\begin{tabular}{|c|c|c|c|c|c|c|c|c|c|}
\hline $\begin{array}{l}\text { Specimen } \\
\text { Description }\end{array}$ & $\begin{array}{l}\text { Length } \\
\text { (in) }\end{array}$ & $\begin{array}{l}\text { Width } \\
\text { (in) }\end{array}$ & $\begin{array}{l}\text { Thickness } \\
\text { (in) }\end{array}$ & $\begin{array}{l}\text { Mass } \\
(\mathrm{g})\end{array}$ & $\begin{array}{l}\text { Measurec } \\
\text { Flexural } \\
(\mathrm{kHz})\end{array}$ & $\begin{array}{l}\text { Young's } \\
\text { Modulus } \\
\text { (GPa) }\end{array}$ & $\begin{array}{l}\text { Poisson's } \\
\text { Ratio } \\
\end{array}$ & \begin{tabular}{|l} 
Poisson's \\
Ratio \\
Required \\
\end{tabular} & $\begin{array}{l}\text { Layer } \\
\text { Orientation } \\
\end{array}$ \\
\hline Ti \# 20p & 1.187 & 0.241 & 0.228 & 3.37 & 33.857 & 106.20 & 0.340 & & Parallel \\
\hline Ti \# 20p & 1.187 & 0.228 & 0.241 & 3.37 & 33.860 & 97.10 & 0.340 & 0.812 & Perpendicular \\
\hline $\mathrm{Ti} \#$ 22p & 1.169 & 0.236 & 0.230 & 3.29 & 35.177 & 107.30 & 0.340 & & Parallel \\
\hline $\mathrm{Ti} \#$ 22p & 1.169 & 0.230 & 0.236 & 3.29 & 35.200 & 103.20 & 0.340 & 0.590 & Perpendicular \\
\hline Ti \# 21p & 1.185 & 0.239 & 0.230 & 3.21 & 32.823 & 93.24 & 0.340 & & Parallel \\
\hline Ti \# 21p & 1.185 & 0.230 & 0.239 & 3.21 & 32.934 & 88.32 & 0.340 & 0.665 & Perpendicular \\
\hline Ti \# 23p & 1.188 & 0.237 & 0.231 & 3.29 & 32.644 & 95.41 & 0.340 & & Parallel \\
\hline $\mathrm{Ti} \#$ 23p & 1.188 & 0.231 & 0.237 & 3.29 & 32.707 & 91.63 & 0.340 & 0.601 & Perpendicular \\
\hline
\end{tabular}

Table 6. Influence of layer orientation on Young's Modulus

Because this analysis was strictly qualitative, the value used for Poisson's ratio (which was required to calculate Young's modulus) was held constant at 0.340 for all tests. As a result of residual porosity, the elastic moduli are smaller than that for solid titanium (110 GPa). The equations used accounted for the specimen's dimensions but not for the layer orientation; therefore, any changes seen in Young's modulus would be due to layer orientation. As can be seen in Table 5, each of the specimens exhibited similar differences. The column labeled "Poisson's Ratio Required" gives what the Poisson's ratio of the perpendicular layer orientation measurement needs to be in order to make the Young's modulus of that measurement the same as that of the measurements taken with parallel layer orientation. As seen, the value is unreasonably large for all specimens.

The examination thus shows that layer orientation does influence the elastic modulus properties of titanium parts. It is further assumed that all metal parts will exhibit the same properties. This assumption required that the effects be examined in greater depth and detail, and to that end, additional substrates were designed.

Planning for this phase of experimentation also includes sintering analysis and includes the installation of a fatigue frame capable of performing the tests. Tests in compression, tension, and fatigue are in progress with parallel projects including:

DOT Hydrogen Fuels Project

Low Acoustic and Thermal Signature Battlefield Power Source - (Navy ManTech Edison Welding Institute Project \#51227GNO, Phase 1

- Low Acoustic and Thermal Signature Battlefield Power Source - (Navy ManTech Edison Welding Institute Project \#51227GNO), Phase 2

- Fuel Cell Design and Manufacturing Technology Development - (Non- ManTech Project\# N00014-07-D-0578).

Once these results are evaluated, a formal statistical analysis matrix will be designed and follow-up testing done. 


\subsection{PALLADIUM BASED MEMBRANE DEVELOPMENT}

\subsubsection{Evaluate palladium and palladium alloys}

Palladium membranes are frequently fabricated on the porous supports by electroless deposition techniques. Most of these efforts have focused on reducing the membrane thickness both to improve the hydrogen permeability rate and to lower the high cost of palladium. Most of the reductions use palladium in the chloride form, and that method was chosen for the initial work with the following deposition reaction:

$$
2 \mathrm{Pd}\left(\mathrm{NH}_{3}\right)_{4}{ }^{2+}+\mathrm{N}_{2} \mathrm{H}_{4}+4 \mathrm{OH}^{-} \rightarrow 2 \mathrm{Pd}^{0}+8 \mathrm{NH}_{3}+\mathrm{N}_{2}+4 \mathrm{H}_{2} \mathrm{O} \text {. }
$$

The general method is:

- Immerse the substrate in stirred oxide slurry for two or three minutes; remove the substrate and rinse gently with DI water; and repeat until a uniform layer of oxide is firmly coated onto the substrate after rinsing.

- Sensitize the substrate by using a $1 \mathrm{~g} / \mathrm{L}$ tin(II) chloride with a drop or two of hydrochloric acid.

- Activate the substrate by using a $0.1 \mathrm{~g} / \mathrm{L}$ palladium(II) chloride solution with a few drops of hydrochloric acid; immerse the substrate in a stirred solution for five minutes; and remove and rinse first with a weak solution of hydrochloric acid and then with DI water.

- Dissolve 2.5 grams of palladium(II) chloride with 20 grams sodium EDTA and $150 \mathrm{~mL}$ saturated aqueous ammonia in one liter of DI water; immerse the substrate in this solution and stir; add a solution of $150 \mathrm{~mL}$ aqueous ammonia, 5 $\mathrm{mL} 1 \mathrm{M}$ hydrazine and one liter of DI water; plate as required to obtain the desired thickness; remove the substrate and set into a fresh bath to continue plating; and rinse the substrate with DI water and allow to air dry.

The Chemistry Department at the University of Montana is also investigating different electroless plating techniques, but work has not yet been completed. In particular, their work on polymer reactions and silica gels suggests that palladium acetate is an excellent candidate for the reaction because it has given stable deposits in other work. A general reaction scheme of the palladium reduction and deposition using the acetate form is shown below:

$$
\mathrm{Pd}(\mathrm{OAC})_{2} \rightarrow 2 \mathrm{Pd}^{2+}+\mathrm{N}_{2} \mathrm{H}_{4}+4 \mathrm{OH}^{-1} \rightarrow 2 \mathrm{Pd}^{0}+\mathrm{N}_{2}+4 \mathrm{H}_{2} \mathrm{O}+8 \mathrm{NH}_{3}
$$

Other palladium compounds are also being investigated, such as $\mathrm{K}_{2} \mathrm{PdCl}_{4}$ and $\mathrm{Pd}\left(\mathrm{NH}_{3}\right)_{4} \mathrm{Cl}_{2}$. Investigations into different reducing agents such as $\mathrm{H}_{3} \mathrm{PO}_{2}$ and $\mathrm{NaH}_{2} \mathrm{PO}_{2}$ compared to hydrazine are also being done, as is the use of moderators such as $\mathrm{NH}_{4} \mathrm{OH}, \mathrm{NaOH}, \mathrm{EDTA}$, and PVA. These are used for modifying the viscosity and the $\mathrm{pH}$ of the plating solution in order to improve the quality of the layer. Work in this area is not yet complete and is continuing after the course of this project. 


\subsubsection{Determine application method}

Once the substrate was being made in a consistent manner and a method for depositing palladium was developed, the initial evaluation of the substrate for palladium deposition could be made. Unlike many other possible methods, only palladium was deposited as an alloying element because the goal was to evaluate the coating, not to maximize strength and durability. Also, a series of scoping tests were conducted to provide background data so that the important variables could be identified and a detailed optimization study could be planned and conducted. A portion of the study results are presented in Figure 31. This figure shows the SEM/EDX spectra of the straight reduction baseline test and indicates that palladium reduction occurs on the

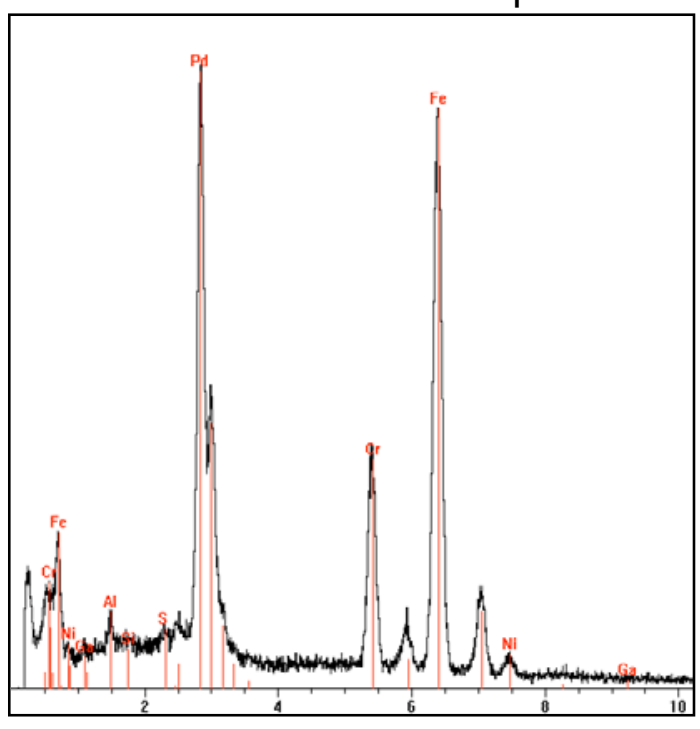
surface but is only partially successful.

Figure 31. SEM/EDX spectra of the baseline only PD reduction

The baseline test reduced palladium onto the substrate without infiltrating an oxide, sensitizing the surface, or activating the stainless steel particle surface. Palladium reduction occurred over a 1.25-hour period. The SEM/EDX spectra of the baseline indicate some palladium reduction does occur on the surface.

Even though reduction does occur, photomicrographs of the substrate in Figure 32 show it is not bonding to the surface. Palladium coating on the stainless steel particles is evident, but the coating is detaching either in part or in whole from the surface. Note that minimal handling of the substrate was done between reduction reaction and SEM analysis to minimize

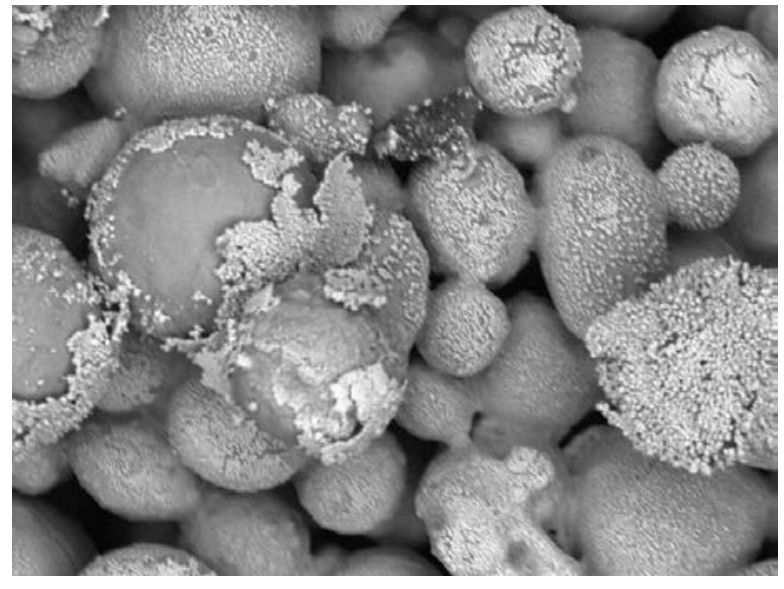

Figure 32. Baseline only-Pd reduction surface view mechanical wear on the surface.

The substrate was sensitized and activated then palladium was reduced into the substrate. This step eliminated the initial oxide step. Palladium reduction occurred over a 1.25-hour period. Figure 33 shows the SEM/EDX spectra of the this baseline test, 
again indicating palladium reduction occurs on the surface but much like the straight reduction discussed above, is only partially successful.

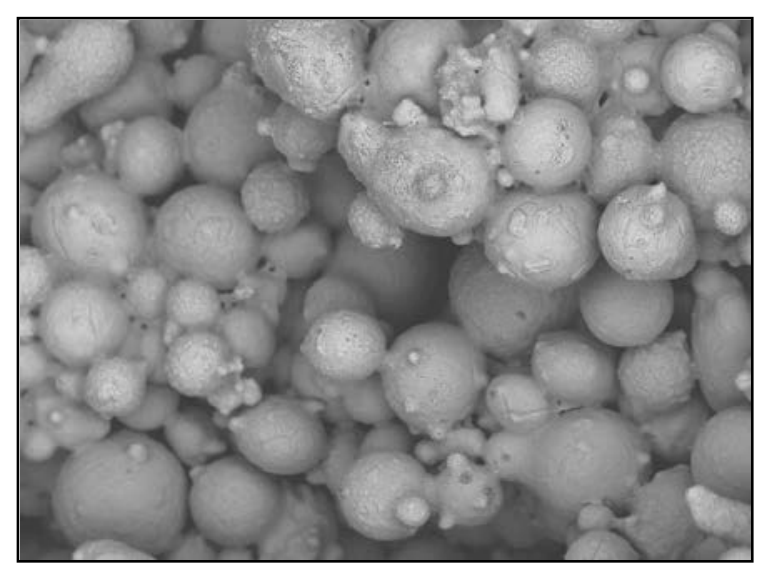

Figure 34: Photomicrograph of the baseline sensitization/activation/Pd reduction

rographs of this test do show surface adhesion is considerably enhanced as seen in Figure 34. Palladium coating is evident on the stainless steel particles and on the fusion-bonded surfaces with no major detachment of the palladium layer evident as was seen in the baseline test results presented in Figure 35. The porous nature of the substrate as well as the sintering bridges are also evident.

Infiltration was done with a 0.1 micrometer zirconium dioxide $\left(\mathrm{ZrO}_{2}\right)$ particulate slurry, the stainless steel particulate was sensitized and activated, and finally palladium was reduced into the substrate, all of which represents the full treatment planned for the substrate. Palladium reduction occurred over a 1.25-hour period.

Figure 35 shows the SEM/EDX spectra of this baseline test, again indicating palladium reduction occurs on the surface. In this case, the contributory peaks from the stainless steel substrate are suppressed almost completely, indicating a uniform, coherent layer over the scan area and by extension the entire surface. 


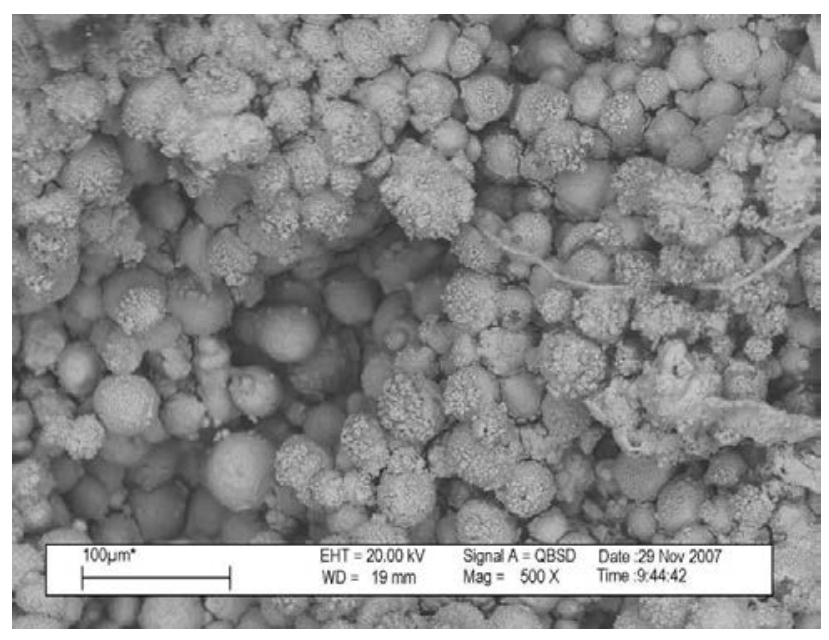

Figure 36. Photomicrograph of the baseline infiltration/sensitization/activation/Pd reduction

Figure 36 shows the photomicrograph of this surface. Palladium coating is evident on the stainless steel particles and on their fusion bonding surfaces. Note the formation of nodular palladium on many of the stainless steel particles. This nodular structure is seen in the straight reduction baseline (Figure 34) but not on the sensitization/activation/reduction baseline. This seems to indicate that a nucleation and growth model is in place when nucleation sites are provided, such as on the surface of the stainless steel particle or on the $\mathrm{ZrO}_{2}$ infiltrant. When the sites are not isolated, such as in the sheet formation the sensitization/activation procedure supplies, the growth continues as a sheet deposition instead of as an island deposition. It is possible that without the particle nucleation sites, the palladium layer is created immediately above the surface as a langmuir layer and then "blankets" over the particles. It is thus likely that the $\mathrm{ZrO}_{2}$ is captured on the stainless steel particles and supplies nucleation sites for the growth of palladium but also provides anchor sites to the particle to prevent mechanical detachment. Because there is little evidence that the pores were filled with $\mathrm{ZrO}_{2}$, it is likely that porosity can be maintained and even enhanced with the nodular palladium growth.

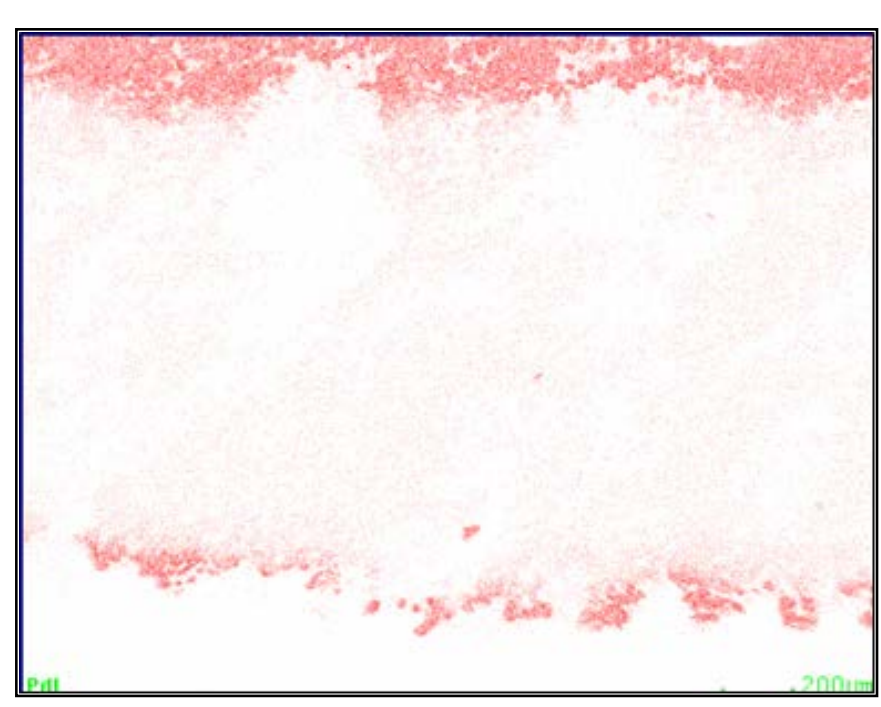

Figure 37. Palladium coating on substrate

Figure 37 is an x-ray digital map of the palladium on the fractured surface of the infiltration/sensitization/activation/reduction baseline. This image shows the viable $\mathrm{Pd}$ profile on the exposed surface utilizing various process parameters. Note also the different thicknesses and layer coherence on both the top and the bottom. The substrates were immersed in stirred bath with the direction of stirring from top to bottom.

\subsubsection{Assess substrate surface treatment}

Once it was determined which variables are important in forming a stable and coherent palladium membrane, an experimental matrix was devised to evaluate and optimize the process. The following variables were identified as important: particle size of the oxide infiltrant, sensitization/activation solution phase concentrations and time of exposure, and solution palladium concentration and time of reduction. The statistical matrix model 
that defined the conditions for high, mid, and low parameter values for each variable for each experiment conducted was based on a "Response Surface Model" that used software developed by STATEASE (Design Expert).

High, mid, and low values for each of the four variables were determined through the scoping experiments. The matrix shown in Table 7 provides the basic unit for experimental evaluation.

\begin{tabular}{|c|c|c|c|c|c|}
\hline & & Factor 1 & Factor 2 & Factor 3 & Factor 4 \\
\hline Std & Run & $\begin{array}{c}\text { A: } \\
\text { Infiltrate } \\
\text { Particle } \\
\text { Size } \\
\end{array}$ & $\begin{array}{c}\text { B: } \\
\text { Sensitization } \\
\text { Time }\end{array}$ & $\begin{array}{c}\text { C: } \\
\text { Activation } \\
\text { Time }\end{array}$ & $\begin{array}{c}\text { D: } \\
\text { Reduction } \\
\text { Time }\end{array}$ \\
\hline & & $\mathrm{nm}$ & $\min$ & $\min$ & hours \\
\hline 1 & 2 & 20 & 15 & 15 & 0.5 \\
\hline 2 & 9 & 20 & 15 & 5 & 0.5 \\
\hline 3 & 15 & 20 & 5 & 15 & 4 \\
\hline 4 & 5 & 1 & 15 & 5 & 4 \\
\hline 5 & 8 & 20 & 5 & 5 & 4 \\
\hline 6 & 4 & 1 & 5 & 15 & 0.5 \\
\hline 7 & 6 & 1 & 15 & 15 & 4 \\
\hline 8 & 18 & 1 & 5 & 5 & 0.5 \\
\hline 9 & 17 & -5.5 & 10 & 10 & 2.25 \\
\hline 10 & 13 & 26.5 & 10 & 10 & 2.25 \\
\hline 11 & 19 & 10.5 & 1.6 & 10 & 2.25 \\
\hline 12 & 3 & 10.5 & 18.4 & 10 & 2.25 \\
\hline 13 & 7 & 10.5 & 10 & 1.6 & 2.25 \\
\hline 14 & 1 & 10.5 & 10 & 18.4 & 2.25 \\
\hline 15 & 11 & 10.5 & 10 & 10 & -0.7 \\
\hline 16 & 16 & 10.5 & 10 & 10 & 5.2 \\
\hline 17 & 10 & 10.5 & 10 & 10 & 2.25 \\
\hline 18 & 20 & 10.5 & 10 & 10 & 2.25 \\
\hline 19 & 12 & 10.5 & 10 & 10 & 2.25 \\
\hline 20 & 21 & 10.5 & 10 & 10 & 2.25 \\
\hline 21 & 14 & 10.5 & 10 & 10 & 2.25 \\
\hline
\end{tabular}

Table 7. Palladium coating matrix

There are four principal parts to the palladium coating: infiltration with oxide particles; tin sensitization of the substrate; palladium activation of the substrate; and the palladium reduction reaction. Both SEM analysis and mercury porosymmetry were done to evaluate the matrix results. Because of the large number of tests, only parts of the results are presented. Figure 38 shows the stainless steel substrate after sensitization at 10 minutes and activation for 10 minutes. Notice the internal porosity of the SEM image on the right, which results from a low temperature sintering meant to maintain porosity while achieving acceptable mechanical properties. The image on the left shows 
an evenly dispersed, very low level palladium map, which results from the activation sequence. As expected, no significant palladium concentration exists because the reduction reaction did not take place.

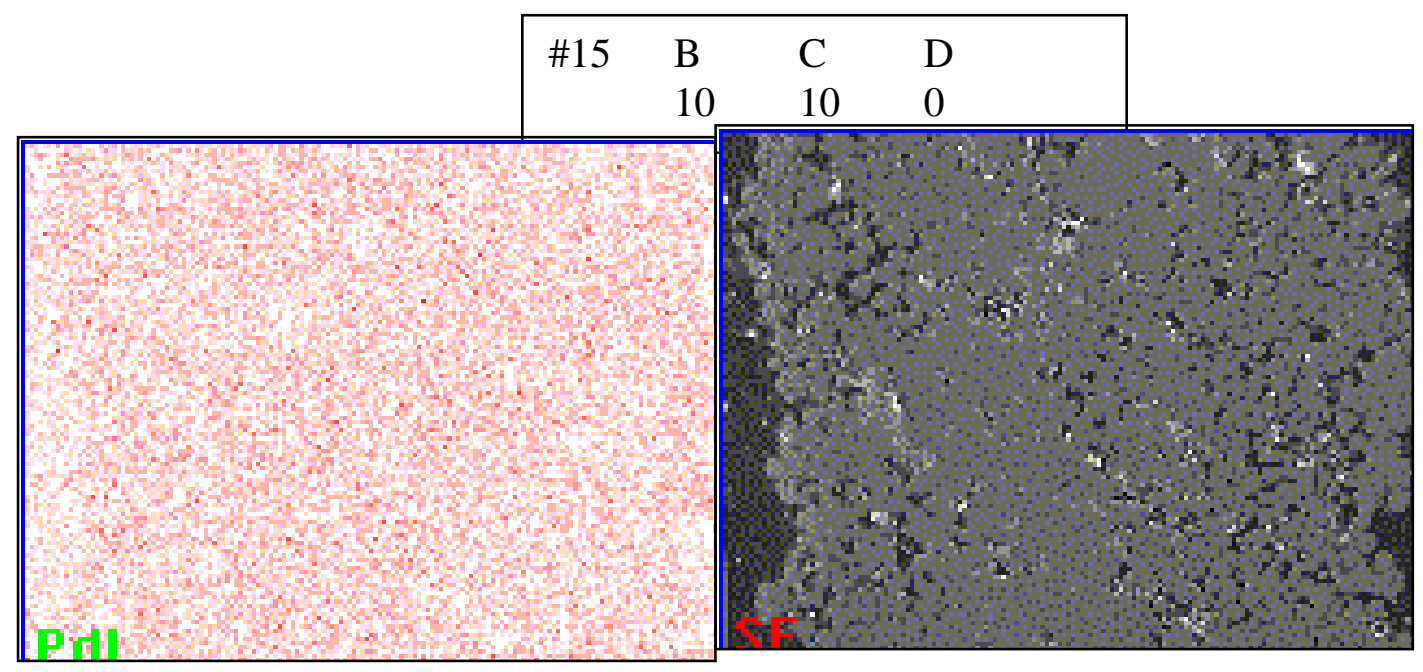

Figure 38: SEM image on stainless steel substrate from matrix testing (no 15)

Figure 39 shows the stainless steel substrate after sensitization for 1.6 minutes, activation for 10 minutes, and after reduction for 2.25 hours. Again, notice the internal porosity of the SEM image on the right. The image on the left shows spots of high palladium levels and indicates palladium coating occurring on the stainless steel spheres. In this image, the low-level palladium has been filtered out for improved contrast. Both sides of the piece show palladium because both sides are coated (orientation parallel to flow). The limited activation time of 1.6 minutes is inadequate because the coating is far from uniform.

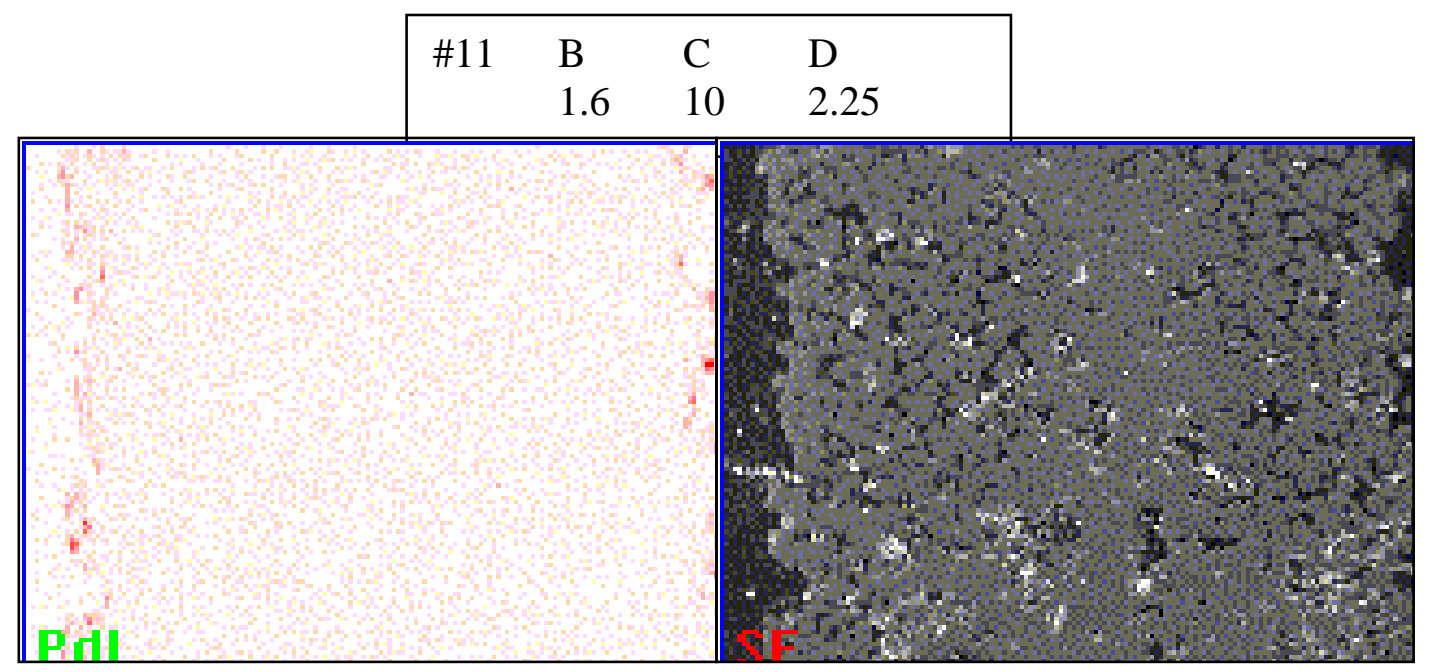

Figure 39. SEM image of stainless steel substrate from matrix testing (no. 11)

Figure 40 shows the stainless steel substrate after sensitization for 10 minutes, activation for 10 minutes, and reduction for 2.25 hours. The image on the left shows an 
increase in the spots of high palladium levels. In this case, because both sides of the piece show palladium, but the right side has substantially less palladium because this piece was aligned perpendicular to the flow in the reduction vessel. This image shows that the ten-minute tin sensitization is probably a minimum, and that preferred coating can be done on one side of a stirred bath if proper orientation is maintained. This would be important in an industrial application, because only a single side would need palladium coating. Moreover, Matrix test \#17 shows that the ten-minute sensitization and activation time followed by the 2.25 hour reduction reaction results in a coating relatively close to what we are looking for.

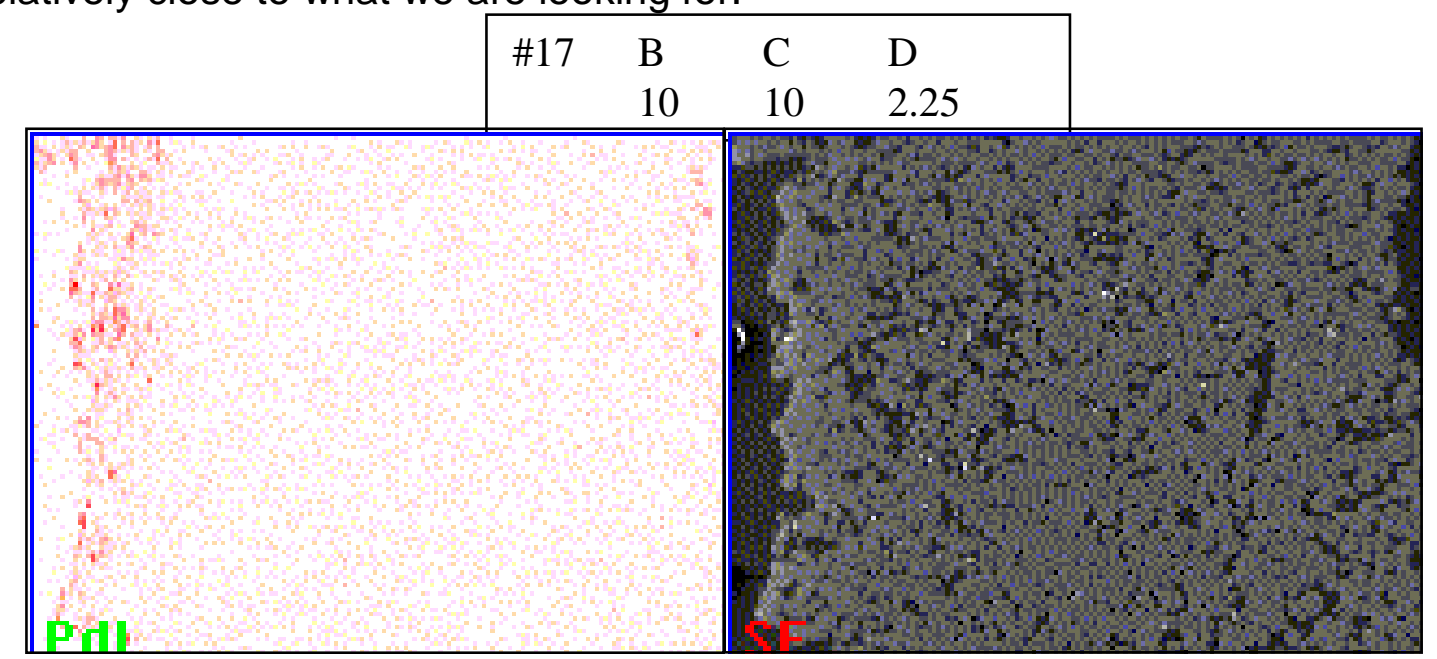

Figure 40. SEM image of stainless steel substrate from matrix testing (no. 17)

Figure 41 shows the stainless steel substrate after sensitization for 18.4 minutes, activation for 10 minutes, and after reduction for 2.25 hours. The image on the left shows a decrease in the spots of high palladium levels over Figure 40. This indicates that tin sensitization has not only a minimum time required but also a maximum time allowed. Both sides have almost equal amounts of palladium because both sides were equally subjected to flow in the reduction vessel (alignment was parallel to flow).

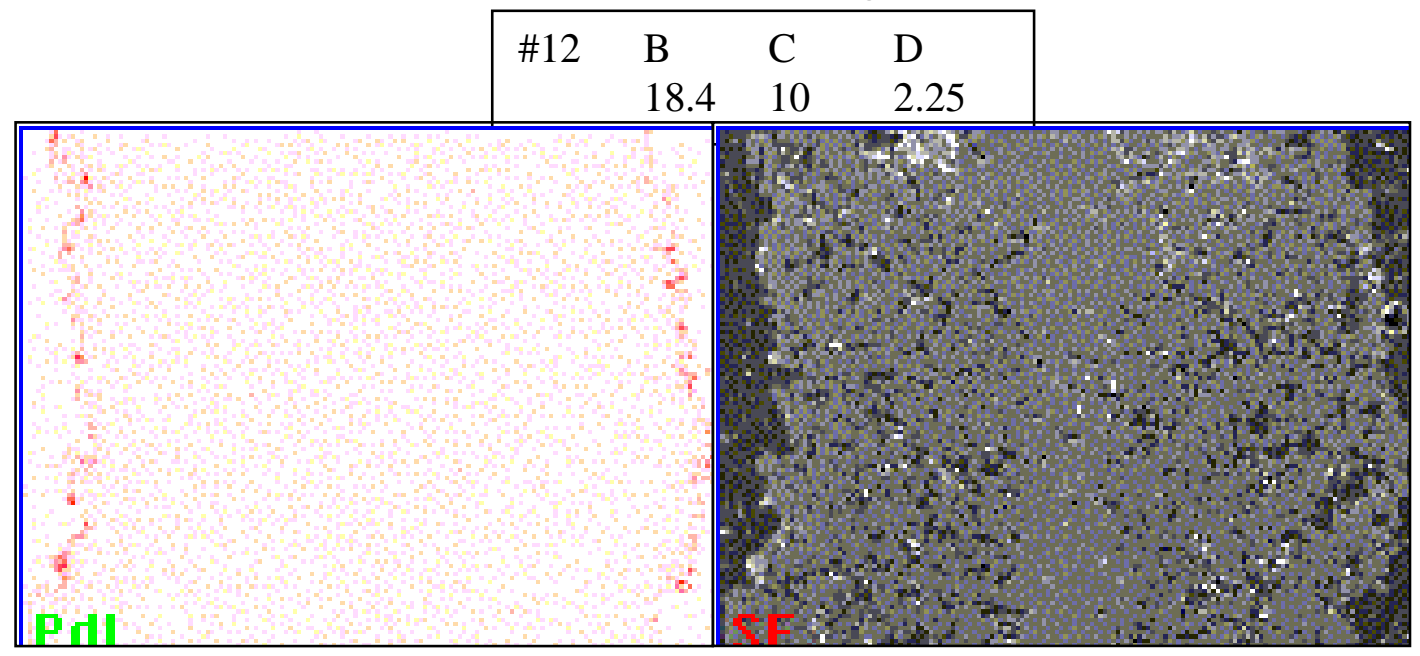

Figure 41. SEM image of stainless steel substrate from matrix testing (no. 12) 
Figure 42 shows the stainless steel substrate after sensitization for 10.5 minutes, activation for 18.4 minutes, and reduction for 2.25 hours. The longer activation time results in a more uniform surface covering of the substrate. Notice the better distribution on the convex surfaces, a result of the directional flow imposed by the reduction vessel.

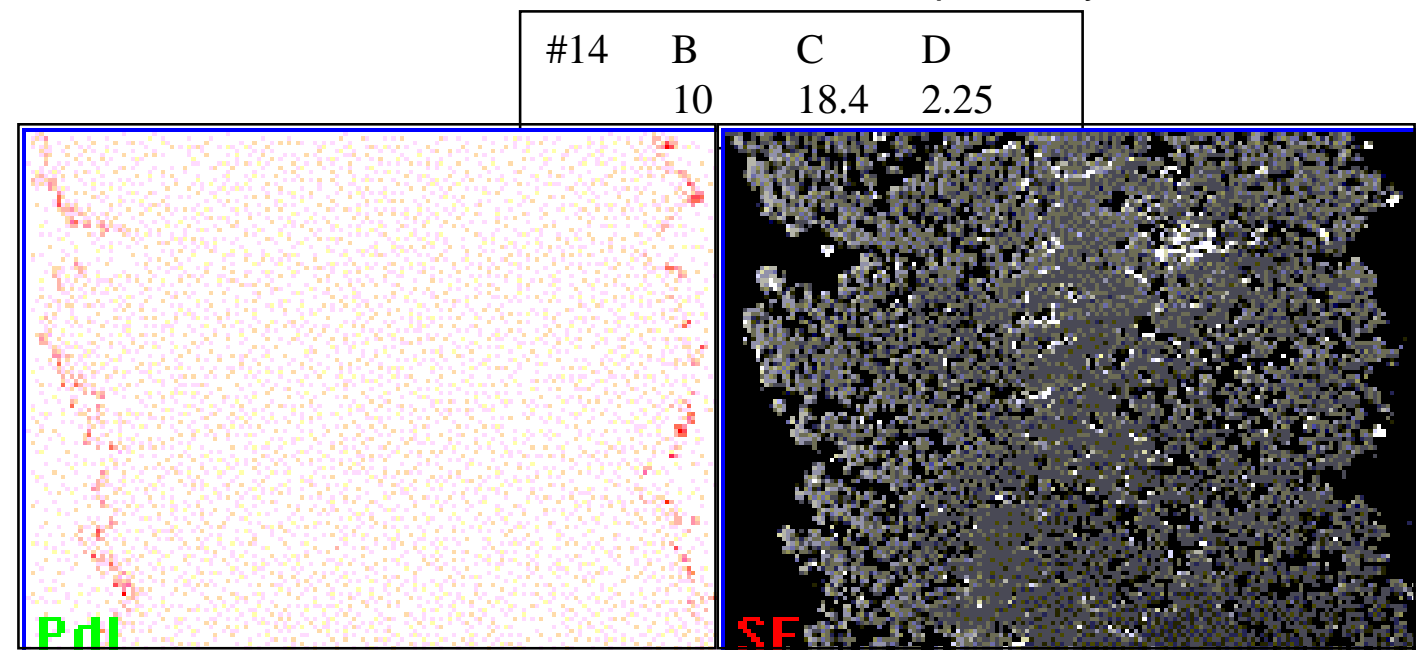

Figure 42. SEM image of stainless steel substrate from matrix testing (no. 14)

Following the destructive evaluation required for the SEM analysis, another matrix set was produced in order to analyze porosimetry. Some of the results are presented in raw form, with the matrix analysis following.

Of particular importance was whether the mercury porosimetry would be able to detect differences in the palladium coated substrate. Because the metal spheres are relatively uniform and the substrate produced in such a way that little if any differences exist, any differences in mercury intrusion should be the result of the palladium reduction layer. If there were little or no differences, then other variables would have to be identified and manipulated.

Figure 43 is an introductory graph that shows the incremental mercury intrusion of all

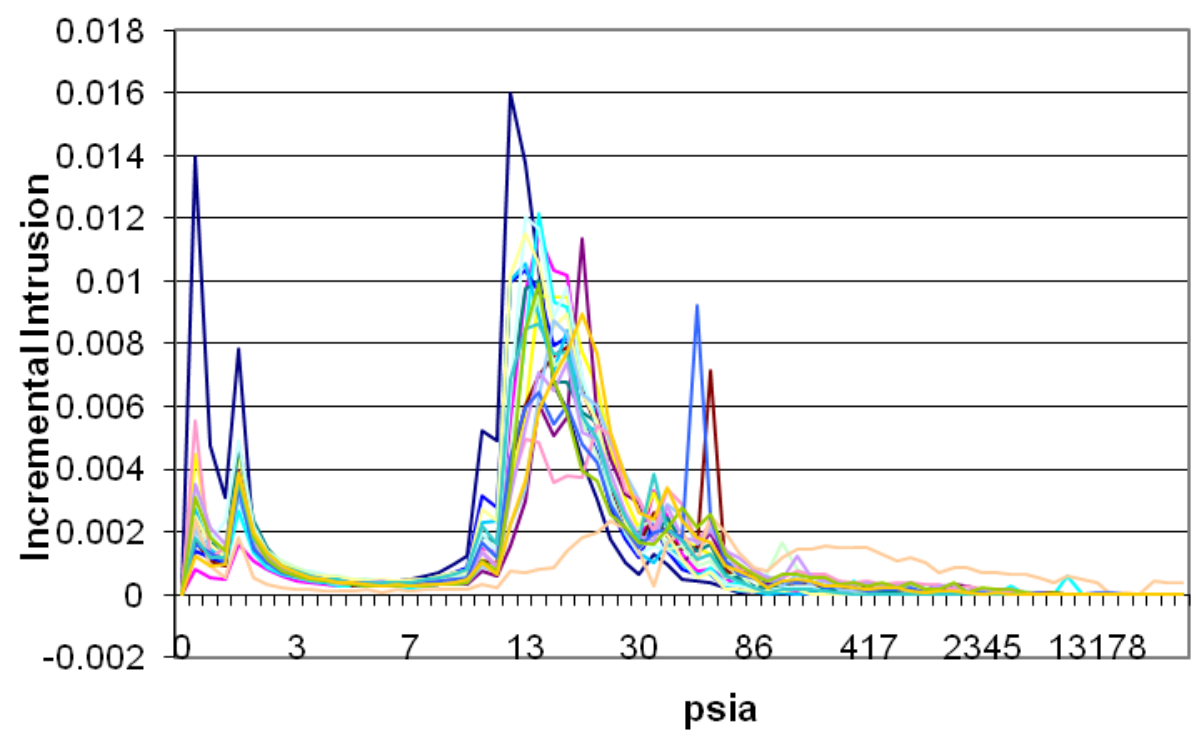

Figure 43. $\mathrm{Hg}$ forced under pressure into the Pd-coated substrates the matrix tests. The equipment measures the volume of mercury forced into the test pieces at different pressures. The incremental intrusion represents one total volume at a pressure less than the total volume at the previously measured pressure. In this case, 
all 21 of the test results are shown for comparison. As can be seen, there is clear differentiation between the tests, indicating the results will be a valid method of evaluating the palladium coated, stainless steel products.

At the same time, it is important to know if the palladium reduction is changing the pore structure. In the preliminary scoping tests, it appeared as if

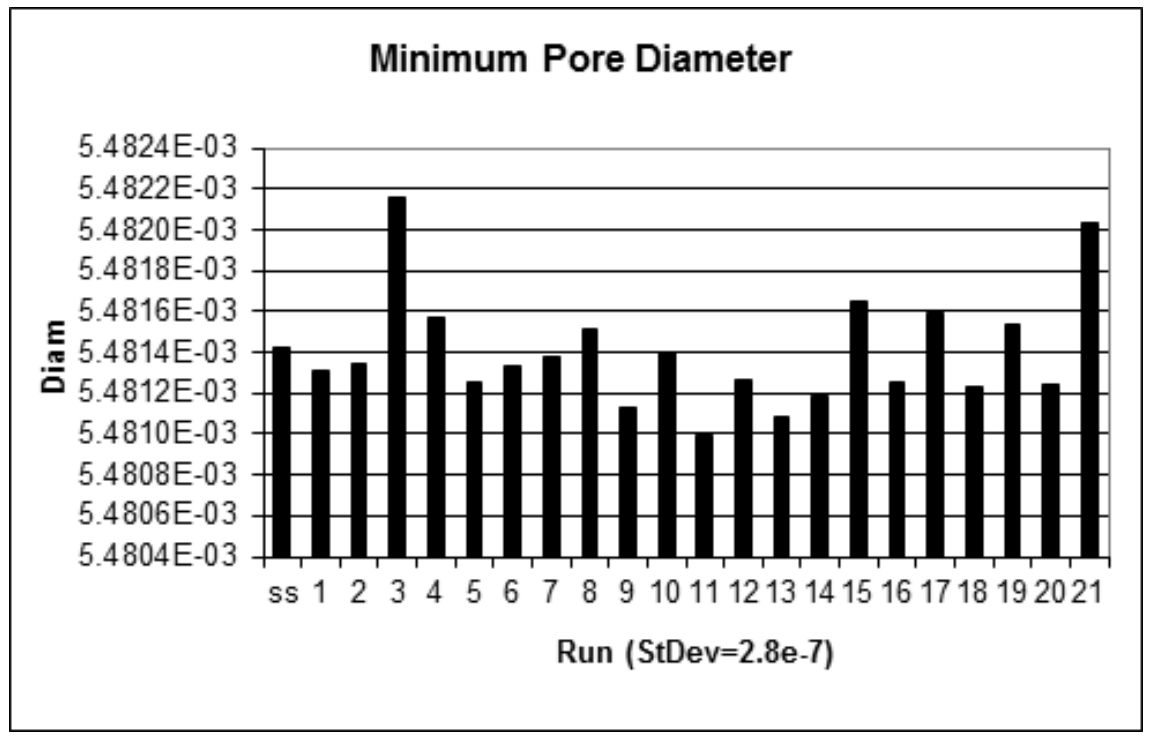

Figure 44. Minimum Pore Diameter of Matrix

palladium was being reduced onto the stainless steel substrate in both a sheet structure and in a nodular (island) structure, depending on the sensitization and activation times used. A sheet structure would close the smaller pores much sooner than a nodular growth structure would, and a nodular structure would increase the back pressure on all the pores far in excess of that seen by a sheet structure. Mercury intrusion data indicate that no substantial difference exists between the various matrix regimens. Figure 44 shows all 21 tests on the same graph, yet no discernable difference in the lines exist when pore diameter is compared to the pressure required to drive the mercury into that particular sized pore. The pore size in the membrane produced is very consistent with very little deviation. We increase the decimal one in this graph to show some difference in diameter in Figure 44. The results indicate that the palladium layer is growing in a consistent manner on the surface instead of there being two different growth models in force.

Further indication of the affect on pore structure by the palladium reduction is shown in Figure 45, where the minimum pore sizes of the various matrix runs are presented. The stainless steel substrate alone is the far left bar. Very little change is seen in the minimum pore size in the substrate, with the standard deviation of the minimum pore size being four orders of magnitude smaller

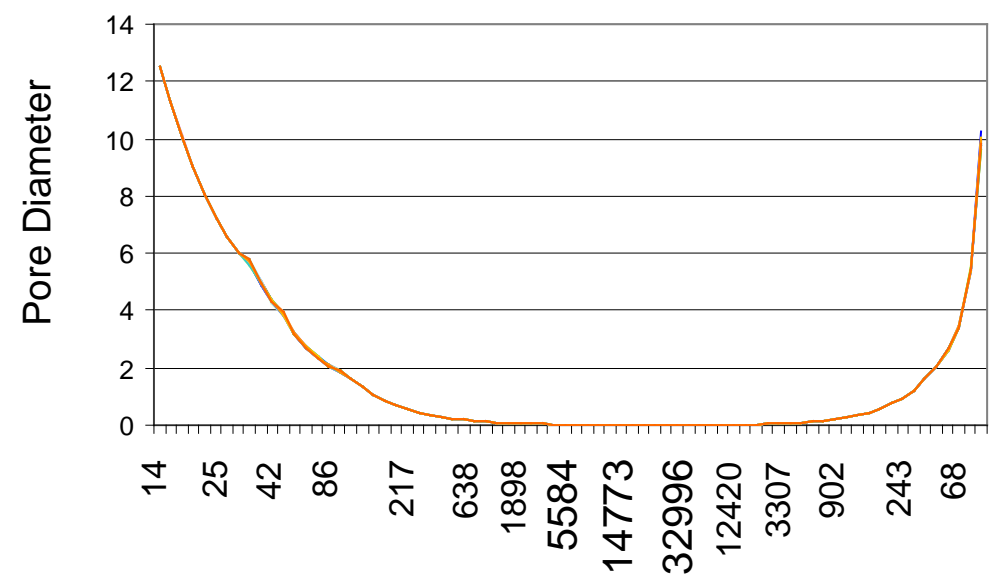

psia

Figure 45: $\mathrm{Hg}$ intrusion into the pore structure 
than the actual pore size itself. This clearly indicates that the spheres comprising the substrate are relatively uniform, that they stack and sinter in a reproducible manner, and finally that the palladium layer itself is thin enough to prevent elimination of even the smallest pores. The design criteria for the substrate are to maintain the pores to the extent that they maximize the surface area and therefore maintain as many gas flow paths as possible. This goal has thus been achieved.

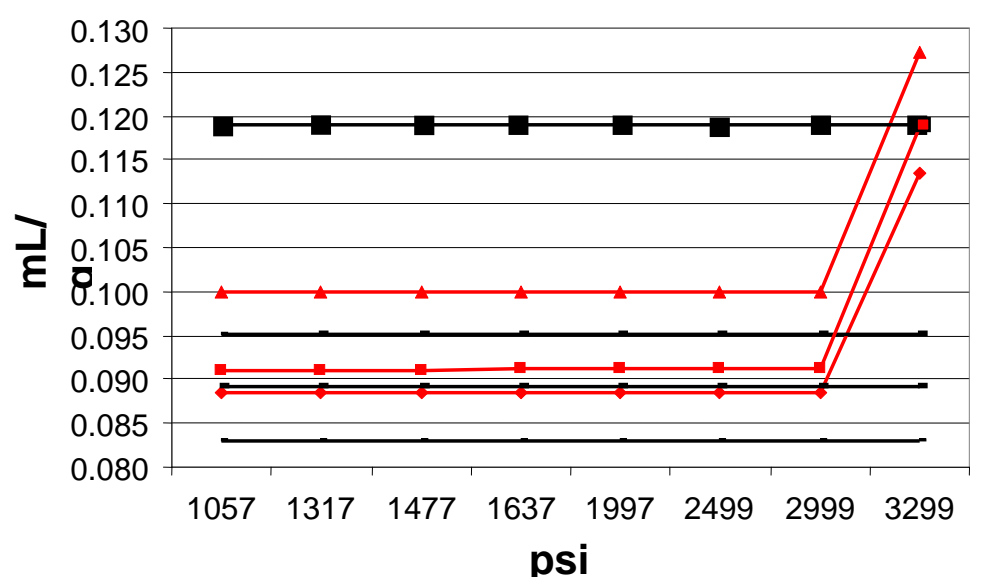

Figure 46. Cumulative intrusion of $\mathrm{Hg}$ at pressure
However, for the substrate and palladium coating to work, the palladium coating must be comprehensive. In addition to maintaining surface area, another major goal was to ensure that the covering is uniform so that the unit would not allow gases other than hydrogen to pass. Although further testing of the uniformity of the covering is required, these initial results show that this goal has also been achieved.

Figure 46 shows the cumulative intrusion of mercury into seven of the matrix tests, with the top line being the stainless steel substrate with no palladium. This graph shows that the palladium coating reduces the amount of mercury that can be forced into the pores even at very high pressures, It also shows that in most cases once a limit is reached, no more mercury can be forced in. However for three of the matrix tests, once the pressure reached approximately $3000 \mathrm{psi}$, the palladium layer ruptured. The result was that more mercury was intruded into the sample. A significant amount of mercury was intruded as well. This indicates that the palladium forms a uniform layer on or near the surface and blocks access to the inner void space that is NOT coated with palladium. Keep in mind that the samples being tested in the porosimeter weigh less than one gram, so that the total volume of the interior space available in the samples is very small.

The final goal was to acquire data that allowed statistical evaluation of the matrix. For this to happen, clear differences had to be seen within the various conditions dictated by the matrix. Figure 47

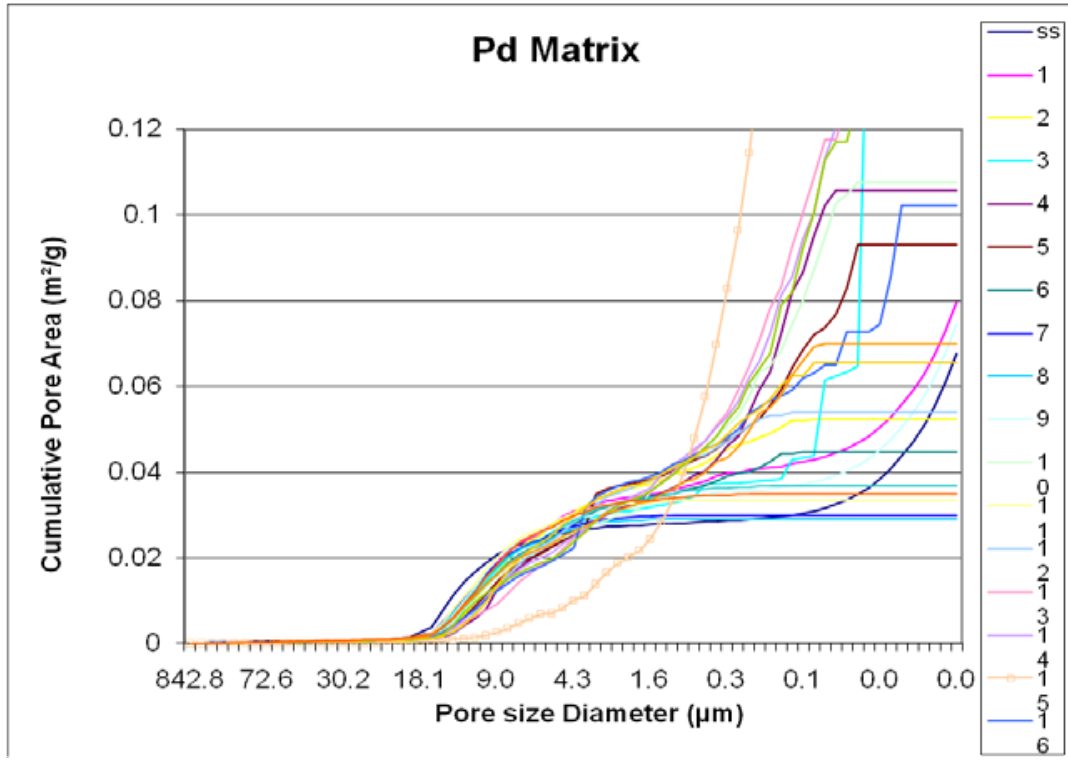

Figure 47. Matrix tests pore area 
shows the cumulative pore area of the matrix tests and clearly indicates that the various conditions imposed by the matrix result in different pore areas. Thus, there is enough variation in key properties to do statistical evaluation.

Analysis of the matrix is ongoing as new equipment arrives and is used to evaluate the samples; however, the basic process optimization has been completed. The Design Expert Response Surface experimental matrix showing the required test conditions is presented in Table 8, with the four steps identified as A, B, C, and D.

\begin{tabular}{|c|c|}
\hline Study & Hg Intrusion Data \\
\hline A & Pore diameter @ 14.5 psi, representing the first move upward \\
\hline B & Pore diameter @ 30 psi, representing the move back to horizontal \\
\hline C & Pore diameter @ 32996 psi, representing the highest pressure \\
\hline D & Cumulative Intrusion @ 37.2 psi, representing the largest difference in values for $\mathrm{Cl}$ \\
\hline E & $\begin{array}{l}\text { Cumulative Intrusion @ } 32996 \text { psi, representing the maximum intrusion (a measure of Pd } \\
\text { breakthrough) }\end{array}$ \\
\hline $\mathbf{F}$ & Average Cumulative Intrusion \\
\hline G & Incremental Intrusion @ 13 psi, representing the largest difference in values for II \\
\hline H & Average Incremental Intrusion \\
\hline I & $\begin{array}{l}\text { Differential Intrusion @ } 9.05 \mu \mathrm{m} \text {, representing the largest difference in values for DI (where } \\
\text { all values are positive) }\end{array}$ \\
\hline $\mathbf{J}$ & Average Differential Intrusion \\
\hline K & $\begin{array}{l}\left.\text { Cumulative Pore Area in } \mathrm{m}^{2} / \mathrm{g} \text { (versus Pore size Diameter in } \mu \mathrm{m}\right) @ 4.6 \mu \mathrm{m} \text { representing the } \\
\text { peak difference in the first move upward }\end{array}$ \\
\hline $\mathbf{L}$ & $\begin{array}{l}\left.\text { Cumulative Pore Area in } \mathrm{m}^{2} / \mathrm{g} \text { (versus Pore size Diameter in } \mu \mathrm{m}\right) @ 0.005 \mu \mathrm{m} \text { representing } \\
\text { the peak difference in the second (and final) move upward }\end{array}$ \\
\hline
\end{tabular}

Table 8. Substrate matrix evaluation studies

Only a sampling of the results is shown below, because the entire analysis is too extensive to include in the text. These results allow process development to begin in earnest. They will be repeated with the 316 stainless substrate and coupled with the statistical analysis for the sintering regimen. Additional analysis of the matrix will be done by using dilatometry, differential scanning calorimetry, and image analysis.

Response D (Cumulative Intrusion @ 37.2 psi, representing the largest difference in values for $\mathrm{Cl}$ )

The following equation describes the influence of the studied variables on response D:

$$
\begin{aligned}
& \text { D1000 }=\{+7.851+(0.086 * \text { Infiltrate Particle Size })\}-\{(0.137 * \text { Sensitization Time }) \\
& +(0.349 * \text { Activation Time })+(0.141 * \text { Reduction Time })\}-\{(0.046 * \text { Infiltrate } \\
& \text { Particle Size }) *(\text { Reduction Time })\}-\{0.01 * \text { Activation Time }\} .
\end{aligned}
$$


Figure 48 shows a

3-D representation of the influence of variables on the " $D$ " response. This is the first move upward for mercury intrusion, representing the initial push into the pore structures. As such, it indicates the uniformity of initial pore diameter and shows the pressure required to overcome the tension between the mercury and the wall structure. Conditions needed to achieve maximum " $\mathrm{D}$ " response are midpoint activation time, largest infiltrate particle size, short sensitization time, and short reduction time. A maximum response here is desirable because it would represent a large pore opening leading to a uniform pore. This maximizes surface area for gas reaction and minimizes both the velocity change into the pore structure and the pressure exerted on the wall's spheres. The relatively flat structure of the response grid is a good indication of the consistency of manufacturing protocols being used, but the non-linear response may be an indication that the sinter bridging is not uniform.

\section{Response E (Cumulative Intrusion @ 32996 psi, representing the maximum intrusion (a measure of Pd breakthrough)}

The following equation describes the influence of the studied variables on response $E$ : E1000 $=+72.464+(0.969$ * Infiltrate Particle Size $)+(3.831$ * Sensitization Time $)+$ $\left(0.797^{*}\right.$ Activation Time $)-\left(0.460^{*}\right.$ Reduction Time $)-\left(0.507^{*}\right.$ Infiltrate Particle Size * Reduction Time $)-(0.143$ * Sensitization Time * Activation Time $)-(1.444$ * Sensitization Time * Reduction Time $)+(0.529 *$ Activation Time

* Reduction Time $)+(2.476$ * [Reduction Time $\left.{ }^{2}\right)$.

Figure 49 shows a 3-D representation of the influence of variables on the "E" response. This is the total amount of mercury intruded into the matrix samples. Previous graphical analysis of this had shown unmistakable evidence that the palladium layer had

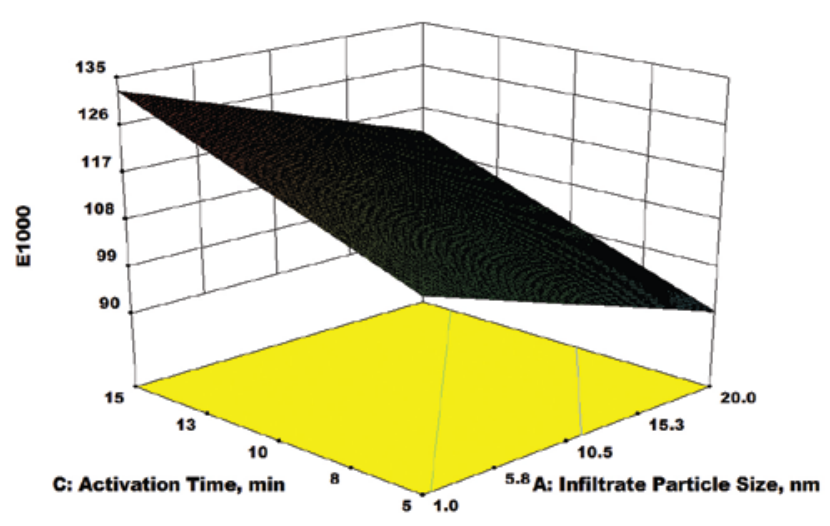

Figure 49. 3-D representation of the influence of variables on "E" response 
ruptured at high pressure on some of the samples. This is further supported by Figure 43in that the sudden movement of mercury onto the samples at the very end of the pressurizing cycle imposed linearity on this study. Thus, while it is problematical to draw conclusions from this study, the importance of the palladium layer thickness is reinforced.

The secondary, 2-dimensional graph shown in

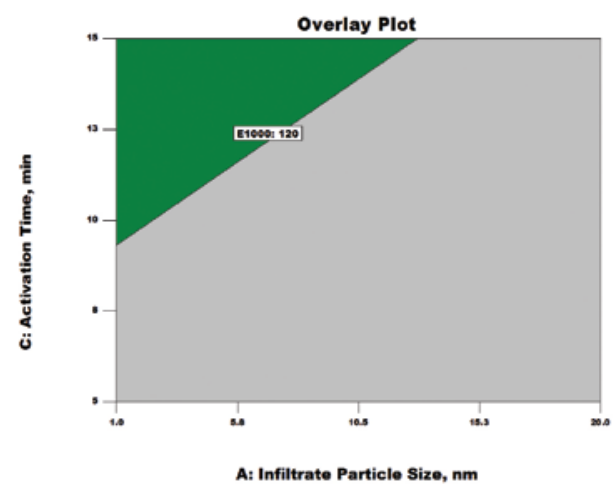

Figure 50. 2-D Overlay plot of influence of variable on "E" response

Figure 50 better illustrates the point. It shows the conditions required to achieve $95 \%$ of the maximum achievable response value. If the palladium layer is to remain intact at high pressures, the conditions in green must be avoided.

\section{Response F (Average Cumulative Intrusion over each step)}

The following equation describes the influence of the studied variables on response $F$ :

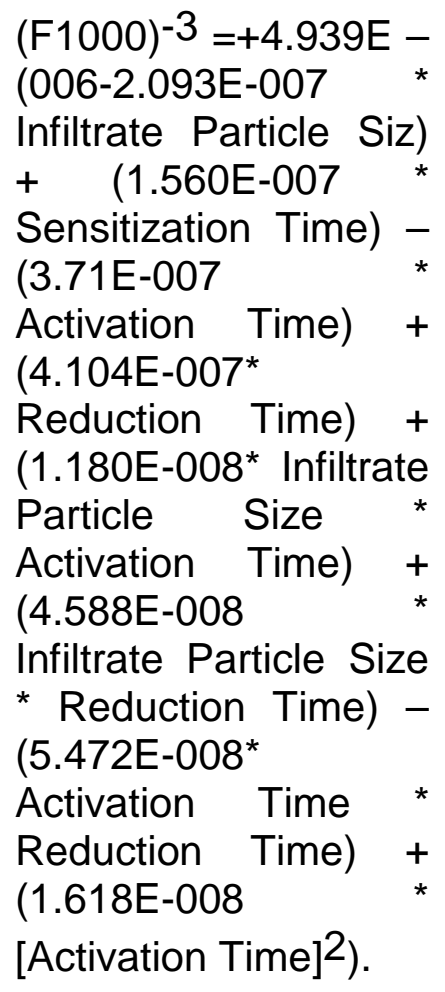

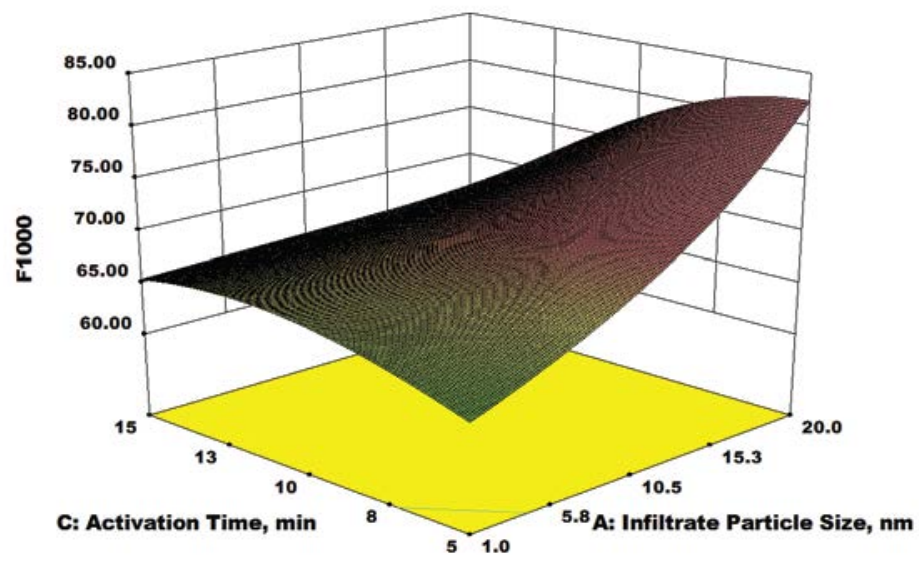

Figure 51. 3-D representation of the influence of variable on "F" response

Figure 51 shows a 3-D representation of the influence of variables on the "F" response. The multiple-sloped response indicates that the infiltrant particle size probably controls the cumulative amount of mercury (and thus the pore size) that can be forced into the construct. This response may be related to whether the palladium is covering the stainless steel spheres in a sheet mechanism or an 
island mechanism. SEM analysis showed both mechanisms being possible. However, an island growth mechanism would promote a less uniform coating and result in a more pronounced stepped cumulative intrusion model being seen over a sheet mechanism. A sheet mechanism would promote a very uniform cumulative intrusion model. The high averages seen in the larger infiltrant end would then be the result of an island mechanism because the mercury would be held up and intrude at each pressure with a larger amount once it overcame the increased resistance of the fingers growing into the pores. Figure 52 shows a 2dimensional contour representation of the influence of variables on "F" response. The conditions then needed to achieve an island growth mechanism would be short activation time, longest infiltrate particle size, short sensitization time, and short reduction time.

\section{Response H (Average Incremental Intrusion, representing the conditions where on average the most mercury intrudes over all pressure steps)}

The following equation describes the influence of the studied variables on response $\mathrm{H}$ :

$(\mathrm{H} 1000)^{-3}=+0.594-0.017^{*}$ Infiltrate Particle Size+0.011* Sensitization Time-0.038* Activation Time- $0.0117^{*}$ Reduction Time+9.43E-004* Infiltrate Particle Size *Activation Time+3.477E-003* Infiltrate Particle Size * Reduction Time+1.243E-003* Activation Time $^{2}$.

Response $\mathrm{H}$ indicates where, on average, the largest amount of mercury intruded into the samples over all the pressure steps. Contrast this with Response $G$, the single point where the most mercury intruded in stepping from one pressure to the next.

Figure 53 clearly shows the substantial variation in average incremental intrusion of mercury. Both the large infiltrant size and the short activation times produce the

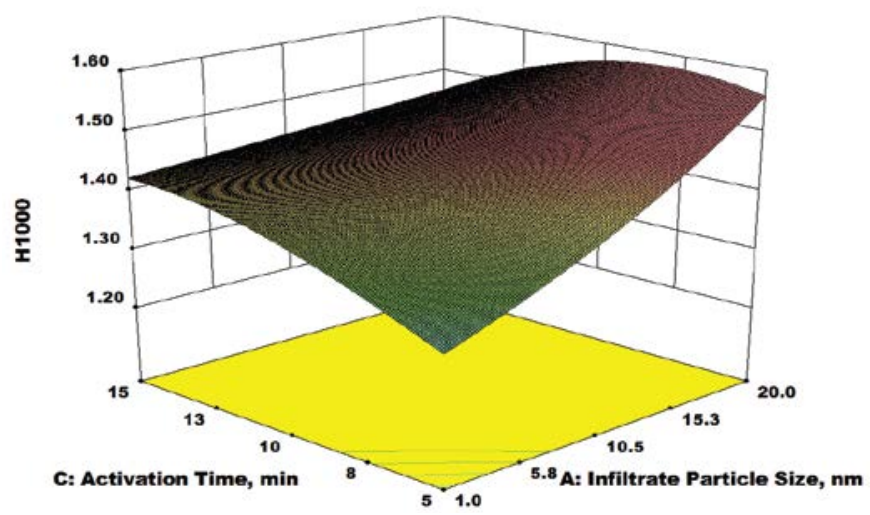

Figure 53. 3-D representation of the influence of variables on the "H" response 
largest average Incremental Intrusion with small infiltrant sizes and with short activation times and thus result in the smallest Incremental Intrusion. This mercury intrusion not only indicates that longer activation times do not overcome the effect of large infiltrant particles, but also indicates that the available surface area of the infiltrant is critical. On the other hand, it is probably detrimental to use smaller infiltrant particles and then long activation times because that approach seems to produce the same type of pore clogging seen in larger infiltrant particles. In general, smaller average intrusion would be preferable because that would translate to increased residence time for a gas at any particular surface reaction site. In this case, given the 0.5 hour reduction time, it appears that a small infiltrant particle, short activation time, short sensitization time, and short reduction time produce optimal results, an indication perhaps that the limiting value in the actual reduction of palladium onto the surface is not dependent on time but rather on solution strength.

Figure 54 shows a much more drastic version of the well seen in Figure 53. All of these figures show that, for smaller infiltrant sizes, the activation time required is low, because of set sensitization and reduction times (5 minutes and 0.5 hours respectively). However, larger infiltrant particles require increasing times to be effective and in this case longer times than were actually done. This finding reinforces

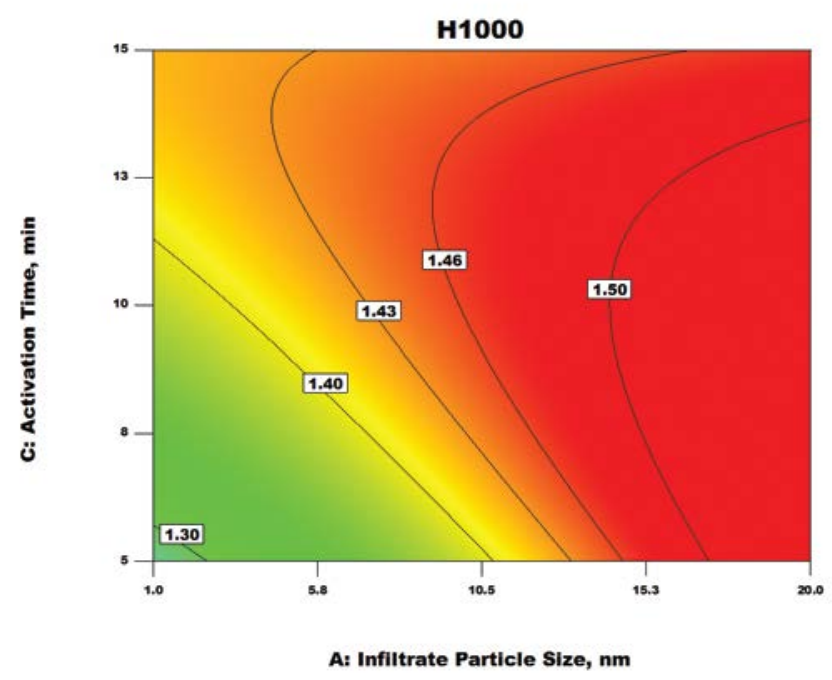

Figure 54. Contour representation of the influence of variables on "H" response the conclusion that larger infiltrant particles are substantially less effective than small infiltrant particles and may be one of the controlling factors of the process, along with solution strength of the palladium reductant solution.

\section{Response I (Defferential Intrusion @ $9.05 \mu \mathrm{m}$, representing the largest difference in values for $\mathrm{Dl}$, where all values are positive)}

The following equation describes the influence of the studied variables on response I:

(I1000)-1.78=+0.0877-8.09903E-004* Infiltrate Particle Size-1.652E-003*

Sensitization Time-7.830E-003* Activation Time+3.976E-003 * Reduction

Time+2.856E-004* Infiltrate Particle Size * Activation Time-6.947E-004* Infiltrate

Particle Size * Reduction Time-0.436E-004* Sensitization Time * Activation

Time+2.715E-003 * Sensitization Time *Reduction Time-1.584E-003* Activation Time

* Reduction Time+5.160E-004* Activation Time 2 . 
Notice the complexity of the generated equation describing this function. Differential Intrusion is a step increase and measures the difference in the amount of mercury intruded when the pore diameters calculated via the operating software change. The greatest amount of Differential Intrusion occurred at a pore diameter change from 10.07 $\mu \mathrm{m}$ to $9.05 \mu \mathrm{m}$. The pore diameters ranged from $842.7587 \mu \mathrm{m}$ to $0.00548 \mu \mathrm{m}$, so 9.05 $\mu \mathrm{m}$ is a relatively small pore. The pore structure envisioned for these constructs consists of three types of outer edge openings leading to the inner pore structures. In the first group, the larger ones are produced by the stainless steel particles not touching but connected by interior sinter bridges to result in the two largest pore openings seen in this matrix, $842 \mu \mathrm{m}$ and $577 \mu \mathrm{m}$. The second group is produced by the stainless steel particles not touching but connected by exterior sinter bridges, which results in the next two largest pore openings seen in this matrix, $436 \mu \mathrm{m}$ and $350 \mu \mathrm{m}$. The third group is produced by direct sintering between adjacent and touching stainless steel particles to result in a more stepped progression of pore openings of 182 $\mu \mathrm{m}, 121 \mu \mathrm{m}, 91 \mu \mathrm{m}$, and $73 \mu \mathrm{m}$. After those sizes, the pore diameter progression takes 10 steps to go from $60 \mu \mathrm{m}$ to the $9 \mu \mathrm{m}$ used in Response I. These steps indicate that the interior pore structure is consistent and that the interior reduction reactions are uniform.

Variation in Differential Intrusion for smaller, interior pore diameters appears to be controlled to a great extent by Sensitization Time. Figure 55 shows the longer sensitization time. Figure 56 shows the shorter sensitization time. The longer Sensitization time displays considerably more variation than the shorter Sensitization time. Notice the difference in scales as well, where the 10 minute Sensitization time of Figure 55 has up to twice the Differential Intrusion of the shorter Sensitization time of Figure 56. It would seem that the longer Sensitization time provides a mechanism by which the smaller pores are less congested and thus pass more

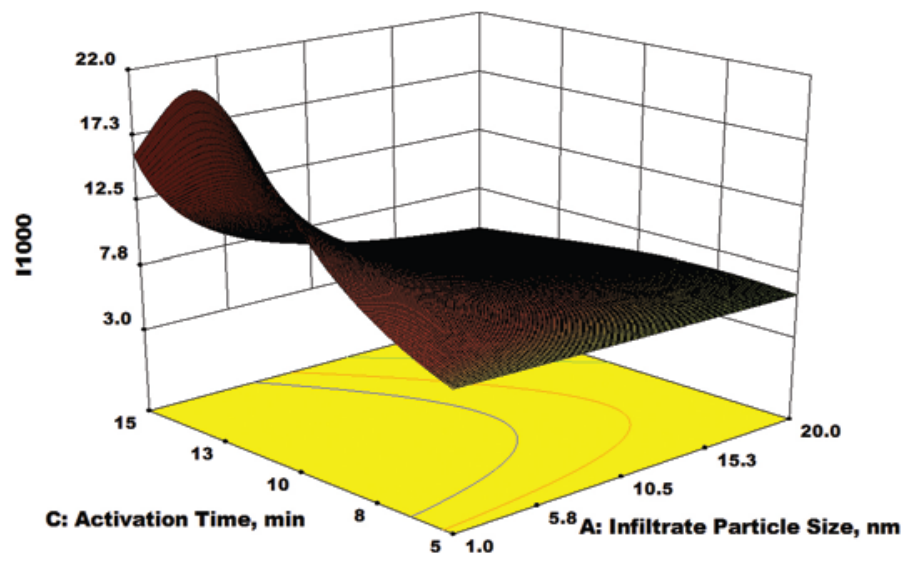

Figure 55. 3-D representation of the influence of variables on the "I" response (10-minute sensitization time)

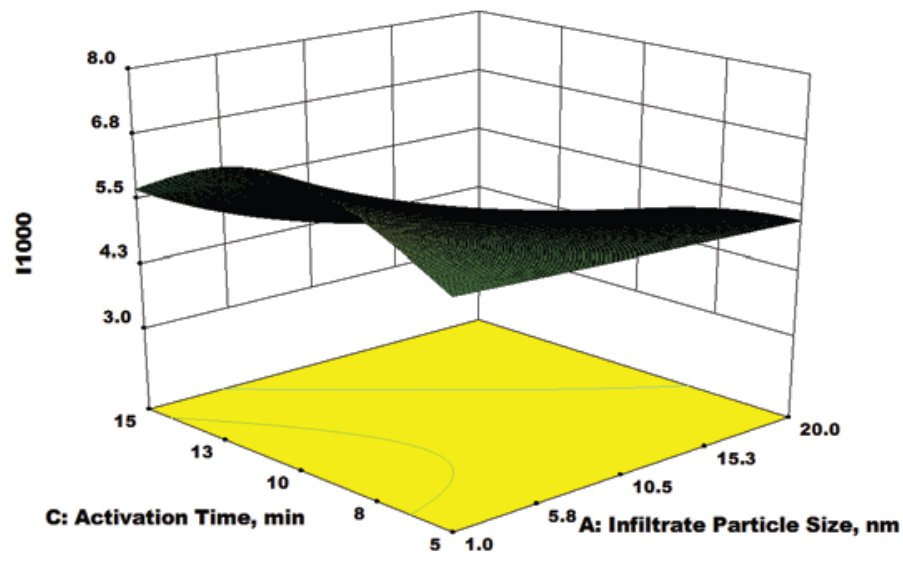

Figure 56. 3-D representation of the influence of variable on the "I" response (5-minute sensitization time) 
mercury through than the same size pores with shorter Sensitization times. This response may well further indicate dual growth mechanisms for the palladium coating where a sheet mechanism produces a smooth inner wall with little impediment to mercury passing. On the other hand, an island mechanism tends to push nodules into the pore opening, not so much lessening the opening but providing considerably more surface area for the mercury to interact with.

Notice that in both cases, there is an optimum Activation time, but that the Infiltrant Particle Size does not particularly affect this Response for either the long or short Sensitization times. The fact that the Infiltrant Particle Size does not affect the Response seems counterintuitive and suggests both that the larger particles are probably not even accessing these pore sizes and that variation would be expected. This then may well indicate that the Infiltrant assists the Sensitization. Furthermore, once minimal Infiltrant particles are available, the stainless steel surface itself must then be sensitized without that assistance and would require additional time. Figure 57 shows a slightly different view of this with an Overlay plot. Here, the green area shows where the optimum conditions are met. Only

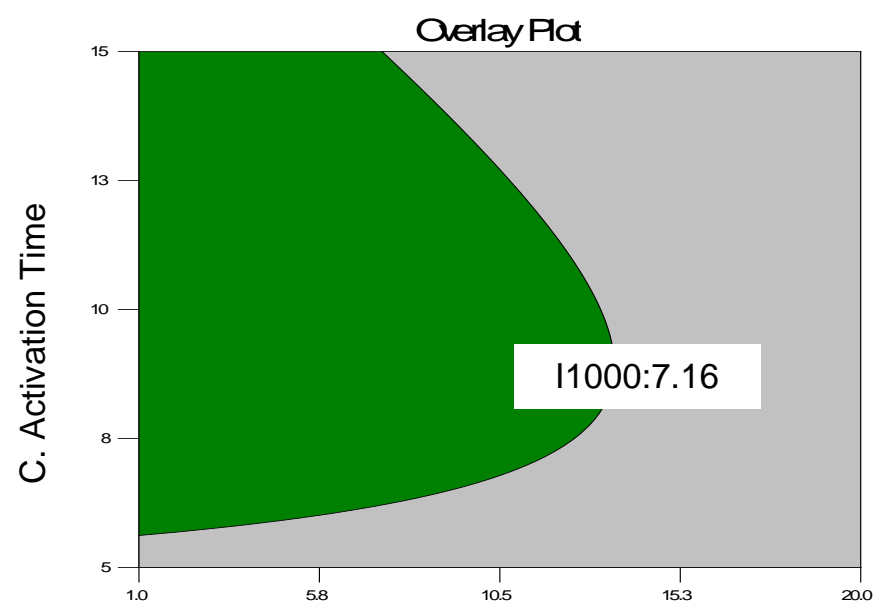

A: Infiltrate Particle Size

Figure 57. 2-D Overlay representation of the influence of variables on "I" response the largest Infiltrant particles are excluded and the Activation time fails only statistically at times approaching zero (0). 


\subsection{PLATE MEMBRANE ONTO SUBSTRATE}

\subsubsection{Develop plating procedure}

Based on the result from the testing matrix, optimized plating procedures are now available and are based on which variables need optimization.

CAMP has also developed capital and operating cost estimates for the metal powder printing and sintering system which uses the current process. Required equipment consists of an R-2R ProMetal 3-D printer manufactured by The ExOne Company (Irwin, PA) and a Series 15 Model $22-2000 \mathrm{~kW}$ vacuum furnace manufactured by Centorr Vacuum Industries (Nashua, $\mathrm{NH}$ ). This equipment represents the minimum practicable scale for forming and sintering objects through the combination of these technologies. PLEASE NOTE that the cost does not include palladium coating.

The capital cost estimate is based on CAMP's recent experience in procuring and commissioning the equipment. As indicated in Table 9, the installed equipment cost totals $\$ 276,500$ (January 2008 US\$).

\begin{tabular}{|l|r|r|r|}
\hline \multicolumn{1}{|c|}{ Category } & 3-D Printer & Vacuum Furnace & \multicolumn{1}{c|}{ Total } \\
\hline Purchased Equipment & $\$ 184,000$ & $\$ 65,800$ & $\$ 249,800$ \\
Installation & $\$ 12,000$ & $\$ 4,700$ & $\$ 16,700$ \\
Training & $\$ 5,000$ & $\$ 5,000$ & $\$ 10,000$ \\
\hline Installed Cost & $\$ 201,000$ & $\$ 75,500$ & $\$ 276,500$ \\
\hline
\end{tabular}

Table 9. Metal powder printing and sintering system capital cost estimate

Operating cost estimates are based on processing a single object in each printing cycle and in each sintering cycle. The vacuum furnace working volume and $8 \mathrm{hr}$ sintering cycle time constrains the system throughput capacity.

Because the 3-D printer operating costs are sensitive to the object's geometry, the operating cost model was constructed to account for the object's dimensions, porosity, and internal void space (when applicable). For the purpose of this estimate, the object is defined as a tube with dimensions of $10 \mathrm{~cm}$ height, $10 \mathrm{~cm}$ outside diameter, and 0.25 $\mathrm{cm}$ wall thickness. The estimated porosity of the printed shape is 0.33 . (In other words, the binder and/or air occupies 33\% of the printed object's filled volume prior to sintering.) A $4.0 \mathrm{~h}$ cycle time is required to print an object with these dimensions and porosity.

The 3-D printer operating costs are summarized in Table 10. The base case estimate assumes that the objects are printed with stainless steel microspheres.

\begin{tabular}{|l|l|l|l|}
\hline Category & $\mathbf{\$ / h}$ & $\mathbf{\$} / \mathbf{c y c l e}$ & $\mathbf{\$ / o b j e c t}$ \\
\hline Labor & 34.80 & 139.20 & 139.20 \\
Consumables & & & \\
$\quad$ Powder & 3.37 & 13.46 & 13.46 \\
$\quad$ Binder & 9.71 & 38.82 & 38.82 \\
Cleaner & 1.62 & 6.50 & 6.50 \\
Utilities & 31.25 & 125.00 & 125.00 \\
\hline Totals & $\mathbf{\$ 8 0 . 7 5}$ & $\mathbf{\$ 3 2 2 . 9 8}$ & $\mathbf{\$ 3 2 2 . 9 8}$ \\
\hline
\end{tabular}

Table 10. Metal powder printing operating cost estimate (stainless steel microspheres) 
Comparable 3-D printer operating costs for forming the similar objects from various titanium powders are compared with the base case in Table 11. Only the powder costs are affected by the material alternatives; the costs of labor, utilities, and other the consumables are fixed.

\begin{tabular}{|l|l|r|r|r|}
\hline \multicolumn{1}{|c|}{ Powder Material } & Labor & Consumables & Utilities & $\begin{array}{c}\text { Total, } \\
\text { \$lobject }\end{array}$ \\
\hline Stainless Steel Microspheres & 139.20 & 58.78 & 125.00 & $\$ 322.98$ \\
\hline Titanium Microspheres & 139.20 & 300.55 & 125.00 & $\$ 564.75$ \\
\hline Titanium Microsponge & 139.20 & 67.48 & 125.00 & $\$ 331.68$ \\
\hline Milled Titanium & 139.20 & 83.02 & 125.00 & $\$ 347.22$ \\
\hline
\end{tabular}

Table 11. Metal powder printing operating cost comparison, titanium vs. stainless steel

Operating costs are highly sensitive to the number and geometry of the objects printed in each cycle because these factors dictate the metal powder consumption rate $(\mathrm{kg} / \mathrm{cycle})$. The unit production cost differences between stainless steel and the various types of titanium powder become substantially greater for more massive objects. For example, the operating cost for printing a $10 \mathrm{~cm}$ by $10 \mathrm{~cm}$ cylindrical monolith that uses titanium microspheres is $\$ 2,930 /$ object as opposed to $\$ 450 /$ object for a similar monolith printed from stainless steel microspheres. Accuracy of the operating cost estimate relies on precise definition of the object's geometry.

The vacuum furnace operating costs are summarized in Table 12. Based on the single object per cycle scenario, the operating cost is $\$ 342 /$ object. By assuming uniform sintering times for objects constructed from the various materials, each operating cost component is a fixed cost.

\begin{tabular}{|l|r|r|r|}
\hline \multicolumn{1}{|c|}{ Category } & \multicolumn{1}{c|}{ \$/h } & \multicolumn{1}{c|}{ \$/cycle } & \$/object \\
\hline Labor & 34.80 & 278.40 & 278.40 \\
Consumables & & & \\
Specialty Gas & 6.25 & 50.00 & 50.00 \\
Utilities & 1.75 & 14.00 & 14.00 \\
\hline \multicolumn{1}{r|}{ Totals } & $\$ 42.80$ & $\$ 342.40$ & $\$ 342.40$ \\
\hline
\end{tabular}

Table 12. Sintering operations cost estimate

In summary, the estimated operating cost for producing the $10 \mathrm{~cm}-\mathrm{by}-10 \mathrm{~cm}$ tube ranges from approximately $\$ 600 /$ object to $\$ 900 /$ object, depending on the type of metal powder used to print the object. As previously noted, the unit cost is highly sensitive to 1 ) the metal powder selection, 2) the number of objects printed per cycle, and to 3) the geometry or, more specifically, to the filled volume of the object.

\subsubsection{Complete membrane plating on substrate}

The final purpose of the palladium coating is to provide a strong, coherent, and gas-tight covering on the substrate. The initial designs were intended for industrial use and thus maximized the surface area. As the project has evolved, it has become apparent, 
however, that a number of test pieces will be needed. One bulb was palladium coated, and it soon became obvious that the initial design for this project would be unworkable because of the cost of coating the surface areas of the initial substrate design of a bulb. With costs in the thousands of dollars to coat a single bulb and as many as thirty required for the planned testing, this design was replaced for initial testing because of cost considerations. Subsequent grants and the continuation of this project for other agencies necessitated a smaller, personal-sized device as well. A proof-of-concept approach scaled to the laboratory was adopted with a redesign of the testing platform for low signature requirements done. Two substrate designs were drawn, printed, and sintered: a small cylinder and a cylinder slice suitable for an in-line stream evaluation design.

The small cylinder slices were used for the initial proof-of-concept testing. The two designs are shown in Figure 58. The slice has been palladium-coated as well, providing contrast between a raw substrate (bullet) and a coated substrate (slice).

The slice design is used in the in-line design, further shrinking the initial scale. This configuration was chosen due to its simplicity of operation. Figure 59 shows the proof-of-concept

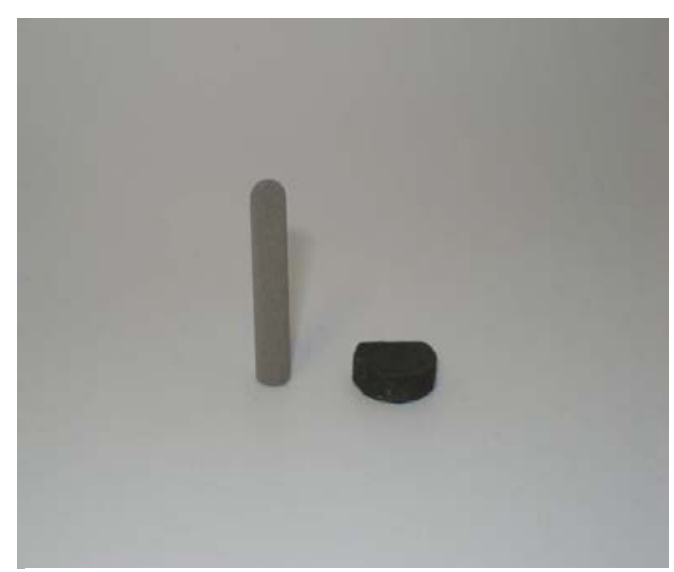

Figure 58. Substrate redesigns (Pd-coated slice) test bed for the hydrogen production. The palladium coated slice is mounted and sealed within the brass fitting as a reactor. That assembly can also be mounted in the stainless steel pipe and suspended within a tube furnace for elevated temperature experiments. Mixed gas is used in this stage, being fed into the reactor under controlled pressures. The exiting gas is fed through the coils suspended in a water bath to cool the mix, and then through the drier tube. Analysis will be done with an Agilent four-channel gas chromatograph.

Three substrates tested and coated as per the current method, one with a final palladium reduction reaction of 15 minutes, one of 30 minutes, and one of 60 minute. These substrates were then fit into the test bed by using o-rings to ensure no gas bypassed the substrate. The heat exchanger portion of the apparatus was

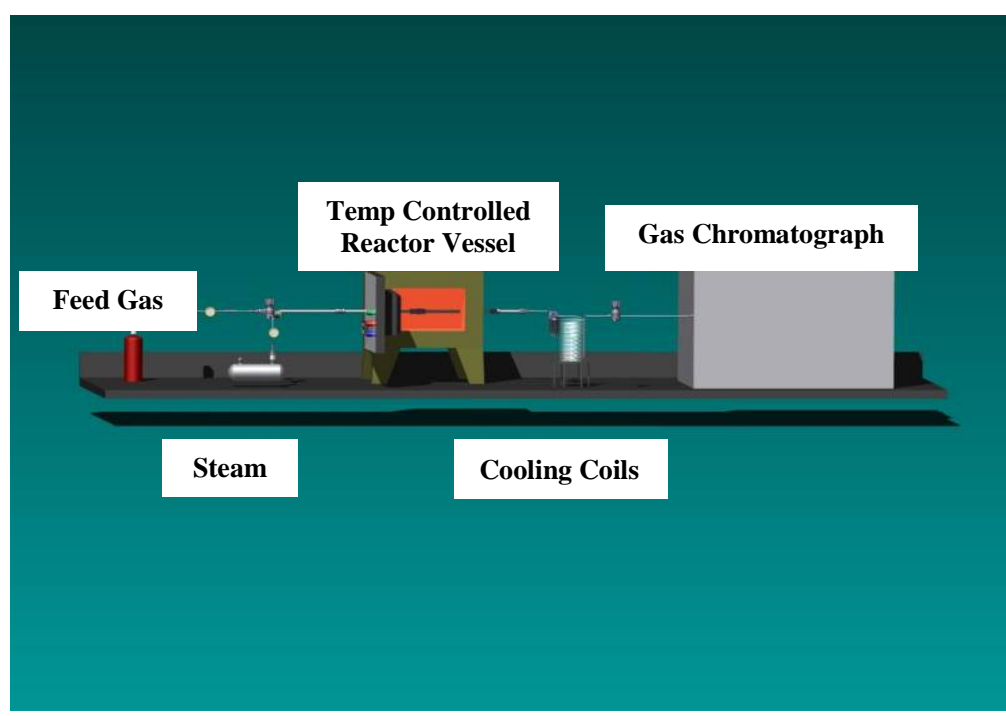

Figure 59. Proof-of-concept test bed for hydrogen production 
removed for the purge cycle tests to help eliminate the gas volume in the tubes. The gas used was 2 molar \% hydrogen and the balance air. Results of the initial tests are shown in Table 13.

\begin{tabular}{|r|r|r|r|r|}
\hline $\begin{array}{c}\text { No } \\
\text { Substrate }\end{array}$ & $\begin{array}{c}\text { 15-min } \\
\text { Coating }\end{array}$ & $\begin{array}{c}\text { 30-min } \\
\text { Coating }\end{array}$ & $\begin{array}{c}\text { 60-min } \\
\text { Coating }\end{array}$ & $\begin{array}{c}\text { \% } \\
\text { Difference } \\
\text { 60-min }\end{array}$ \\
\hline 1.824 & 1.936 & 2.046 & 2.355 & $29.11 \%$ \\
\hline 2.076 & & 1.813 & 3.042 & $46.53 \%$ \\
\hline 1.818 & & & 2.207 & $21.40 \%$ \\
\hline
\end{tabular}

Table 13. Initial hydrogen purification tests $($ molar $\% \mathrm{H})$

In follow-up tests, the same three substrates were re-tested with a non-coated substrate. A line purge was included, done for 15 seconds, and then purification begun with the purge maintained until the GC began to pull the sample. The gas used was 4 molar \% hydrogen and the balance air. Table 14 shows the results of the follow-up testing.

\begin{tabular}{c|c|c|}
\hline $\begin{array}{c}\text { No } \\
\text { Coating }\end{array}$ & $\begin{array}{c}\text { 60-min } \\
\text { Coating }\end{array}$ & $\begin{array}{c}\text { \% } \\
\text { Difference }\end{array}$ \\
\hline 4.041 & 5.483 & $35.68 \%$ \\
\hline 4.076 & 5.673 & $39.18 \%$ \\
\hline
\end{tabular}

Table 14. Follow-up hydrogen purifications tests $($ molar $\% \mathrm{H})$

Results in both tests are encouraging, showing a definite increase in molar \% hydrogen.

\subsubsection{Evaluate plating effectiveness}

Given the results of the initial proof-of-concept tests, tests to determine the proper coating thickness are underway. Two issues are paramount: the first being the thickness required for complete sealing of the substrate, and the second being maximizing flux through the coating. Required thicknesses have been initially examined in conjunction with the initial hydrogen purification experiments which were described in the previous section.

Visual examination of the substrates was also encouraging. The substrates consist of randomly stacked and sintered microspheres. A palladium over-layer would need to cover the spheres but would also need to close the random paths through the construct created by the interior porosity. Three-dimensional imaging was done with a Hyrox digital microscope to evaluate the palladium coating. Figure 60 shows a 15minute reduction reaction (the same substrate used in the above tests). This is a top view and clearly shows the porosity pipes on the left side. Note, however, that even using what is considered the minimal amount of time necessary to plate a palladium over-layer on the substrate, the great bulk of this area has no open porosity. Note also that the surface of the

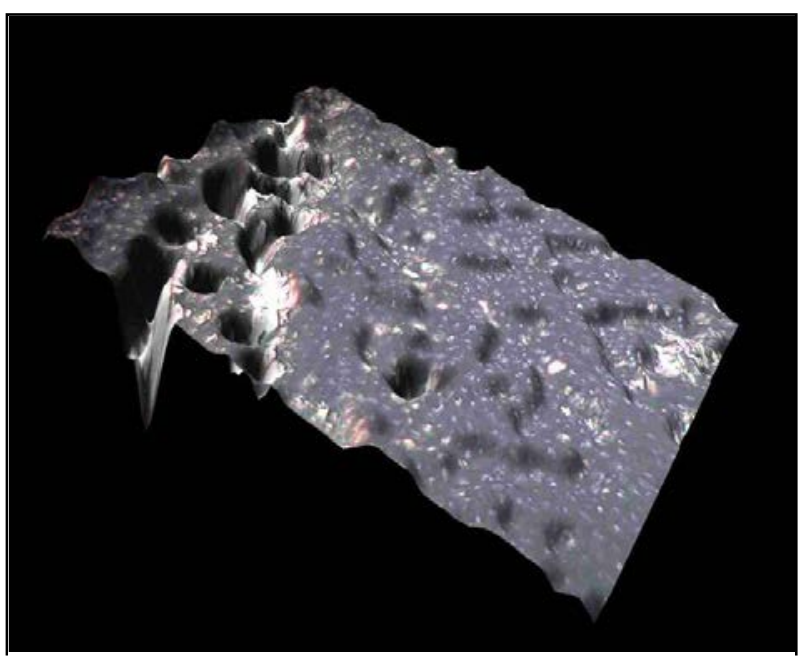

Figure 60. Top view of 15-minute $\mathrm{Pd}$ reduction reaction on SS substrate 
substrate retains substantial area derived from the spheres, one of the initial design criteria.

If the view is rotated so that the pores are seen from the bottom to measure their size, one can see that roughly 200 $\mu \mathrm{m}$ pipes are evident. This may not be the true extent of the pipes, but rather the limit of the microscopes threedimensional ability in this particular case. Nonetheless, Figure 61 clearly shows the "icicle" form of the inner pores as palladium is reduced into the pore space.

The 30 minute reduction shows much the same result. Note the open porosity in Figure 62 as well. This indicates that the smaller pores fill with the initial laying down of the Langmuir layer but that the larger pores require a different mechanism to close.

Viewed from beneath with consistent magnification, Figure 63 shows that the open pores are similar in size and shape between 15-minute and 30-minute reduction times.

The 60-minute reduction shows a radically different result. Notice the lack of open porosity in Figure 64, with piping seen in the top center portion and along the bottom edge.

Viewed from beneath, the results as seen in Figure 65, again show substantial differences, with even the larger piping porosity visible but limited to small, rounded shapes

(the lower right edge is now the far right edge to show the corner porosity more clearly). These preliminary results indicate that the pores are not closing by setting palladium inward from an edge, as has been seen in some methods, but

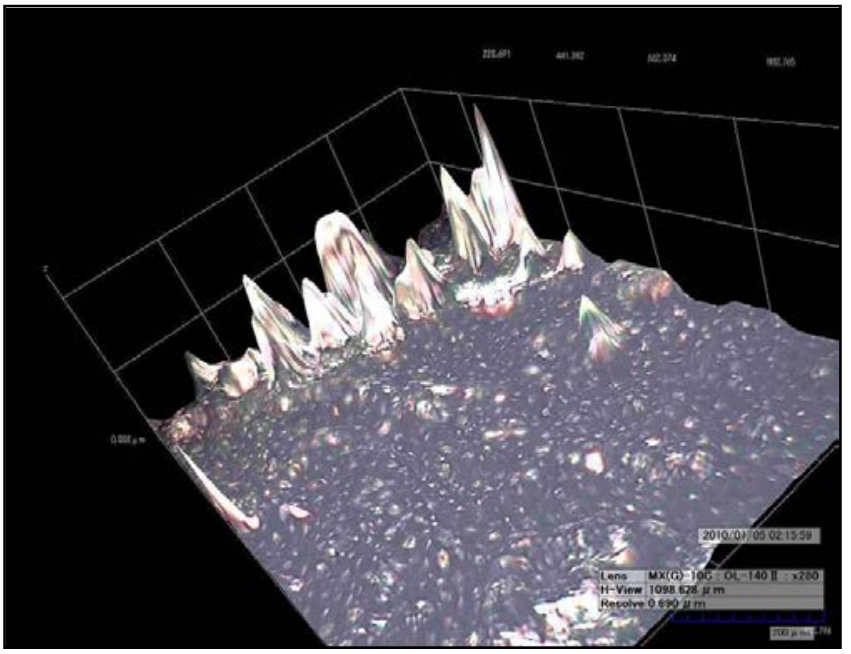

Figure 61. Bottom view of 15-minute Pd reduction reaction on SS substrate

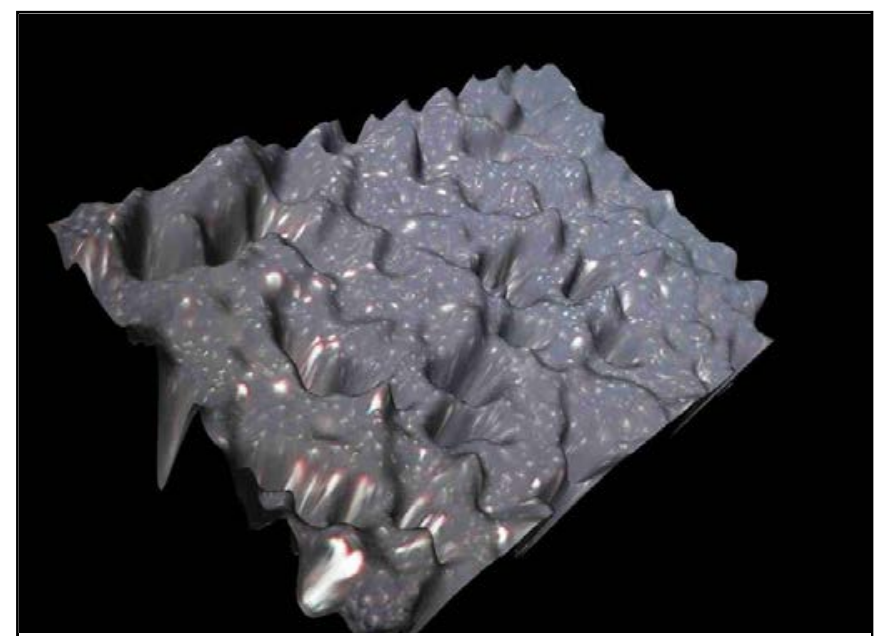

Figure 62. Top view of 30-minute $\mathrm{Pd}$ reduction reaction on SS substrate

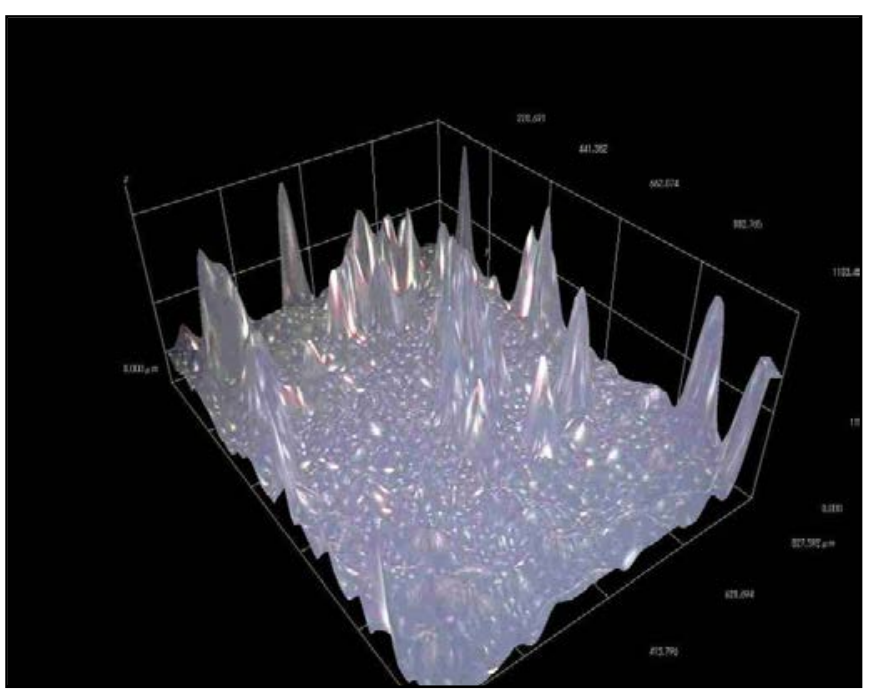

Figure 63: Bottom view of 30-minute Pd reduction reaction on SS substrate 
rather by filling them from the bottom up. This increased thickness would limit hydrogen passage through the larger pore areas; however, because these larger pores appear to be in the minority, the effect on flu rate should be minimal. This anchoring of palladium into the macro-pore space should increase the stability and longevity of the palladium over-layer when it is compared to that deposited solely on a surface either by plasma or by vapor deposition.

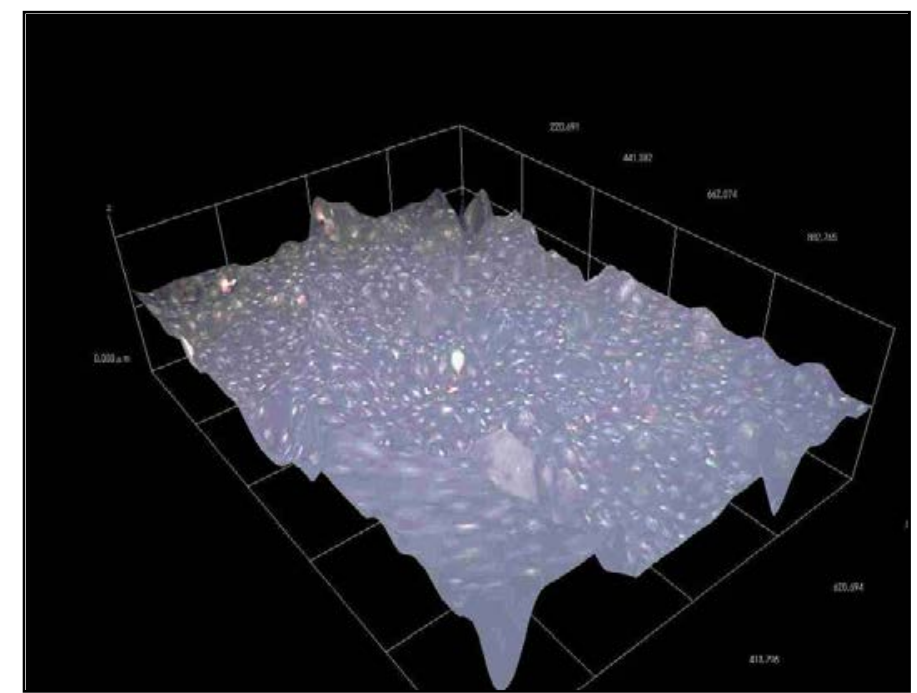

Figure 64: Top view of 60-minute Pd reduction reaction on SS substrate

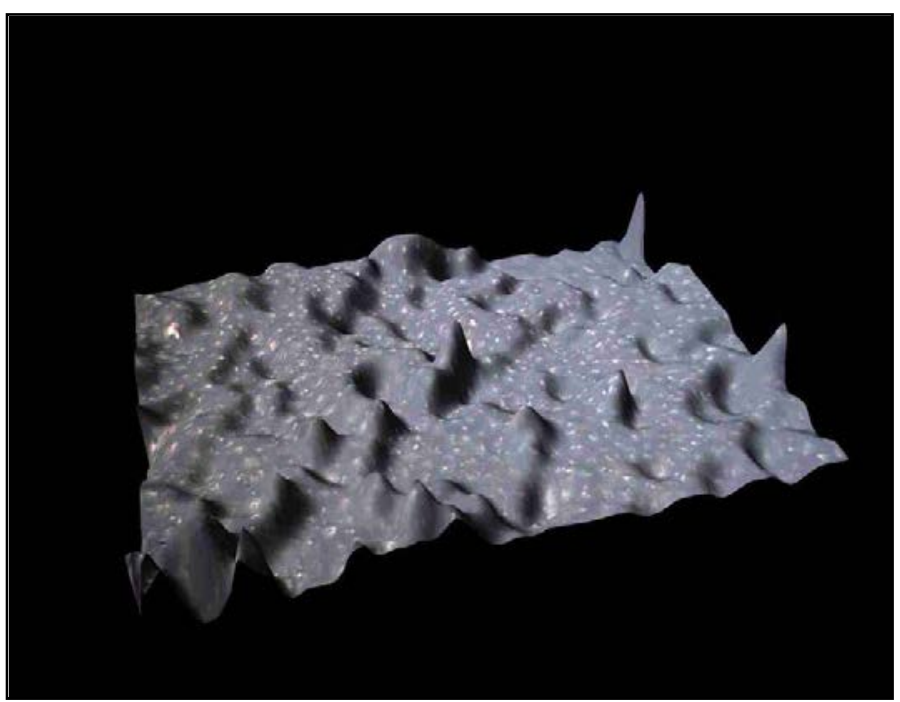

Figure 65. Bottom view of 60-minute Pd reduction reaction on SS substrate 


\subsection{SEPARATION MODULE TESTING}

\subsubsection{Design and fabricate testing apparatus with safety emphasis}

As described above, the proof-of-concept test bed has been designed and operated safely. Additional designs have been done and include the original, industrial design. As discussedabove, this design will not be used in final flux rate testing because of the cost of coating the bulb. However, work is being done on a way to attach the substrate to conventional gas flow equipment in order to connect the substrate to a reactor. Preliminary plans had originally called for welding the bulb

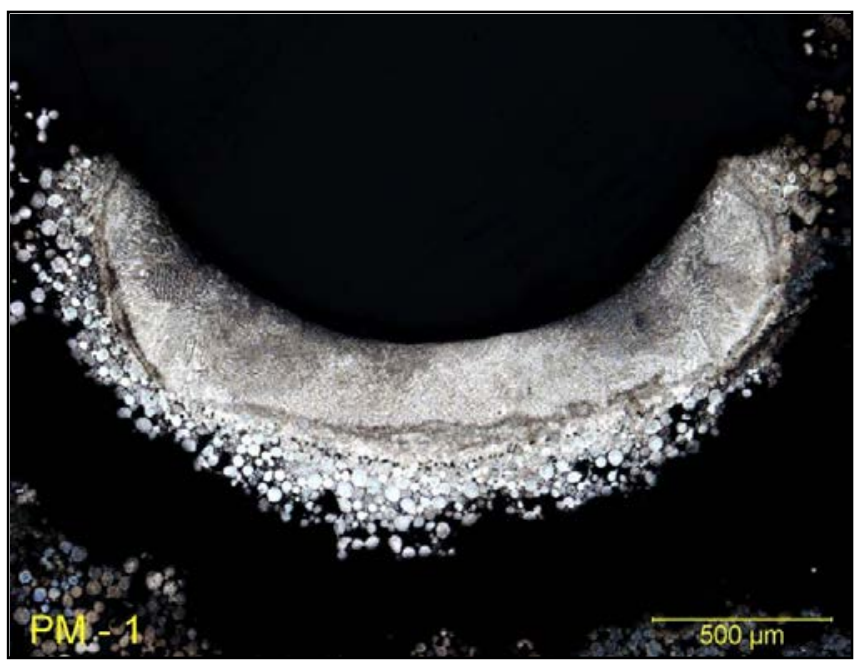

Figure 66. Welding on porous SS substrate (courtesy EWI) to a suitable fitting and using the fitting to mount to the reactor vessel. The Edison Welding Institute (EWI), acting as a partner on subsequent grants, performed initial Bead-on-Plate tests to characterize the effect of the welding process on the porous substrate. They did not recommend welding in this case. As seen in Figure 66, the stainless steel spheres contract when welded, leaving a large pore space below the weld bead. EWI continues to investigate other welding methods, but their results required re-evaluation of the joining methods. Brazing tests are underway.

\subsubsection{Test membrane integrity}

Given that the substrate and membranes are only now complete as a system, no integrity testing has yet been done. The effort/work of performing the integrity testing/durability studies of the membranes is still ongoing and funded through another program (Federal Initiative Program through the Office of Navy Research).

\subsubsection{Test hydrogen separation effectiveness}

Initial testing has been done, with follow-up testing ongoing. Engineering studies to gauge and improve the effectiveness of the separation membrane are ongoing and will be done as the joining problems are resolved. These studies are still on-going and funded through the Federal Initiative Program through the Office of Navy Research as stated above.

\subsubsection{Test operating condition durability}

Given that the substrate and membranes are only now complete as a system, no durability testing has yet been done. Follow up on work will be performed under the DoD US Navy, Edison Welding Institute (EWI) - Fuel Cell Design and Manufacturing Development Project. 
Task 1 Patents: Invention Disclosure and Provisional Patent filing Acknowledgement have been submitted on the Palladium-Based Membrane on a Porous Steel Substrate. Provisional Patent Application, docket No MTT-110P Filing date January 23, 2009, entitled "Palladium-Based Membrane on a Porous Steel Substrate"

\section{Task 1 Publications/Presentations:}

An abstract submitted to 12th Annual Small Fuel Cells Conference April 12-13, 2010. Presentation entitled "Porous Metal Substrates for Hydrogen Purification"

"Development of Palladium Alloy Hydrogen Purification Membranes" International Precious Metals Institute Conference of Precious Metals, June, 2012

"Morphologies and mechanisms in the autocatalytic electroless reduction of palladium" SME, 2012

"Improved Palladium Coatings for Hydrogen Purification" TMS, 2012.

"Free Form Fabrication of Catalytic Substrates" TMS, 2012.

"Important Variables in the Autocatalytic Coating of Palladium" International Precious Metals Institute Conference of Precious Metals, June, 2011.

"Autocatalytic Palladium Coating of Hydrogen Purification Membranes," Hydrogen and Fuel Cells 2011 International Conference and Exhibition, June, 2011.

"Autocatalytic Palladium Coating of Porous Metal Catalytic Substrates," International Precious Metals Institute Conference of Precious Metals, June, 2010.

"Porous Metal Substrates for Hydrogen Purification." Small Fuel Cells 2010 Conference. Spring, 2010

"Electroless Plating of Palladium on Stainless Steel Substrates in Hydrazine Solutions: A Study of the Relationships Between Bath Parameters, Deposition Mechanisms, and Deposit Morphologies." Stacy Davis. A thesis submitted for the Master's Degree in Metallurgical and Mineral Processing Engineering, Montana Tech of the University of Montana. 2011

"Fabrication and Characterization of Porous 420 Stainless Steel Substrates Produced Using Rapid Prototyping Technology and Thermally Strengthened Using Solid State Sintering." Tyler Salisbury. A thesis submitted for the Master's Degree in Metallurgical and Mineral Processing Engineering, Montana Tech of the University of Montana. 2011

"Studies Directed to the Development of Long Lived Palladium Membranes." Glenn Pinson. A dissertation to be submitted for the Doctoral degree in Chemistry, the University of Montana. 2012 


\section{TASK 2}

\section{COMPOSITE HYDROGEN-PRODUCING MATERIALS}

Report Period: August 1, 2006- June 1, 2010

Date of Report: June 1, 2010

Recipient: Montana State University - Bozeman

Award Number: DE-FG36-06G086060

Working Partners: Montana State University - Bozeman; Montana State University Billings; Montana Tech of the University of Montana

Contact: John W. Peters (Lead Investigator) john.peters@chemistry.montana.edu, Montana State University, (406)994-7211

Trevor Douglas (Co Investigator) tdouglas@chemistry.montana.edu, Montana State University, (406)994-6566

Mark Young (Co Investigator) myoung@montana.edu, Montana State University, (406)994-5158

DOE Project Manager: Jim Alkire, (303) 275-4795, Fax (303) 275-4753, James.Alkire@go.doe.gov

DOE HQ Technology Manager: Roxanne Garland (202) 586-7260 Roxanne.Garland@ee.doe.gov

DOE Field Project Officer: Katie Randolph (303) 275-4901 katie.randolph@go.doe.gov 


\section{Task 2}

\section{Use of Biological Materials and Biologically Inspired Materials for $\mathrm{H}_{2}$ Catalysis}

\section{Executive Summary}

\section{Background}

There is tremendous promise in using materials derived from biology for light driven hydrogen production. Hydrogenase enzymes are highly evolved catalysts that support high catalytic rates of hydrogen production in the absence of Nobel metals. Proteins can be used as template support for the synthesis of photocatalysts and hydrogen production catalysts. The promise of using biological materials in large scale processes for photocatalytic hydrogen production depends on overcoming a number of key barriers including the limited stability of biological materials and the ability to effectively coupling of exogenous sacrificial electron donors, photocatalysts, redox mediators, and hydrogen production catalysts.

\section{Biological Materials Overview}

The project has placed an emphasis on probing the ability to overcome key barriers in terms of the durability of biological materials as catalysts for hydrogen production and the controlled protein templated synthesis of versatile hydrogen producing and photocataytic materials. The major goal of the project is to overcome the inherent limited durability of biological materials in order to exploit the abundance, high catalytic activities, and versatility of biomaterials. The work is directed toward the long-term application of bioderived and bioinspired materials into devices.

\section{Major Challenges}

Biological materials are inherently less durable with shorter effective half-lives than synthetic catalysts. In addition, many hydrogenases are sensitive to oxygen and even if oxygen tolerant, those that have the highest activity do not operate in the presence of oxygen. The limited examples of enzymes that do operate in the presence of oxygen have relatively low catalytic activities at least in comparison to other hydrogenases. For hydrogenases to practical for use in materials for large scale hydrogen production for energy, the stability must be enhanced to approach that we are more familiar with for industrial materials. For metal-containing synthetic catalysts, an important factor is maximizing the metal surface that can participate in catalysis. This is especially important in catalysts that utilize rare metals in finite abundance. Optimally hydrogen production from alcohols or waste organic acids could be economically feasible and therefore the generating a single platform to synthesize photocatalysts that could be tuned to use different sacrificial electron donors is highly desirable.

\section{Results}

We have been able to show that hydrogenases can be immobilized and encapsulated into silica oxide gel (sol-gel) and polyviologen gels and retain activity. The optimization of sol-gel immobilization and the incorporation of carbon nanotubes to enhance electron transfer resulted in observed hydrogenase activities equal to or in access of maximal activities observed in solution. The incorporation of stable hydrogenases found in 
nature ([NiFe]-hydrogenase from Thiocapsa roseopersicina) into the electroactive carobn nanotube sol-gel matrix resulted in hydrogen producing materials that had significantly longer shelf lives, that could support continuous hydrogen production over extended periods, and that could be reused. We (and others) have shown that hydrogenases can be attached to electrode surfaces and support hydrogen production in the presence of applied overpotential. Protein templates such as ferretin, heat shock particles, and viruses have been shown to effective means for the synthesis of high surface area / high catalytic activity Pt and Pd hydrogen producing nanoparticles. The synthesis of particles can be controlled at the particles size to maximize surface area and particles as previously mentioned for hydrogenases can be incorporated into electroactive three-dimensional matrices or attached to conducting surfaces in an active state. We have shown that catalytic materials can be coupled to photocatalytic materials (iron oxide and titanium oxide) via redox mediators and incorporated into prototype photcatalytic hydrogen producing devices.

\section{Major Conclusions}

Bioderived materials have tremendous promise for biotechnology because of their high specificity, catalytic efficiencies and versatilities. For hydrogen production and utilization, hydrogenase enzymes do not use Nobel metals and have high catalytic activities. There are a number of barriers to using hydrogenase and other bioderived materials for large scale energy production including their cost and stability / durability. In this work we have shown that hydrogenases and protein derived mimetic catalysts having high specific activities toward hydrogen production can be stabilized and incorporated into materials resulting in robust hydrogen producing materials. Further optimization of these materials coupled with parallel work focused on optimizing hydrogenase expression and maturation will pave the way for the incorporation of bioderived hydrogen producing materials into our global energy portfolio. 


\section{Introduction}

There is significant interest in the use of hydrogen gas as an alternative fuel for the rapidly evolving hydrogen fuel cell technology. The practicality of the increased use of hydrogen fuel cell technologies is dependent on the ability to produce stores of hydrogen gas in an efficient, economically feasible, and environmentally sound manner. The development of catalysts for the production of hydrogen gas efficiently from a renewable source is of paramount importance. Biological production of hydrogen is likely to play a key role in the emerging hydrogen economy. In particular, a group of enzymes, hydrogenases $\left(\mathrm{H}_{2}\right.$ ases $)$, have attracted a great deal of attention because of their ability to efficiently catalyze the reversible reduction of protons to form $\mathrm{H}_{2}$. The catalytic rates observed for these enzymes are far superior to existing hydrogen production catalysts. The catalytic site of hydrogenase enzymes consist of unique biological metal clusters (Fe or NiFe) stabilized by carbon monoxide and cyanide ligands.

\section{Approach}

We have adopted a two-pronged approach a) the use of hydrogenase enzymes themselves incorporated into stabilizing polymer matrices for efficient $\mathrm{H}_{2}$ production and b) the development biomimetic catalyst systems combining reduced metal nanoparticles $(\mathrm{Pd}, \mathrm{Pt}, \mathrm{Fe}, \mathrm{Co}$, and $\mathrm{Ni})$ within engineered protein architectures to mimic the activity of hydrogenase enzymes. We have examined the determinants of stability in natural occurring in natural occurring hydrogenases of superior stability and we have examined approaches to stabilized hydrogenses in materials that facilitate the couple of enzymes directly to redox mediators and photcatalyts. We have developed composite materials that consist of hydrogen-generating catalytic materials (either hydrogen enzymes or Pd, $\mathrm{Pt}, \mathrm{Fe}, \mathrm{Co}$, Ni or mixed metal mimics) coupled to photocatalytic materials (light energy), which are either molecular or nanomaterial based. These composite materials represent practical sustainable means of generating hydrogen gas from fully renewable sources. Using biomimetic approaches nanoparticle catalysts have been synthesized which mimic the catalytic properties of the enzyme but can be mass produced more readily with desirable features in the context of durability and oxygen tolerance.

\section{Objectives}

- Optimize the hydrogenase stability and electron transfer

- Examine protein cage architectures for the synthesis of catalysts for hydrogen production

- Optimize the semiconductor nano-particle photocatalysis, oxygen scavenging, and electron transfer properties of protein nano-cages

- Examine gel/matrix and surface immobilization of hydrogeases and nanomaterials to enhance stability and facilitate electron transfer.

- Device fabrication for $\mathrm{H}_{2}$ production 


\section{Technical Barriers}

This project addresses the following technical barriers from the Hydrogen Production section of the Hydrogen, Fuel Cells and Infrastructure Technologies Program Multi-Year Research, Development and Demonstration Plan:

(AL) Light Utilization Efficiency

(AM) Rate of Hydrogen Production

(AN) Hydrogen Re-oxidation

(AP) Systems Engineering

\section{Technical Targets}

Photoelectrochemical Hydrogen ProductionProtein-Based Hydrogen Production Materials/Devices:

This project is conducting fundamental studies of hydrogenase enzymes and biomimetic nanoparticle mimics and their incorporation into durable materials. Insights gained from these studies will be applied toward the design and synthesis of hydrogen production materials/devices to probe specific metrics for competitive evaluation including:

Shelf life of the hydrogen catalyst

Longevity of catalyst under sustained hydrogen production

Thermal stability

\section{Accomplishments}

Demonstrated that hydrogenase enzymes can be encapsulated within silica gel matrices for enhanced ease of fabrication, without loss of activity, and with some stabilization towards degradation.

Demonstrated that hydrogen production activity of encapsulated hydrogenases is sensitive to $\mathrm{pH}$.

Demonstrated that encapsulated hydrogenase materials can be reused and recycled.

Demonstrated that electroactive gel matrices (polyviologen and viologen doped silica gels) can be manipulated to effect hydrogen production activity.

Demonstrated efficient hydrogen production with noble metal nanoparticles synthesized using protein cage architectures. Hydrogen production rates are competitive with enzyme catalyzed (hydrogenase) reactions.

Discovered that hydrogen production can be achieved with pure noble metal and noble metal alloy composite nanoparticles.

Demonstrated size dependent catalytic efficiency on a range of nanoparticle constrained nanoparticles and demonstrated that nanoparticle size affect catalytic 
Demonstrated thermal stability of both hydrogenase enzymes and synthetic biomimetic catalyst composites up to $90^{\circ} \mathrm{C}$ with hydrogen production.

Determined a potential structural basis for the observed enhanced thermal stability observed for the [NiFe]-hydrogenase from Thiocapsa roseopersicina.

\subsection{INTRODUCTION TO HYDROGENASE}

Hydrogenase enzymes are present in a variety of microorganisms and function either to catalyze hydrogen oxidation or proton reduction $\left(\mathrm{H}_{2} \Leftrightarrow 2 \mathrm{H}^{+}+2 \mathrm{e}^{-}\right)$. Hydrogenases contain either $\mathrm{Ni}$ and $\mathrm{Fe}$ or $\mathrm{Fe}$ alone on the basis of their metal content (Figure 67). The $\mathrm{NiFe}$ hydrogenases have a bimetallic NiFe active site in which an $\mathrm{Fe}$ atom bound by bridging thiolates possesses both carbon monoxide and cyanide ligands. For the Feonly class, the active site "H cluster" consists

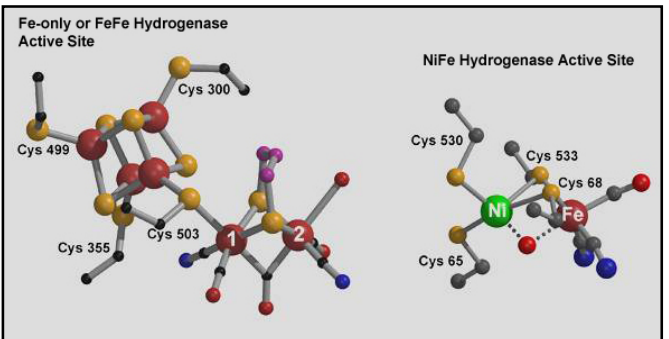

Figure 67. Active site clusters of the Fe-only (1) (left) and NiFe (right) hydrogenases of a [4Fe-4S] cubane bridged to a di-iron subcluster, which is coordinated by a nonprotein dithiolate bridging ligand and carbon monoxide and cyanide ligands. In our previous work we have been able to make a number of key contributions to establishing relationships between the structure and chemical mechanism of hydrogenase enzymes.

\subsubsection{Characterization of Ni particle formation by T. roseopersicina stable [NiFe]- hydrogenase}

In this study, working from some suggestions made by our collaborators in Pushchino Russia, we made the observation that the [NiFe]-hydrogenase from $T$. roseopersina could directly couple hydrogen oxidation to reduce $\mathrm{Ni}$ ions to $\mathrm{Ni}$ metal. We are very interested in the physiological role of the hyn encoded [NiFe]-hydrogenases. These enzymes have been observed to be significantly more stable than hydrogenases from other sources and are observed to form supermolecular circular assemblies. We are interested in the physiological role of these enzymes to

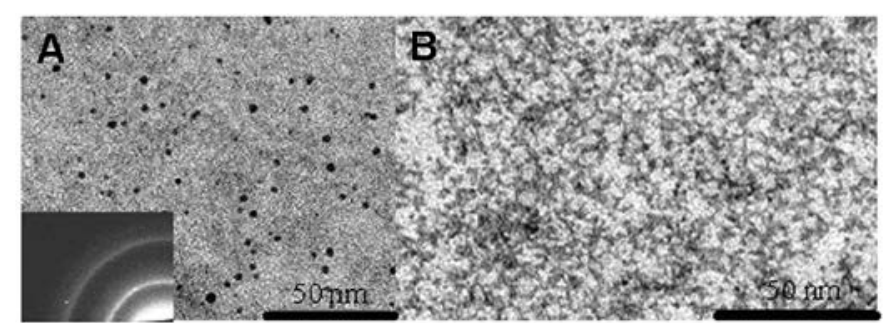

Figure 68. TEM analysis of Ni nanoparticles. Unstained TEM of Ni nanoparticles (A), inset: electron diffraction, average diameter of $2.6 \pm 0.6 \mathrm{~nm}$. Stained TEM of $\mathrm{Ni}$ nanoparticles stained with $2 \%$ uranyl acetate (B). Scale bar for both images is $50 \mathrm{~nm}$. better aid out search in natural systems for stable hydrogenases for biotechnological applications. The ability of the $T$. roseopersicina hydrogenase to reduce $\mathrm{Ni}$ ions directly suggest that the hydrogenase may function in nature in metal tolerance making environments high in metals likely sources for bioprospecting for novel hydrogenases with desirable properties. We have 
shown that $T$. roseopersicina can tolerate elevated levels of $\mathrm{Ni}$ ions in the presence of hydrogen and that these cells accumulate Ni particulate. In parallel we have shown that purified preparations of $T$. roseopersicina [NiFe]-hydrogenase can reduced $\mathrm{NiCl}_{2}$ to $\mathrm{Ni}$ metal and that the $\mathrm{Ni}$ metal forms uniform $\mathrm{Ni}$ nanoparticles within the core of the hydrogenase circular assembly (Figure 68).

\subsubsection{Hydrogenase and encapsulation and stabilization}

The NiFe hydrogenase enzyme from Thiocapsa roseopersicina, has also been adsorbed onto a glassy carbon electrode surface and the cyclic voltammetry shows a clear reduction of the catalytic metal cluster. In addition, we are extending this work to the attachment of other conducting surfaces in advance of the fabrication of a hydrogen production device. We have examined the stability of hydrogenases in solution and immobilized in electroactive gels. We have demonstrated that hydrogenases can be incorporated into electroactive gels such as methyl viologen doped slica gels (Figure 69) and polyviologen gels. Hydrogenases encapsulated in both of these gel matrices retain activity and are protected from protease degradation of the enzyme

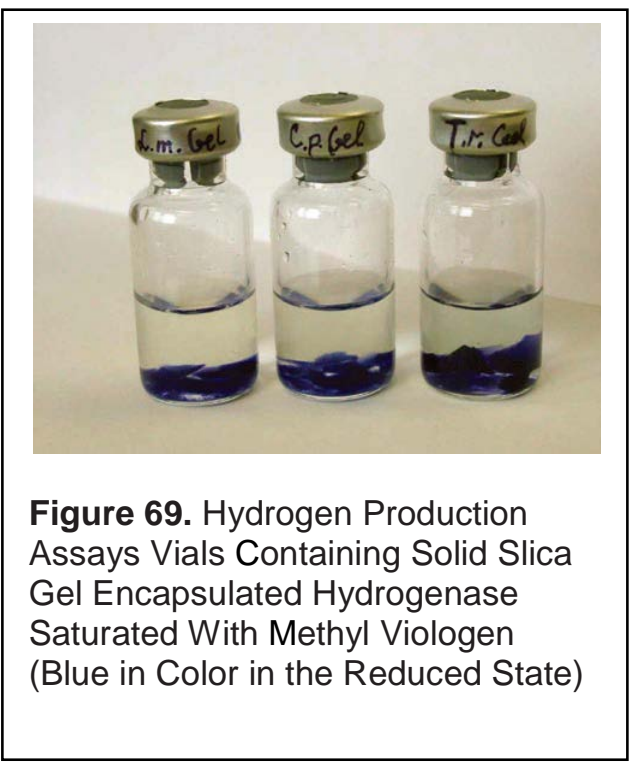
illustrating the real potential for incorporating these biological catalysts into robust materials. In methyl viologen saturated silica gels, hydrogenases can exhibit sustained hydrogen production for more than sixty minutes.

\subsubsection{Reusability}

We had made the observation in our previous studies examining the encapsulation of hydrogenases in Sol Gels that incubation of hydrogenase containing Sol Gels with dithionite and methyl viologen resulted in hydrogen production but that over time reduced methyl viologen appeared to accumulate in the gel. This was apparent by a persistent purple color and could be attributed to immobilization of the methyl viologen by specific electrostatic interactions between the positively charge methyl viologen and the negatively charged silica gel. Presumably in this scenario, molecules of methyl viologen remain reduced because they are not in close enough proximity to donate

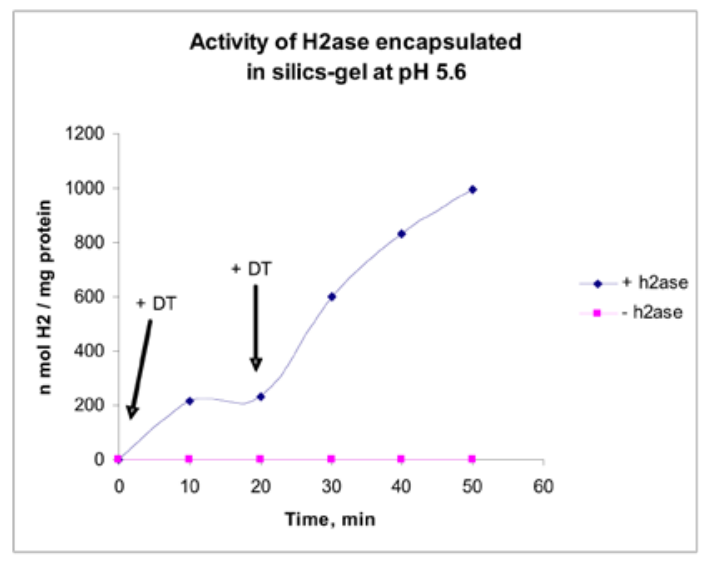

Figure 70. Activity of nanotube doped sol-gels measure in $1 \mathrm{ml}$ gels in $8 \mathrm{ml}$ sealed wheaton vials. Activity was measured in the absence of the redox mediator methyl viologen typically used in hydrogen production assays. Addition of sodium dithionite (DT) as an electron donor is shown. 
electrons to encapsulated hydrogenase. This could also be caused by a shift in the midpoint potential of methyl viologen as a result of specific interactions with the gel. The stained purple gels where thought to be "fouled", but in fact they were still active and the addition of more dithionite to these "fouled" purple gels again produces hydrogen. Exposing the gels to aerobic conditions turns them clear because the methyl viologen is oxidized by oxygen but by returning the same (now clear) gel to anaerobic conditions and adding dithionite, the gel turns purple. The solution does not turn purple, suggesting that the methyl viologen is localized on the gel. This purple gel is again able to reduce hydrogenase and hydrogen gas is produced. The capture of electrons by the gel matrix is not ideal for efficient coupling of electron transfer to hydrogen production and thus we have been examining ways in which to overcome these issues. We have during this quarter that the midpoint potential of methyl viologen appears not to be significantly altered in the gels and thus cannot be used to explain the inability of the gels to be fully oxidized by hydrogenase even when the terminal electron donors is limiting. We believe that the strong electrostatic interactions between the uniformly negatively charged gel and the positively charged methyl viologen effectively sequester a portion of the viologen mediator such that electron transfer between the mediator and the hydrogenase does not occur. Attempts to weaken the interaction between the gel and the mediator by increasing the ionic strength in the gels has not resulted in eliminating the effect and high ionic strengths can result in enzyme inhibition.

\subsubsection{Optimized conditions for developing composite materials based on encapsulation of hydrogenase and multiwall carbon nanotubes into sol-gel}

We have optimized conditions for hydrogen production by the $T$. roseopersicina hydrogenase encapsulated into sol-gel. We have shown that hydrogenase encapsulated into sol-gel remains active in presence of carbon nanotubes. The results of these experiments provide the important information about the properties of composite materials composed of silica-gel, carbon nanotubes and encapsulated hydrogenases indicating that carbon nanotubes have high efficiency to conduct electron flow from electron donor/acceptor to hydrogenase in silica-gel (Figure 71). Different type of carbon nanotubes (single- or multi-wall nanotubes) has been developed for this application. The results of our experiments with single- or multi-wall carbon nanotubes show no difference in the activity of hydrogenase encapsulated into sol gel in presence of $4 \mathrm{mM}$ methyl viologen (MV) as an electron carrier.

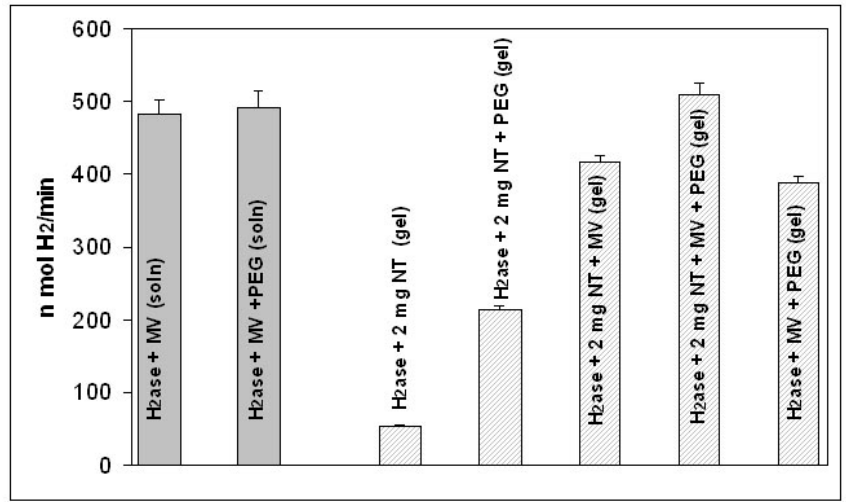

Figure 71. Impact of polyethylene glycol, carbon nanotubes and methyl viologen on activity of encapsulated hydrogenase. Hydrogen production activity of the sol-gel (gel) encapsulated hydrogenase from Thiocapsa roseoperisicina resulting from addition of dithionite in $50 \mathrm{mM}$ phosphate buffer, $\mathrm{pH} 5.5$. Solution (soln, solid shaded bar) assay is shown for comparison. 
We have shown that increasing the concentration of nanotubes increases the hydrogen production by the hydrogenase in presence of MV. We have also shown the direct transport of electrons through multiwall carbon nanotubes to the hydrogenase without using MV as an electron carrier. Addition of MV increases the hydrogen evolution by encapsulated hydrogenase. The hydrogen production by this system was significantly dependent on the $\mathrm{pH}$ of the

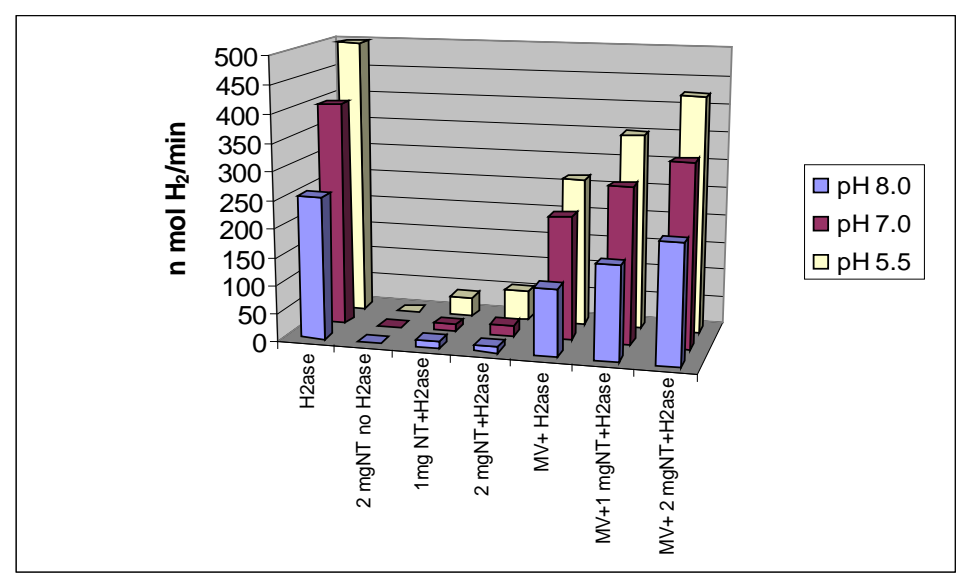

Figure 72. Effect of $\mathrm{pH}$ and concentration of multiwall carbon nanotubes on the hydrogen production by encapsulated hydrogenase. reaction mixture and was 5 times higher at $\mathrm{pH} 5.5$ in compare to $\mathrm{pH}$ 8.0. It has been shown that activity of hydrogenase in solution also dependent on $\mathrm{pH}$ and was $\sim 2$ times higher at $\mathrm{pH} 5.5$ than at $\mathrm{pH} 8.0$ (Figure 72) (Zorin et al. 1996).

We have examined the effect of the addition of polyethylene glycol (PEG) to gels on the activity of $T$. roseopersicina hydrogenase at different $\mathrm{pH}$. Previously it has been shown that the addition of PEG to sol gels can modulate the pore size of the gels and have significant effects on mass transfer (Sato et al., 1990). The reaction mixture consists of $50 \mathrm{mM}$ phosphate buffer $\mathrm{pH}$ 5.5, 7.0 and 8.0 and polymerized sol gel. The sol gel was prepared from tetramethoxy silane with the addition of different concentrations of PEG with molecular weight 400 (PEG 400) and/or multiwall nanotubes in presence of 2 or $4 \mathrm{mM}$ methyl viologen (Figure 5). Sol gel was polymerized during $10 \mathrm{~min}$ with the addition of an equal volume of $0.8 \mathrm{mg} / \mathrm{ml}$ hydrogenase in $50 \mathrm{mM}$ phosphate buffer $\mathrm{pH}$ 7.5. The results of our experiments show that increasing PEG concentration from $0 \%$ to $20 \%$ increases the activity of hydrogenase, whereas $40 \%$ PEG inhibited the hydrogen production by encapsulated hydrogenase. The addition of PEG did not influence on the hydrogenase activity in solution. The results of our experiments show that optimum conditions for the development of composite material based on encapsulation of hydrogenase and nanotubes consist of 20\% PEG and $2 \mathrm{mg}$ nanotubes and $4 \mathrm{mM}$ methyl viologen at $\mathrm{pH}$ 5.5. Under these optimal conditions for encapsulation, hydrogenase activities equivalent to the maximum activities in solution were observed.

\subsubsection{Photoinduced $\mathrm{H}_{2}$ production $\mathrm{T}$. roseopersicina hydrogenase covalently linked to Ru(II) photosensitizer}

Most recently we have been examining the coupling of the $T$. roseopercicina $\mathrm{Ru}(\mathrm{II})$ complex. We have been able to couple the $\mathrm{Ru}(\mathrm{II})$ complex, $\left[\mathrm{Ru}(\mathrm{bpy})_{2}\left(\mathrm{NH}_{2}\right.\right.$ phen $\left.)\right]\left(\mathrm{PF}_{6}\right)_{2}$ to surface carboxylates of the $T$. rosepersicina hydrogenase in a manner in which most of the activity of the hydrogenase is maintained. Using EDTA as an electron donor to the $\mathrm{Ru}(\mathrm{II})$ complex we have been able to demonstrate light dependent hydrogen 


\begin{tabular}{|c|c|c|c|c|}
\hline Sample & $\begin{array}{c}\mathrm{nmol} \\
\mathrm{H}_{2} / \\
\mathrm{mg} \\
\text { protein }\end{array}$ & $\begin{array}{l}\% \text { of } \\
\text { activity }\end{array}$ & $\begin{array}{c}\mathrm{nmol} \mathrm{H}_{2} / \\
\mathrm{mg} \\
\text { protein/ } \\
\mu \mathrm{g} \mathrm{Ru}\end{array}$ & $\begin{array}{c}\text { \% of } \\
\text { activity/ } \\
\mu g \text { Ru }\end{array}$ \\
\hline $\mathrm{H}_{2}$ ase $+\mathrm{MV}(\mathrm{Zn})$ & 510 & 100 & - & - \\
\hline $\begin{array}{c}\mathrm{H}_{2} \text { ase- } \mathrm{Ru}(\mathrm{c})+\mathrm{MV} \\
(\mathrm{Zn})\end{array}$ & 286 & 56 & - & - \\
\hline $\begin{array}{c}\text { EDTA + Ru(c) + } \\
\text { MV (light) }\end{array}$ & 0 & 0 & - & - \\
\hline $\begin{array}{c}\text { EDTA + Ru(c) + } \\
\mathrm{H}_{2} \text { ase (light) } \\
\end{array}$ & 0 & 0 & - & - \\
\hline $\begin{array}{c}\text { EDTA + Ru(c) + } \\
\mathrm{MV}+\mathrm{H}_{2} \text { ase } \\
\text { (light) }\end{array}$ & 224 & 44 & 226 & 100 \\
\hline $\begin{array}{c}\text { EDTA + } \mathrm{H}_{2} \text { ase- } \\
\mathrm{Ru}(\mathrm{c}) \text { (light) }\end{array}$ & 0 & 0 & 0 & 0 \\
\hline $\begin{array}{c}\text { EDTA + } \mathrm{H}_{2} \text { ase- } \\
\text { Ru(c) + MV } \\
\text { (light) }\end{array}$ & 121 & 24 & 4936 & $\begin{array}{c}22 \\
\text { times }\end{array}$ \\
\hline
\end{tabular}

production and we have been able to show that the covalent attachment affords a 22x increase in activity when an equal molar of attached and unattached $\mathrm{Ru}(\mathrm{II})$ are compared (Table 15). We have also recently been able to show that the system will operate in the presence of oxygen. These are very significant results and we are current reproducing these results and optimizing the system to assess the level of oxygen tolerance.

Table 15. Light dependent hydrogen production of the [NiFe]-hydrogenase from $T$. roseopersicina

\subsubsection{Structural analysis of the [NiFe]-hydrogenase from Thiocapsa roseopersicina}

We have been working on structural characterization of $T$. roseopersicina [NiFe]hydrogenase because this enzyme has a high inherent stability and resists proteolysis. It has been shown that this hydrogenase is stable to high temperature and oxygen. These properties make this enzyme attractive in the application for hydrogen producing materials. It has been shown that at high protein concentration $(\sim 10 \mathrm{mg} / \mathrm{ml})$ this enzyme forms the supermolecular complex (Sherman et al., 1991). The specific interactions that stabilize this structure are likely significant to the overall stability of this enzyme and the structure of this assembly is of significant interest in order to identified these factors. We have been able to determine the structure of the enzyme in collaboration with Laing Tang and the University of Kansas to 5-8 $\AA$ resolution. This has been a difficult project our preliminary studies on small angle $x$-ray scattering and dynamic light scattering (Figure 73) indicate that the enzyme adopts a supermolecular structure that is very concentration dependent. This work has indicated however that at concentrations greater than $15 \mathrm{mg} / \mathrm{ml}$ that largely homogenous preparations of the supermolecular complex can be maintained. We have exploited the knowledge of the behavior of the $T$. roseopersicina hydrogenase in developing the appropriate conditions for highresolution electron microscopy (EM). Numerous structures of the hydrogenase were examined by EM

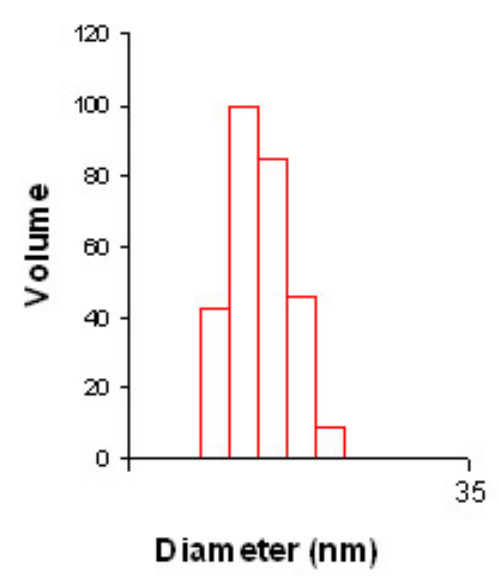

Figure 73. Dynamic light scattering of $T$. roseopersicina hydrogenase reveals a particle diameter of $\sim 13.0 \mathrm{~nm}$ resulting in a three-dimensional structure that reveals the salient features of the supermolecular structure (Figure 74). The structure exists as 
a heterododecameric complex in which individual large and small subunits are arranged in an alternating fashion. This structure is unprecidented for a hydrogenase and since the complex is not as stable at lower concentrations we have in parallel been able to examine the structure of individual dimers by EM and with avaiable structures of dimeric [NiFe]-hydrogenase with substatial sequence identities we have been able to asseble a reliable reconstruction of the supermolecular structure. This is highly significant since it is our hypothesis that the supermolecuar structure holds the keys to thermal stability and perhaps even provides insights into oxygen tolerance. Revealing the structural determinants of these two properties that represent major barriers in the successful implementation of the use of hydrogenases in hydrogen producing materials. We have been able to identify a number of complentary interactions between the individual dimers that stablize the complex and we are designing mutagenesis experiments to test whether some of these residues have a direct role in stability of the complex and associated thermal stability. We have also made an exciting observation in the structure in that the extended $\mathrm{C}$-terminus of the small subunit of the $T$. roseopersicina enzyme (shown in yellow in figure 74) when compared to other hydrogenases appears to have a key role in complex formation. We are also designing mutagensis experiments to probe this unique property of this hydrogenase to assess the role of the $\mathrm{C}$-terminus in thermal stability. These results are very signficant in terms of defining thermal stability in this hydrogenase and also represents, to our knowledge the smallest structure to be determined at this level by EM.
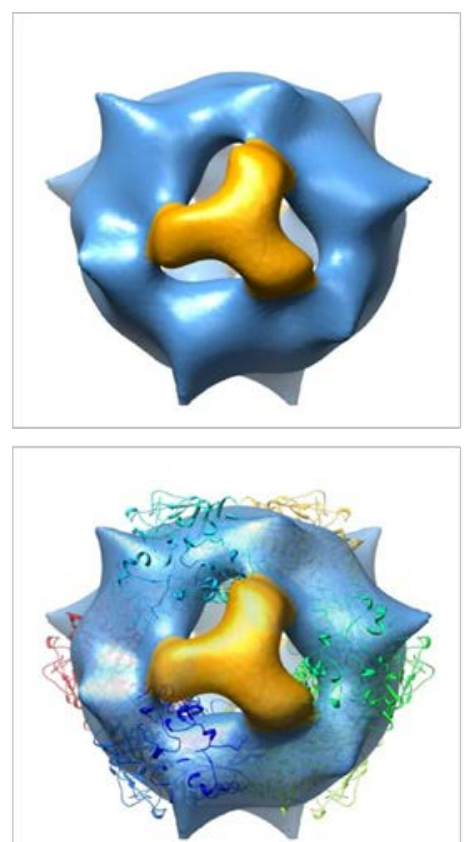

Figure 74. High resolution structure of $T$. roseopersicina hydrogenase with reconstruction
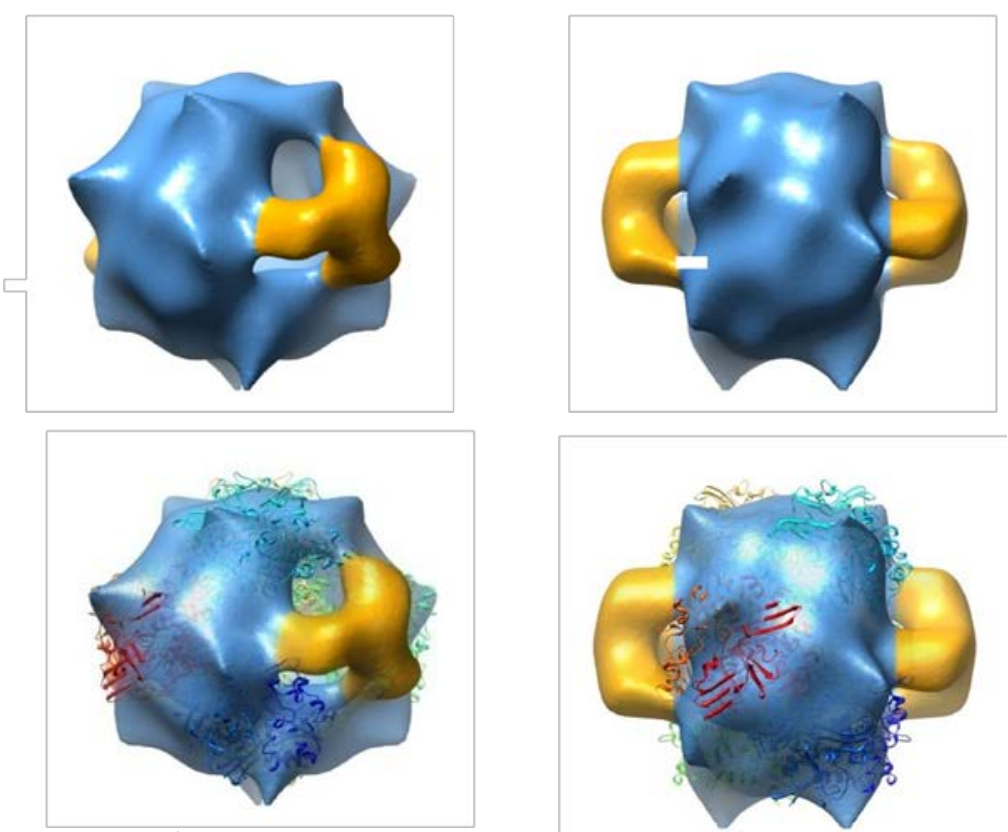


\subsection{TASK 2 Composite Hydrogen -Producing catalytic Materics}

\section{Objectives}

- Optimize the hydrogenase stability and electron transfer

- Optimize the semiconductor nano-particle photocatalysis, oxygen scavenging, and electron transfer properties of protein nano-cages

- Gel/Matrix immobilization and composite formulation of nano-materials and hydrogenase

- Device fabrication for $\mathrm{H}_{2}$ production

\section{Introduction}

There is significant interest in the use of hydrogen gas as an alternative fuel for the rapidly evolving hydrogen fuel cell technology. The practicality of the increased use of hydrogen fuel cell technologies is dependent on the ability to produce stores of hydrogen gas in an efficient, economically feasible, and environmentally sound manner. The development of catalysts for the production of hydrogen gas efficiently from a renewable source is of paramount importance. Biological production of hydrogen is likely to play a key role in the emerging hydrogen economy. In particular, a group of enzymes, hydrogenases $\left(\mathrm{H}_{2}\right.$ ases), have attracted a great deal of attention because of their ability to efficiently catalyze the reversible reduction of protons to form $\mathrm{H}_{2}$. The catalytic rates observed for these enzymes are far superior to existing hydrogen production catalysts. The catalytic site of hydrogenase enzymes consist of unique biological metal clusters (Fe or NiFe) stabilized by carbon monoxide and cyanide ligands.

\section{Approach}

We have adopted a two-pronged approach a) the development biomimetic catalyst systems combining reduced metal nanoparticles ( $\mathrm{Pd}, \mathrm{Pt}, \mathrm{Fe}, \mathrm{Co}$, and $\mathrm{Ni}$ ) within engineered protein architectures to mimic the activity of hydrogenase enzymes b) the use of hydrogenase enzymes themselves incorporated into stabilizing polymer matrices for efficient $\mathrm{H}_{2}$ production. We have developed composite materials that consist of hydrogen-generating catalytic materials (either hydrogen enzymes or $\mathrm{Pd}, \mathrm{Pt}, \mathrm{Fe}, \mathrm{Co}, \mathrm{Ni}$ or mixed metal mimics) coupled to photocatalytic materials (light energy), which are either molecular or nanomaterial based. These composite materials represent practical sustainable means of generating hydrogen gas from fully renewable sources. Using biomimetic approaches nanoparticle catalysts have been synthesized which mimic the catalytic properties of the enzyme but can be mass produced more readily and have desirable features in the context of durability and oxygen tolerance.

\subsubsection{Protein Cage-based synthesis of nanomaterials and catalysts}

As part of an ongoing effort to move away from Pt as the catalytically active metal center, we have explored alloying platinum with various other transition metals. We 
have continued to pursue our goals of developing biomimetic approaches to the synthesis of active nanocatalysts. We have characterized and defined reaction conditions yielding well defined-catalytically active nanoparticles of $\mathrm{Pt}, \mathrm{Pd}, \mathrm{Zn}$, Ni using a library of protein cages as templates for the biomimetic synthesis of active $\mathrm{H}_{2}$ generating catalyst. These protein-metal nanomaterials are composites in which the protein cage serves to direct the formation of the metal cluster and serves to isolate the active nanoparticle within an open framework.

We have built on our established synthesis for mineralizing $\mathrm{Pt}^{0}$ in ferritin and heat shock protein, and determined synthetic conditions for mineralizing palladium as well as alloys of both $\mathrm{Pd}$ and Pt. We have successfully alloyed both $\mathrm{Pd}$ and $\mathrm{Pt}$ with zinc and nickel in ratios of 3Pt/Pd:1M (M = Ni, Zn) (figure 75).

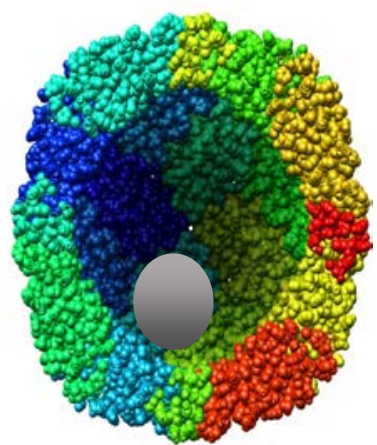

Figure 75: Cut-away view of ferritin with a nanoparticles of what could be Pt, Pd, PtZn, PtNi, PdZn, or PdNi The reactions have been accomplished in ammonium acetate at $\mathrm{pH} 5.0$ in the presence of an excess of the reducing dimethyl amine borane complex. Sonication was found to be more effective than stirring. We've already shown Pt to be a highly active catalyst for

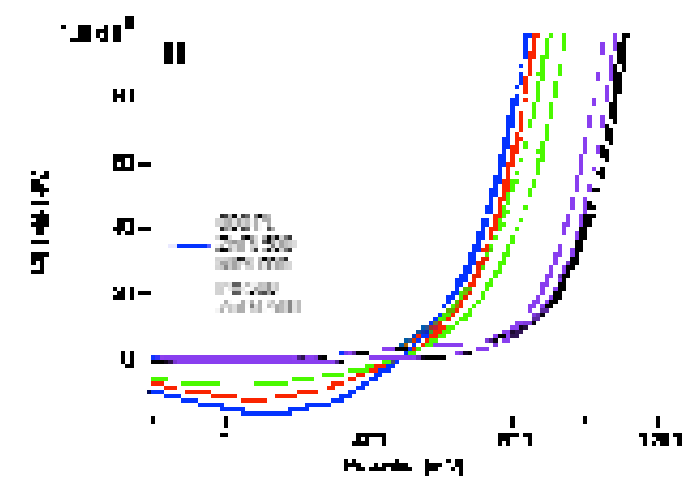

Figure 76: Cyclic voltammograms of $\mathrm{Pt}, \mathrm{Pd}$, and $\mathrm{Pt} / \mathrm{Pd}$ alloys with $\mathrm{Ni}$ and $\mathrm{Zn}$,

encapsulated within the Fn protein cage.

$\mathrm{H}_{2}$ production, but we've also seen very high activities with the Pt/Pd-alloys as well. To characterize the activity of the materials we have used protein-film voltammetry (figure 76). The onset potential and intensity (amperes) of the wave seen are indicators of the how effective a catalyst will be.

The importance of Pt (and Pt group metals) as hydrogen catalysts is undisputed. However, their utility is limited by the limited abundance

and expense in extracting the metal. As part of our effort in this thrust we have explored the most efficient utilization of $\mathrm{Pt}$ for proton reduction reactions to make $\mathrm{H}_{2}$. It has been suggested that there is a lower limit to the size of a Pt cluster where it will no longer act as an effective $\mathrm{H}_{2}$ catalyst. This is estimated at about 50 atoms of Pt. However, direct observation of a $50 \mathrm{Pt}$ atom cluster is beyond the detection ability of most analytical instrumentation. Also it is difficult to differentiate distribution of cluster sizes in this range. In the last reporting period we have begun work to chemically synthesize, in a controlled manner, and analyse atom-by-atom growth of Pt nanoclusters within

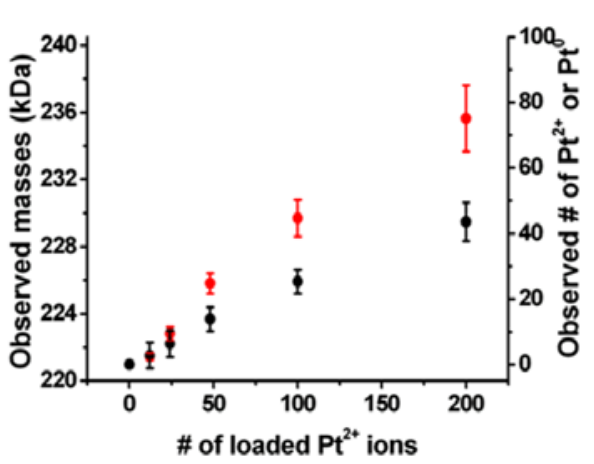

Figure 77. Plots of the observed masses of the $\mathrm{Pt}^{2+}$ bound (circles) and the $\mathrm{Pt}^{0}$ mineralized (sqaures) LiDps cages according to the initial $\mathrm{Pt}^{2+}$ input numbers. Deviations of $\mathrm{Pt}^{0}$ contents in the broaden peaks were determined by calculating half-width at the half-height of each peak and comparing with 0 loading control. 
a protein cage architecture. The analysis has been accomplished using direct measurement of the protein cage mass over the course of a chemical synthesis of Pt nanoparticles. We have genetically and chemically modified a small protein cage from Listeria innocua Dps (LiDps) for the controlled synthesis of platinum (Pt) nanoclusters, analyzed the $\mathrm{Pt}^{0}$ nanocluster growth by non-covalent mass spectrometry, and verified core formation by using these nanoclusters as a hydrogen production catalyst. As shown in figure 78, charge state distributions of both $\mathrm{Pt}^{2+}$ ion bound (black) and $\mathrm{Pt}^{0}$ nanoclustered (red) LiDps were shifted to higher $\mathrm{m} / \mathrm{z}$ compared to the untreated LiDps in accordance with the increasing numbers of $\mathrm{Pt}^{2+}$ loaded. Only one population was observed at each $\mathrm{Pt}^{2+}$ loading implying that binding or nanocluster formation events occur homogeneously throughout the cage population rather than in an all-or-nothing manner.

We have demonstrated efficient hydrogen production using the $\mathrm{Pt}^{0}$ mineralized Hsp cages using a coupled Ru(bpy) ${ }_{3}{ }^{2+} /$ methyl viologen based photosystem. Using a similar approach, reaction mixtures were illuminated at $25{ }^{\circ} \mathrm{C}$ using a $150 \mathrm{~W}$ Xe arc lamp equipped with an IR filter and a UV cutoff filter ( $<360 \mathrm{~nm}$ ) and the hydrogen produced was monitored by gas chromatography (GC). The photosensitizor control showed small amounts of hydrogen without a Pt catalyst. While the LiDps samples with theoretical loadings equal to or less than $45 \mathrm{Pt}^{0}$ (theoretical load of $100 \mathrm{Pt}^{2+} /$ cage) produced hydrogen near at baseline levels, the 75 $\mathrm{Pt}^{0}$ (theoretical load of $200 \mathrm{Pt}^{2+} /$ cage) containing LiDps generated approximately four times more hydrogen than the background level (Figure 78). This data clearly support the idea that the $75 \mathrm{Pt}$ atoms form a single nanocluster rather than multiple nanoclusters in the LiDps. In contrast, the $45 \mathrm{Pt}^{0}$ or lower $\mathrm{Pt}^{0}$ containing cages appear to fail to form a sufficiently large cluster to catalyze hydrogen production.

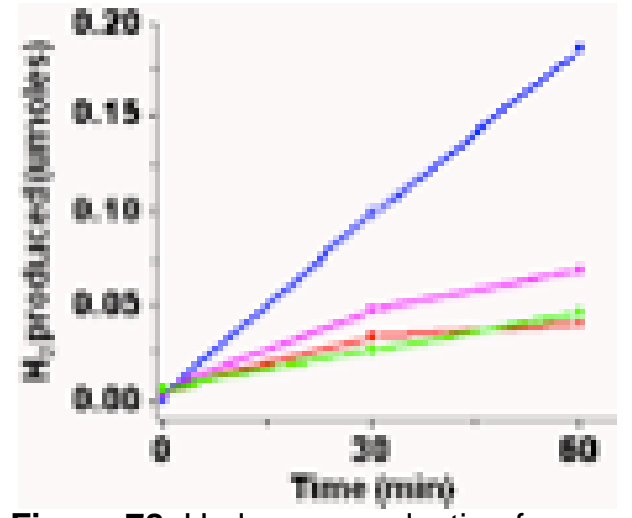

Figure 78. Hydrogen production from the $\mathrm{Pt}^{0}$ mineralized LiDps. (A) Gas chromatographic traces of blank (hexagons), Ir complex only (squares), $25 \mathrm{Pt}^{\circ}$ (reverse triangles), $44 \mathrm{Pt}^{\circ}$ (triangles), and $75 \mathrm{Pt}^{0}$ (circles) mineralized LiDps after $1 \mathrm{hr}$ of illumination. (B) Time dependent hydrogen productions of sensitizor only (squares), $25 \mathrm{Pt}^{0}$ (reverse triangles), $44 \mathrm{Pt}^{0}$ (triangles), and $75 \mathrm{Pt}^{0}$ (circles) mineralized LiDps.

\section{Synthesis of Protein cage encapsulated $\square \mathrm{Fe}_{2} \mathrm{O}_{3}-$ a visible bandgap semiconductor.}
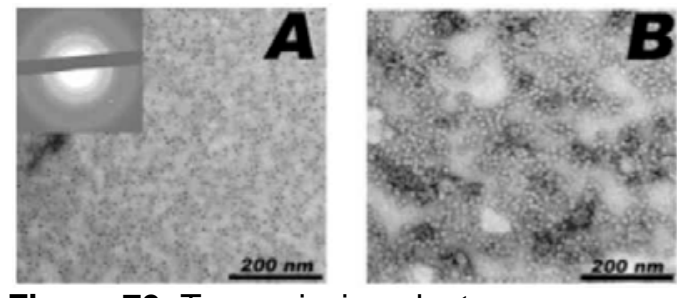

Figure 79. Transmission electron micrographs of $(A)$ unstained and $(B)$ stained refluxed PF-Fn. The dark electron dense cores in $(A)$ have an electron diffraction pattern (insert) consistent with $\alpha$ $\mathrm{Fe}_{2} \mathrm{O}_{3}$.
Investigations into metal and oxidative stress in microbes from high temperature environments have identified a number of proteins that exhibit remarkable temperature stability. The ferritin from Pyrococcus furiosus (a hyperthermophilic archaeon) can successfully be used to synthesize uniform inorganic nanoparticles of ferrihydrite (a disordered iron oxide), which can be transformed 
into hematite (ordered iron oxide) at elevated temperature $\left(\sim 100^{\circ} \mathrm{C}, 1-5\right.$ days). The hematite samples exhibited behavior indicative of a visible band gap semiconductor making them of interest for energy production. Photocurrents have been measured using a coupled electrochemical system, in ethanol (as sacrifical reductant) and methyl viologen as electron transfer mediator, with a transparent ITO working electrode, and ITO counter electrode and a Ag pseudo reference. The ability to reduce $\mathrm{MV}^{2+}$ under these conditions means we can couple this system to enzymes that can utilize reduced viologen as electron source.

\section{Virus-based protein cage synthesis and encapsulated $\mathrm{TiO}_{2}$ semiconductors}

Using a biomimetic approach to the synthesis of virus encapsulated $\mathrm{TiO}_{2}$ nanoparticles, which are size and shape constrained by the interior surface of the viral capsid. The structure of these materials was determined using the PDF (pair distribution function) analysis using High-energy X-ray scattering collected at beamline 11-ID-B at the Advanced Photon Source at Argonne National Laboratories. The best fit was obtained by assuming a crystalline domain size of $1.3 \mathrm{~nm}$ and performing a multi-component fit with $\beta$ $\mathrm{TiO}_{2}$ and $\mathrm{NaCl}$ (which was present in the protein solution). The low- $r$ regime is dominated by the $\beta-\mathrm{TiO}_{2}$ contribution, while the high- $r$ regime is dominated by scattering from the $\mathrm{NaCl}$ contaminant. Analysis using TEM shows $\mathrm{TiO}_{2}$

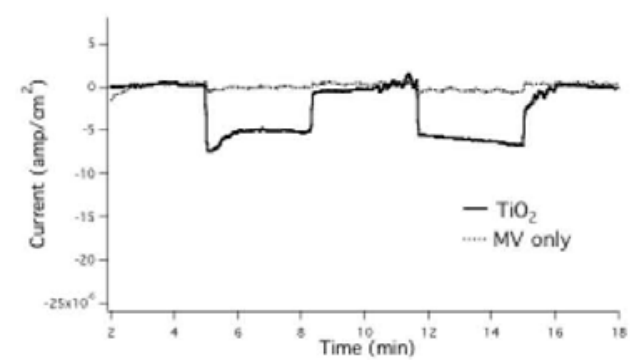

Figure 80. Photocurrent generated from CCMV-TiO ${ }_{2}$ in ethanol. particle sizes of $20 \mathrm{~nm}$, so it is clear that the virus-templated nanoparticles are polycrystalline and/or contain a significant amorphous component. We have measured the photocurrent of these $\mathrm{TiO}_{2}$ materials (Figure 80) using a coupled electrochemical system, in ethanol (as sacrifical reductant) and methyl viologen as electron transfer mediator, with a transparent ITO working electrode, and ITO counter electrode and a Ag pseudo reference.

\section{Synthesis of ZnSe and CdSe nanoparticles encapsulated within ferritin protein cages}

Horse spleen ferritin was used as a template for the synthesis of CdSe and ZnSe zinc nanoparticles. $\mathrm{Zn}(\mathrm{Cd}) \mathrm{Se}-\mathrm{Fn}$ protein cages were purified by size exclusion chromatography, and characterized by transmission electron microscopy (Figure 81), dynamic light scattering and UV-visible spectroscopy. While electron dense particles of the semiconductors were visible by TEM, they were largely amorphous by electron diffraction. We tested their photocatalytic activity towards the reduction of methyl viologen $\left(\mathrm{MV}^{2+}\right)$, with sodium sulfite $\left(\mathrm{Na}_{2} \mathrm{SO}_{3}\right)$ as a reductant. Both the $\mathrm{Cd}$ - and $\mathrm{ZnSe}$ particles were

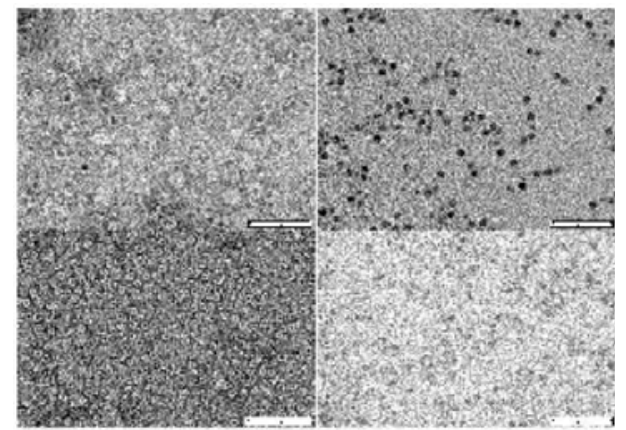

Figure 81. TEM of CdSe-Ferritin (top) and ZnSe-Ferritin (below), the left images show stained samples and unstained cores on the right. 
able to reduce $\mathrm{MV}^{2+}$ to the characteristic blue $\mathrm{MV}^{+\cdot}$, demonstrating their semiconductor activity.

\section{Characterization of surface adsorbed protein cage catalysts}

Our starting point for characterizing electron and ion transport in our surface adsorbed materials is analytical electrochemistry since this suite of techniques can be used to measure both mass transport and rate of electron transfer. Cyclic voltammetry $(\mathrm{CV})$ is sensitive techniques for measuring current generated by interfacial redox reactions. We have preformed these experiments to measure electrons consumed by reduction of hydrogen ions to form hydrogen, catalyzed by surface-immobilized protein cages filled with platinum (Fig.82 a). In a second type of experiment, the redox couple is present

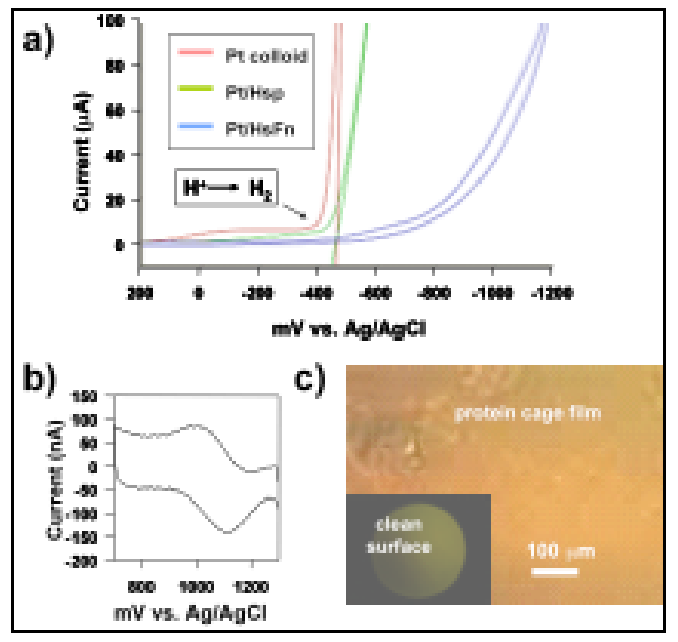

Figure 82. Electrochemical reactions in protein
cage assemblies. a) type I experiment; Pt
encapsulated in either Hsp or ferritin was
immobilized at an interface; reduction of
hydrogen ions $\left(\mathrm{H}^{+}\right)$to hydrogen $\left(\mathrm{H}_{2}\right)$ was
followed by polarography; b) a) type II
experiment; A Li DPS genetic construct with
cys on the exterior was functionalized with
(Ru(II)Bpy B $\left._{3}\right)$ using the scheme presented in
Fig.76. Cyclic voltammetry was used to follow
the oxidation and reduction of the (Ru(II)Bpy $\left.{ }_{3}\right)$
immobilized in the film; c) epi-fluorescence
microscopy was used to confirm the presence
of (Ru(II)Bpy ${ }_{3}$ ) in the protein cage film.

only at the electrode interface. Here the potential is cycled between two limit points that span the redox potential of the couple all the electrons generated by the redox reaction are collected. We have performed this type of experiment to characterize electron transport from RuBpy 2 covalently linked to a protein cage immobilized at an electrode surface (Figure $82 \mathrm{~b}$ ). By collecting data for a range of scan rates that are relatively fast, a rate constant for the electron transfer process can be determined.

\subsubsection{Protein Cage Modification for enhanced electrode attachment}

\section{Covalent attachment of Cages to surfaces (electrodes)}

To effectively perform protein-film voltammetry with our Fn-noble metal composite materials we have incorporated using a covalent linker between the working electrode and our protein cages. Doing this eliminates the possibility of desorption as well as buffer effects which may introduce artifacts into the voltammogram. To create this covalent bond we have incorporated the use of a carbodimide linkage with carboxylates on the surface of the electrode and terminal amines on the exterior of the protein, such 
as lysines (Figure 83). We can test the robustness of the linkage by monitoring the covalently attached protein on the electrode electrochemically.

In order to directly attach redox mediators to the metalized protein cages, we have developed mutants necessary for the direct covalent attachment. To this end we have created a unique thiol mutant $\mathrm{H} 14 \mathrm{C}$ in the subunit of the ferritin cage, which we predict from the atomic resolution structure, will be presented on the exterior of the assembled cage (Figure 84).

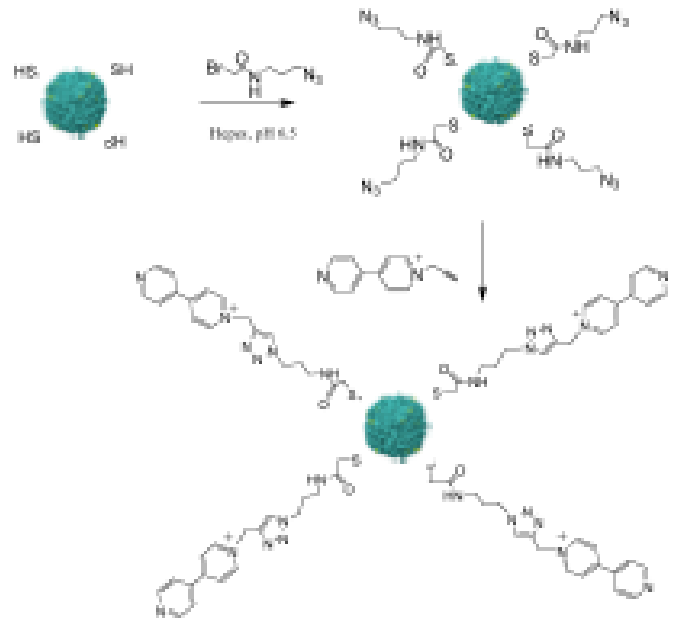

Figure 84: Schematic showing the H14C mutant with surface thiols covalently attached with a viologen mediator coupled through a "click" reaction between azide and alkyne functionalities

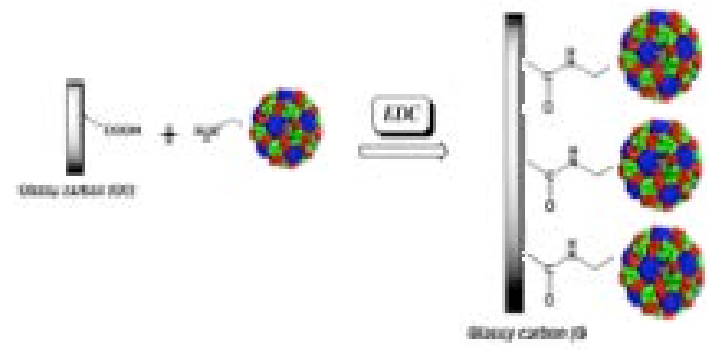

Figure 83. A schematic for the covalent attachment terminal amine on a protein to a carboxylate on the electrode surface mediated by EDC.

The unique thiol allows us to attach a azide moiety to which we can selectively couple a viologen mediator. This will allow us to create a nanoparticle that incorporates an active Pt particle on the inside and a redox mediator on the exterior (coupled to the cage through a covalent linkage to the cysteine thiol). The mutant was generated using a PCR-based site directed mutation and the resulting construct sequenced to confirm the correct DNA sequence. Expression of the protein was confirmed by gel electrophoresis and mass spectrometry was used to confirm the subunit mass of the mutant. Our contention is that the hydrogen production efficiency of our system, while good, can be improved by enhancing the electron transfer between the exterior of the protein cage to the active noble metal nanoparticle inside the cage.

\section{Electron transport in protein cages}

Since we are interested in using protein cages as scaffolds for assembling composite materials in which the spatial arrangement of combinations photocatalytic semiconductor nanoparticles, light harvesting organic molecules and redox catalysts is optimized for energy conversion purposes such as light-driven hydrogen production. To realize the long term goal of using these assemblies for energy conversion we need to understand electron transport within individual protein cages (through the shell) and between protein cages assembled into higher order structures. To this end, we are using electrochemical measurements (cyclic voltammetry) to characterize the conductance between an electrode and electrons generated by two types of redox 

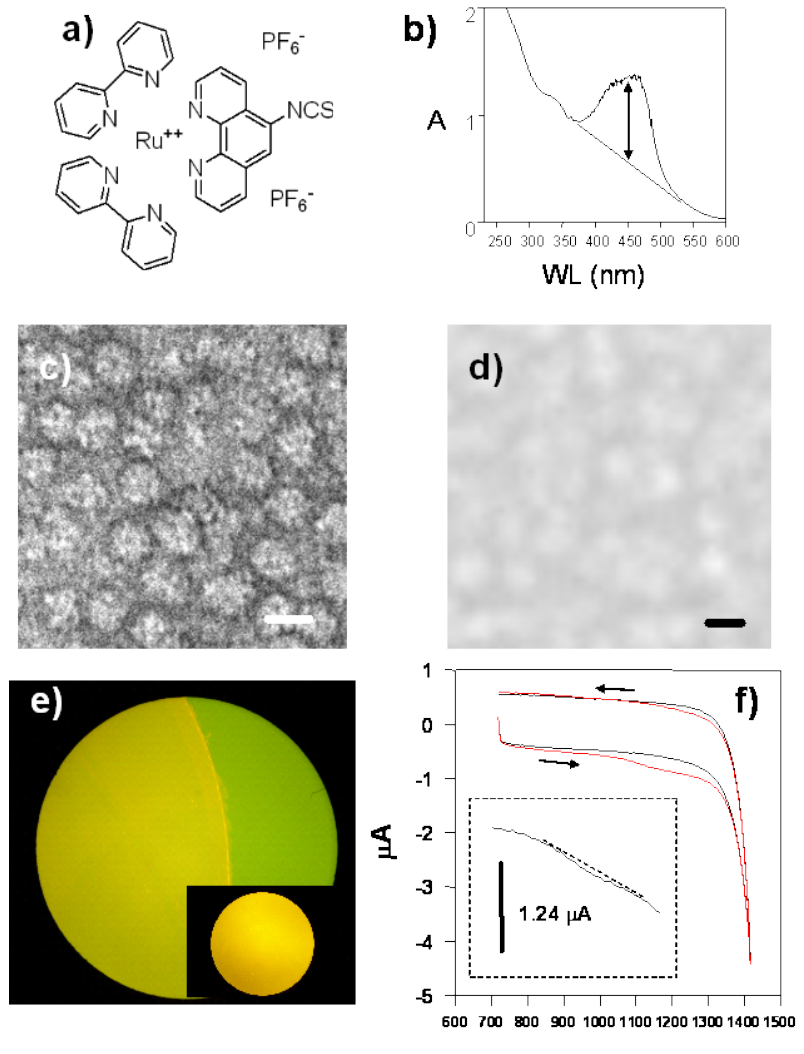

$m V$ (vs NHE)

Figure 85. Electron transport from a redox couple conjugated to a protein cage. a) $\mathrm{Ru}(\mathrm{bpy})_{3}$ phen- $\mathrm{SCN}^{2+}$ conjugation agent; b) UV-VIS spectrum of the functionalized protein cage (G41C Ru(bpy) ${ }_{3}$ phen$\mathrm{SCN}^{2+}$ c) TEM image of G41C Ru(bpy) ${ }_{3}$ phen-SCN ${ }^{2+}$ (scale, $12 \mathrm{~nm}$ ); d) FE SEM image of G41C G2.5 $\mathrm{Ru}(\mathrm{bpy})_{3}{ }^{2+}$ on poly-L-lysine coated silicon (scale, 12 $\mathrm{nm}$ ); e) epi-fluorescent image of G41C

$\mathrm{Ru}(\mathrm{bpy})_{3}$ phen-SCN ${ }^{2+}$ adsorbed to an ITO electrode surface from a drop; green region is the clean ITO surface; inset is an image of G41C Ru(bpy) ${ }_{3}$ phen$\mathrm{SCN}^{2+}$ adsorbed to poly-L-lysine coated plastic well; f) CV trace of buffer (black) and ITO electrode with a film of G41C Ru(bpy) ${ }_{3}$ phen-SCN ${ }^{2+}$ (red); inset is detail of the oxidation curve reactions. In each case the electrically active components were scaffolded by protein cages, which were, in turn, immobilized at the electrode surface.

\section{Molecular Conjugation and measurement of Electron Conduction}

A derivative of the transition metal complex $\mathrm{Ru}(\mathrm{bpy})_{3}{ }^{2+}$ was conjugated to an exceptional stable form of the small heat shock protein from Methanococcus jannschii (G41C). G41C is a genetic construct that presents cysteines on its interior surface. G41C provided a robust nanoplatform that allowed relatively high loading of an isothiocyanate derivative of $\mathrm{Ru}(\mathrm{bpy})_{3} \mathrm{phen}^{2+}$ (Figure $85 a$ ) onto the cage via conjugation to primary amines. The absorbance from the $\mathrm{Ru}(\mathrm{bpy})_{3} \mathrm{phen}^{2+}$ at $450 \mathrm{~nm}$ was prominent in the cage preparations (Figure 85b). The ratio of $\mathrm{Ru}(\mathrm{bpy})_{3} \mathrm{phen}^{2+}$ to monomeric subunit was estimated as 2.5 based on the UV-VIS absorbance and protein content determined by a BCA assay. This translates to $60 \mathrm{Ru}(\mathrm{bpy})_{3} \mathrm{phen}^{2+}$ per cage. The functionalized cage appears as intact 12 diameter particles on TEM grids. It forms films on silicon wafers coated with poly-Llysine visualized using FE SEM (Figure 85d). According to particle counts acquired from these images the fractional area coverage is 0.56 , which conforms to that expected from the random sequential adsorption (RSA) model (0.55). 
The G41C Ru(bpy) ${ }_{3}$ phen $^{2+}$ conjugate was adsorbed to an ITO electrode. We found that an ITO electrode provided the most favorable background for the expected potential range of the $\mathrm{Ru}(\mathrm{bpy})_{3} \mathrm{phen}^{2+}$ redox couple $\left(E_{\mathrm{o}}=\right.$ 1.26). The red fluorescence from the $\mathrm{Ru}(\mathrm{bpy})_{3}$ phen $^{2+}$ was evident in images acquired using epi-fluorescence microscopy (Figure 85e). The red hue appears slightly less intense than that of the conjugate adsorbed to poly-L-lysine coated plastic microtiter plate wells (Figure 86e). This difference in fluorescence perceived by the eye is validated by the difference in the ratios of the red channel to the total luminescence, which is less for the conjugate adsorbed on the ITO surface (1.15) than for the poly-Llysine coated surface (1.25). Cyclic voltammograms (CVs) were acquired from the adsorbed film (Figure 86f). There were clear differences between the $\mathrm{CV}$ of the buffer (100mM sodium acetate, $\mathrm{pH} 5.7$ ) and the adsorbed film. Based on the interpretation that the feature in the positive sweep originates from the oxidation current, the area

under this feature yields the total electrons transferred from the $\mathrm{Ru}(\mathrm{bpy})_{3} \mathrm{phen}^{2+}$ conjugated to G41C in the film. The inset shows that this area is actually quite small. Assuming that the adsorbed amount of G41C in the film conforms to the RSA model, this quantity of electrons would be expected to be transferred if only one of the $\mathrm{Ru}(\mathrm{bpy})_{3}$ phen $^{2+}$ per cage were in electrical contact with the electrode surface. The height of the oxidation curve expected if electrons from all the $\mathrm{Ru}(\mathrm{bpy}){ }_{3}{ }^{2+}$ conjugated to the cage in the film were transferred is shown by the vertical bar in the inset.

These results suggest strongly that G41C is fairly insulating. The estimate of $\mathrm{Ru}(\mathrm{bpy})_{3}$ phen $^{2+}$ in electrical contact with the electrode depends directly on the estimation of the adsorbed surface coverage and thus could be low. Based on the differences in fluorescence from the adsorbed films mentioned above a rough estimate suggests that perhaps the coverage on the ITO electrode is $50 \%$ that on the poly-Llysine coated surfaces. However, the difference between the expected height of the oxidation curve if all electrons from the film were collected, and the actual height, is still striking.

\section{Electron Conduction to Cage encapsulated Pt Nanoparticles}

A series of experiments were performed to measure electron flow at an electrode from the reduction of protons to hydrogen, catalyzed by platinum $(\mathrm{Pt})$ mineralized within a 
genetic construct of Listeria DPS (S138C), a small $9 \mathrm{~nm}$ diameter protein cage. We can obtain a prominent catalytic wave from this redox reaction if $\mathrm{Pt}$ colloid is adsorbed to a gold electrode (Figure $86 \mathrm{~b}$ ). We formed films of $\mathrm{S} 138 \mathrm{C}(\mathrm{Pt})$ on a gold surface and monitored the adsorption behavior using the quartz crystal microbalance (QCM) (Figures 86c and d). We used the Layer-by Layer method to assemble biotinylated $\mathrm{S} 138 \mathrm{C}(\mathrm{Pt})$ into multilayer films using the streptavidin-biotin interaction to mediate coupling between the layers (Fig.86d). CVs were then obtained directly from films adsorbed onto the QCM chips (Fig.86f). The CVs appear quite similar to those obtained from QCM chips exposed to the buffer (100mM sodium acetate, $\mathrm{pH} 5$ ) (Figure 86e) suggesting that there was little or no electrical contact between the Pt mineralized within $\mathrm{S} 138 \mathrm{C}(\mathrm{Pt})$ and the electrode.

The finding that protein cages are fairly insulating is not surprising in light of the literature on conduction through proteins. We are in a position to take advantage of their insulating properties. It is known that aromatic residues, especially tryptophan can act as conductive wires when they are located in a chain at distances of 5 angstroms or less. We genetically insert residues into protein cages routinely. This opens up the possibility of engineering trytophan wires which could electrically connect the interior cavity with the exterior surface, or which could conduct electrons around the exterior surface. The two types of experiments mentioned above can be used to verify that conductive wires have been engineered into the protein cage nanoplatforms.

\subsubsection{Synthesis of Martices for Catalyst Immobilization}

Synthesis of electroactive crosslinked poly(viologen) gel Polyvinyl benzyl chloride, used as a back-bone structure, has been crosslinked with 4,4' dipyridyl to form a porous gel structure that provides an electroactive matrix for catalyst immobilization. A key advancement that contributes significantly to the practicality of using these electroactive gels in materials and devices is the observation that the density of the crosslinking of these gel structures can be modified by using a small percentage of viologens that are assymetrically methylated at one of the pyridine nitrogens (Figure 87). Inclusion of the methylated

dipyridyl limits crosslinking and results in a gel structure that is more open and porous, but which is still

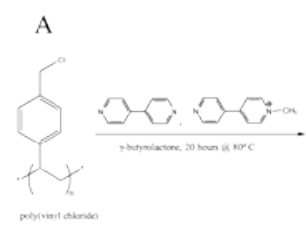

Figure 87. Chemical synthesis of a poly(viologen) matrix with controlled porosity. A.

Poly(vinylbenzyl)chloride is reacted with 4,4'-dipyridyl reagents to give $B$. a partially crosslinked polymer matrix

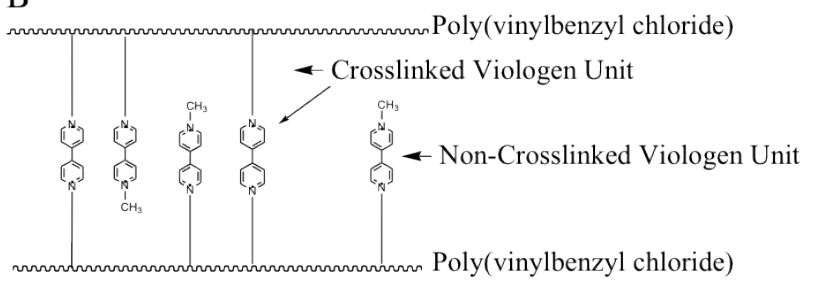

cationic,

facilitating the

binding of the protein based catalyst systems.

B 
The morphology of the poly(viologen) gel matrix has been investigated by SEM (Figure 88). The matrix is brittle and can be processed into a fine bead form that is easily manipulated. The results indicate that modulating the degree of methylation can result in effectively modulating the consistency of the electroactive material. In addition, varying the extent of methylation in the material will effectively modulate the pore size and accessibility of the gel based redox mediators to immobilized catalysts. We are now in a position to examine a variety of gel formulations including embedding powdered

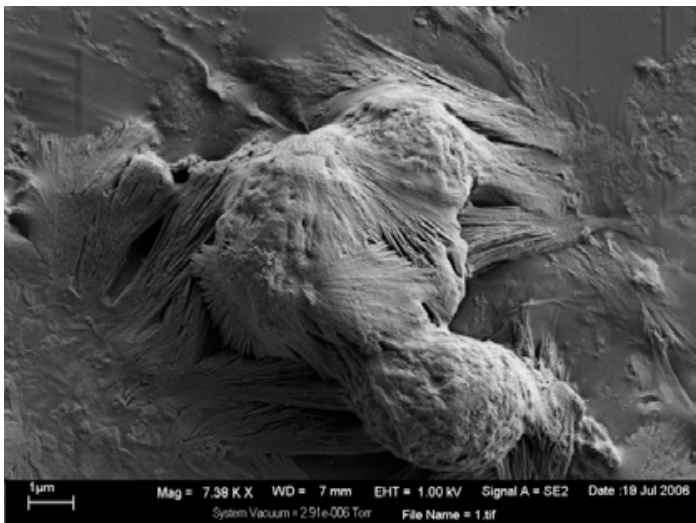

Figure 88. An SEM of the partially crosslinked poly(viologen) matrix. viologen gels into other solid matrices such as sol-gels. Gel formulations will be tested using the device test prototypes described below.

\section{Incorporation of catalysts into poly(viologen) gels}

Binding of the mimetic and enzyme catalysts to the crosslinked poly(viologen) gels has been achieved. Binding is $\mathrm{pH}$ dependent and the protein does not bind well below $\mathrm{pH}$ of 6.5. For the biomimetic catalysts, we have determined the $\mathrm{P}_{z c}$ (point of zero charge) of the protein-gel colloid to be 5.5. Therefore under low $\mathrm{pH}$ conditions (necessary for $\mathrm{H}^{+}$ reduction) the protein does not bind strongly. We have demonstrated qualitatively that the catalysts will communicate electronically with the gels by monitoring the color change associated with hydrogen oxidation coupled to the reduction of the gel matrix indicated by the appearance of blue-violet color of reduced viologens. Although the first generation of incorporation of enzymes and mimetic catalysts demonstrated relatively weak binding, we have developed a number of strategies to overcome these problems including the further modification of gels to modulate the overall charge and the aforementioned strategy of incorporating these polyviologen gels into other three dimensional matrices such as silica gels.

Synthesis of poly-viologen matrix materials using $\mathrm{Cu}(\mathrm{I})$ catalyzed 'click' reaction. We have refined the synthesis

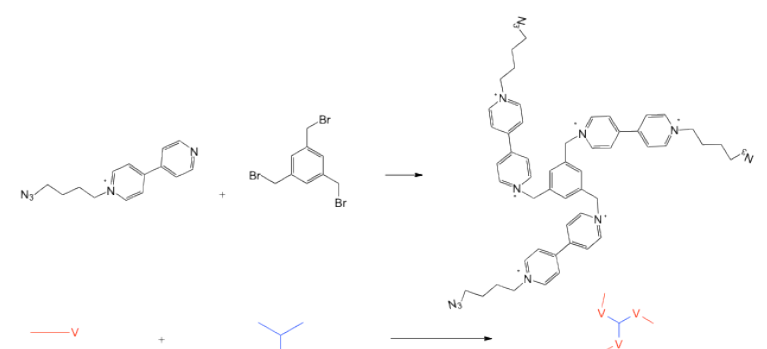

Figure 89. (Top) Schematic of the synthesis of a viologen - azide building bock. (Bottom) schematic of the polymerization of viologen using azide and alkyne substituents to direct the spatial arrangement of the monomer coupling reactions.

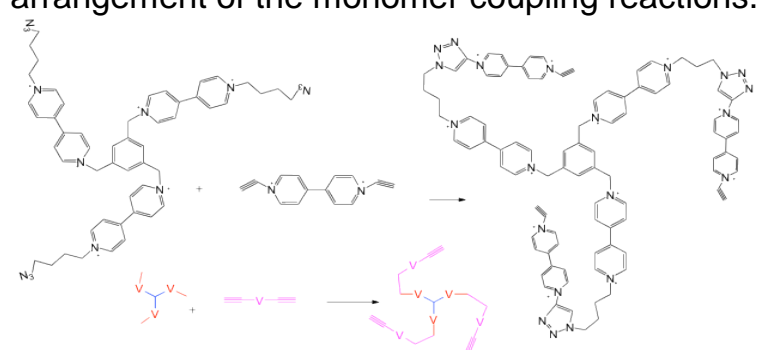


of poly-viologen-based gel matrix materials using asymmetric synthesis of viologen moeities and directed azide-alkyne 'click' reactions to make bulk conducting polymeric materials. In this way the viologen is directy incorporated into the polymer through a dendrimer-type growth process. As shown in Figure 89, we have made the asymmetrically azide substituted viologen which was subsequently reacted with the trisbromobenzyl molecule shown in the figure. This tri-branched molecule serves as one of the monomers for the click polymerization with the di-substituted alkyne- viologen. The resulting polymeric materials are electrically conductive and are currently being characterized.

\section{Building hierarchical structures of Protein-cage nanoparticles}

Our efforts towards building a device that incorporates biomolecular $\mathrm{H}_{2}$ catalysts have been focused on building "bottom up" hierarchical structures. There are three scale levels upon which we can organize materials, which correspond to the hierarchy in the fabrication process that proceeds from the molecular/biomolecular scale, through the nanoscale to the microscale. Our present expertise lies in leveraging directed selfassembly to manipulate order on the first two scales. This versatile approach employs the use of nanoscale building blocks whose precise spatial self-assembly into higher order structures is based on specific intra-particle interactions. At the molecular level, protein cages can be viewed as scaffolds for stereo specific placement of functional groups. The cages have a general architecture that can be described as a porous spherical shell that encloses an interior cavity. High-resolution structures are available so that functional groups can be positioned at precise positions in the structure by covalent addition to specific amino acid residues, most commonly lysines, glutamic and aspartic acid and cysteines.

At the nanoscale (10 $\mathrm{nm}$ to microns) protein cages can be viewed as building blocks for constructing nanostructured composite materials. The protein cages are themselves supra-molecular structures composed of 12,24 , or 180 monomeric protein subunits that

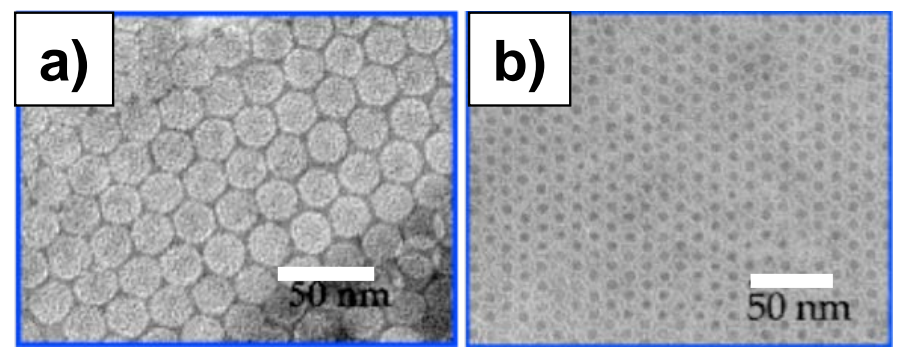

Figure 90. Hexagonally packed, two-dimensional arrays of protein cages. arrays were formed by association with mica followed by carbon coating and negative staining. a) Cowpea chlorotic mottle virus (CCMV); b) ferritin. Scale bars are $50 \mathrm{~nm}$. assemble spontaneously. By forming a cage from mixtures of differentially functionalized subunits we can dial in the stoichiometry of the multifunctional labeling. We can also assemble the cages into higher order structures. One of the essential prerequisites for the application of nanotechnological methodologies to future manufacturing paradigms involves the fabrication of spatially precise planar arrays. The fabrication of protein macromolecules into twodimensional arrays is of considerable practical importance for the development of devices for $\mathrm{H}_{2}$ generation. Supramolecular arrays of biological molecules represent a 
versatile system with respect to nanotechnology, given their inherent propensity for selfassembly into two and threedimensional architectures. Often biological macromolecules also display a hierarchical level of assembly, which may be exploited in the fabrication of a number of distinct morphologies from a single precursor. There are a variety of techniques available for fabrication of planar arrays of proteins. One of the simplest, methods involves the crystallization of protein molecules onto the surface of freshly cleaved mica. This technique has been found to be especially successful for the production of two-dimensional arrays protein cages used as templates for our materials synthesis efforts (Figure 90).

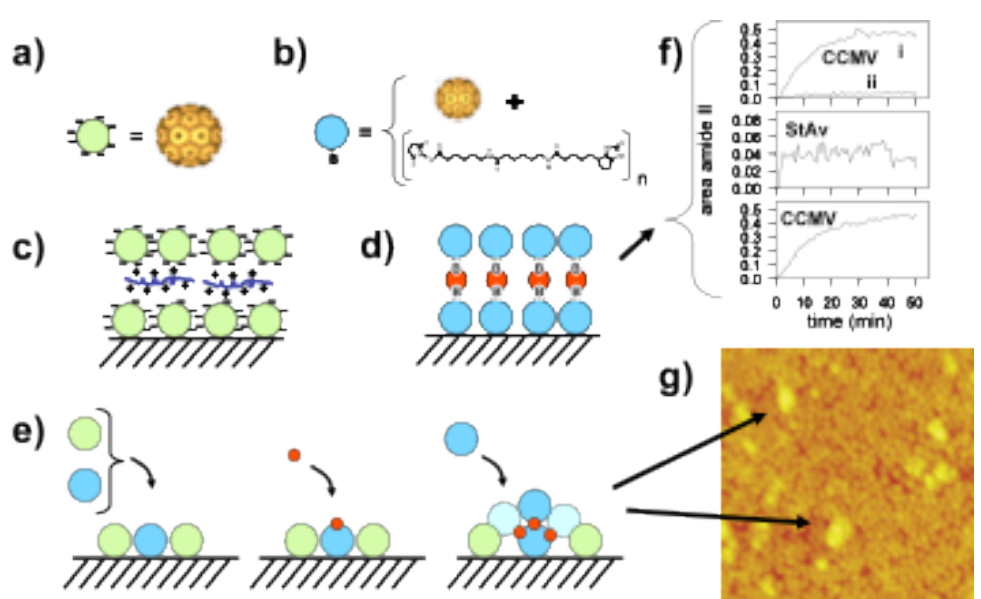

Figure 91. Protein cage multilayer assemblies. a) CCMV as a building block; b) CCMV functionalized with biotin for engineered complementary interactions; c) scheme for building multilayers using electrostatic interactions; the intervening layer is a cationic polymer; d) scheme for building multilayers using complementary biological interactions; inter-layers mediated by streptavidin (StAv)/biotin (B) interactions; e) scheme for building clusters using complementary biological interactions; $f$ )

Formation of multilayers followed using vibration spectroscopy (ATR-FTIR); g) AFM image of clusters formed via complementary biological interactions on a monolayer of CCMV electrostatically bound to a silicon substrate.

Three-dimensional lattices of protein cages can also be produced by superposing multiple layers of nanoparticles. The lamellar structure of multilayer films comprised of protein cages can be engineered by a relatively simple method known as layer-by-layer (L-b-L) assembly. We have used both electrostatic and complementary biological interactions to direct the assembly of multilayer films (Figure 91). Using this approach has allowed us to overcome some of our previous difficulties with protein cage adherence to electrode surfaces.

\subsubsection{Incorporation of Protein-cage catalysts into Devices}

We have incorporated some of the protein-cage based photocatalysts into an electrochemical device as shown in Figure 92. Two different materials have been evaluated $\mathrm{n}$ these devices; the $\mathrm{a}-\mathrm{Fe}_{2} \mathrm{O}_{3}$ inside ferritin and the $\mathrm{TiO}_{2}$ inside the CCMV virus capsid. The hematite samples exhibited behavior indicative of a visible band gap semiconductor making them of interest for energy production. Photocurrents have been measured using a coupled electrochemical system, in ethanol (as sacrifical reductant) and methyl viologen as electron transfer mediator, with a transparent ITO working electrode, and ITO counter electrode and a Ag pseudo reference. The ability to reduce $\mathrm{MV}^{2+}$ under these conditions means we can couple this system to enzymes that can utilize reduced viologen as electron source. 
The CCMV $\mathrm{TiO}_{2}$ particle sizes of $20 \mathrm{~nm}$, so it is clear that the virus-templated nanoparticles are polycrystalline and/or contain a significant amorphous component. We have measured the photocurrent of these $\mathrm{TiO}_{2}$ materials and the data are shown in Figure 80.
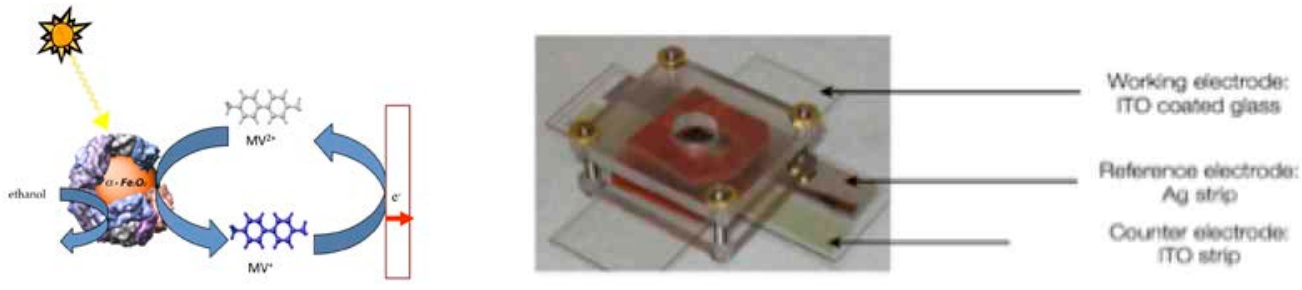

Figure 92. Aschematic of the photocurrent measurement of protein cage semiconductors (left).

The device for measuring the photcurrent (right) 


\section{Task 2 \\ John Peters}

Publications

O.A. Zadvornyy, S.K. Brumfield, Z. Varpness, M. Allen, N.A. Zorin, L. Serebriakova, T. Douglas, and J.W. Peters "Hydrogenase Dependent Ni particle formation enhances Ni Ion Tolerance in Thiocapsa roseopersicina" Environ Sci Technol. 2010 44:834-840.

O.A. Zadvorny, A.M. Barrows, N.A. Zorin, J.W. Peters, and T.E. Elgren "Hydrogenase Encapsulated in Sol-Gel Material Doped with Carbon Nanotubes Yields Solution Levels of Hydrogen Production Activity" J. Mat. Chem. 2010 Epub ahead of print.

O.A. Zadvorny, J. Radar, N.A. Zorin, T. Douglas, T.E. Elgren, J.W. Peters "Photohydrogen production in the presence of oxygen. In preparation

\section{Presentations}

- June, 2007 "Hydrogenase, Structure, Function, and Biosynthesis" Conference on the Biogenesis in Iron Sulfur Proteins: Cluster assembly and Regulation, Villard-de-Lans, France

- July, 2007, "Hydrogenase, Structure, Function, and Biosynthesis" Invited Plenary Speaker - 8th International Conference on Hydrogenase, Breckenridge, CO

- Sept., 2007 "H cluster biosynthesis and FeFe-hydrogenase maturation" European BioH2 Workshop, Berlin, Harnack-Haus, Free University of Berlin, Berlin, Germany

- Oct., 2007 Department of Chemistry \& Astrobiology Program, University of Washington

- Oct., 2007 Laboratory for Basic Biological Problems, Pushchino, Russia

- Nov., 2007.AFOSR BiosolarH2 Review Meeting, Princeton, NJ

- Jan., 2008.Gordon Conference on Protein Cofactors, Radicals and Quinones, Ventura, CA

- Jan., 2008RCN/TBI Research Coordination Workshop, Yellowstone National Park, WY

- Feb., 2008 Department of Chemistry and Biochemistry, Arizona State University

- March, 2008Department of Chemistry and Biochemistry, Cal. State University, Fullerton

- March, 2008 Department of Chemistry, University of Montana

- April, 2008 Department of Chemistry, Hamilton College

- April, 2008 Astrobiology Science Conference, Santa Clara, CA

- June, 200 Gordon Conference on Iron-Sulfur Enzymes, New London, NH

- July, 2008 Fourth International Symposium on Biorganometallic Chemistry, Missoula, MT

- Jan., 2010 Invited Session Chair - Gordon Research Conference on Protein Cofactors, Radicals and Quinones, Ventura, CA

- Feb., 2010 Invited Speaker - Gordon Research Conference on Metals in Biology, Ventura, CA 


\section{Trevor Douglas}

\section{Presentations}

- March, 2007Using the interfaces in self-assembled protein cage architectures for materials synthesis", Invited Speaker, American Physical Society, Denver, CO

- April, 2007 "Self-assembled protein cage architectures for materials synthesis", Invited Speaker, American Chemical Society, Chicago, IL

- April, 2007 "Viruses - dynamic, responsive nanostructures with materials applications", Invited Speaker, Materials Research Society, San Francisco, CA

- March, 2008 Astrobiology Center Madrid, Spain

- March, 2008University Seville, Spain

- March, 2008 University of Barcelona, Spain

- April, 2008 NanoSpain08 Conference, Braga, Portugal

- April, 2008 University of Rome, Italy

- April/May, 2008 Gordon Conference on Organic Structures \& Properties, II Ciocco, Lucca, Italy

- CO Nov., 2008 Astrobiology Center, University of Colorado Boulder, CO

- Dec., 2008 "Protein Cage Architectures: templates for molecular and materials science" Hunter College, NY

- Feb., 2009 "Viral Capsids And Other Self-Assembled Protein Cage Architectures: Supramolecular. Templates For Molecular And Materials Encapsulation" Harvard University, MA

- Feb., 2009 "Capsids for synthetic encapsulation: polymers, molecules and nanosolids." Invited speaker at Gordon Research Conference on Physical Virology, Galveston, TX

- April, 2009 "Self-Assembled Protein cage Architectures - Supramolecular Templates for Nanomaterials Synthesis" Invited Speaker at 12th International Seminar on Inclusion Compounds, Stellenbosch, South Africa.

- April, 2009 "Self-Assembled Protein cage Architectures - Supramolecular Templates for Nanomaterials Synthesis" University of Minnesota,

- Oct., 2009 Keynote Speaker at the $7^{\text {th }}$ annual "Composites at Lake Louise" meeting (Oct 25-30, 2009), Canada.

- Feb., 2010 Invited Speaker, Metals in Biology Gordon Research Conference, Ventura CA

Patent Application - PCT/US06/018,900 


\section{TASK 3}

Project Title: Characterization of Platinum-Group Element Nanoparticles using Laserinduced Breakdown Spectroscopy

Report Period: August 1, 2006-June 1, 2010

Date of Report: January 30, 2010

Recipient: Montana State University-Billings

Award Number: DE-FC36-06G086060

Working Partners: Stuart Snyder, Will Wickun

Cost-Sharing Partners: PLUG Power, Montana State University-Billings Laboratory Support

Contact: Stuart Snyder, Montana State University-Billings, ssnyder@msubillings.edu, 406-657-2190

DOE Managers: DOE HQ Technology Manager: Roxanne Garland, DOE Field Project Officer: Terry Payne 


\section{TASK 3}

DE-FC36-06GO86060

\section{Executive Summary}

\section{Background}

The cost and durability of polymer electrolyte membrane (PEM) fuel cells is a major concern to the integration of hydrogen fuel cells into the nation's transportation and electrical power infrastructure. Of particular interest is reducing the cost and improving the lifetime of the cathode catalyst layers that sandwich the PEM. The cathode catalyst layer usually consists of nanoparticles of platinum dispersed on a carbon membrane. Platinum is obviously expensive. It is therefore desirable to construct the cathode catalyst layer with a lesser expensive platinum group (PGE) element such as palladium or a non-PGE element. In addition to the cost, the cathode catalyst layer is susceptible to degradation over time due so several mechanisms, most notably oxidation of the carbon membrane. Research and development of new materials, designs, and manufacturing techniques for the cathode catalyst layer, the PEM, and other major components of the fuel cell are addressing these important issues.

\section{MPRI Laser Spectroscopy Overview}

Beginning in August 2006 and ending in May 2009, Montana State University-Billings (MSU-Billings) conducted research sponsored by the U. S. Department of Energy (DOE) through the Montana Palladium Research Initiative (MPRI) and in partnership with PLUG Power to characterize PGE nanoparticles in aqueous suspension using the pulsed-laser technique of laser-induced breakdown spectroscopy (LIBS). This work was done to support field studies conducted on the campus of MSU-Billings to assess long-term performance and degradation of eight stationary PEM fuel cells, four of which used platinum as the catalyst, and the remaining four using palladium as the catalyst.

The presence of PGE nanoparticles in the fuel cell reformate water is evidence of cathode catalyst layer degradation. The goal of the MPRI Laser Spectroscopy program was to develop LIBS as a sensitive technique to detect and quantify the presence of PGE nanoparticles in the fuel cell water and determine if the catalyst layers degraded during the field trials. LIBS is a technique that in this application is nondestructive and does not interrupt the operation of the fuel cell.

\section{Experimental Challenges}

LIBS is a well-known technique for trace species detection and analysis, but it has not been applied extensively to aqueous suspensions. Performing LIBS on aqueous suspensions is difficult. Conventional LIBS data is acquired by the accumulation of many successive laser shots. In the case of aqueous suspensions, the signal-to-noise ratio is unacceptably low if the particle concentration is dilute. This is because the vast majority of LIBS signals generated from the microplasma formed on the surface of the water do not contain the desired spectral information of the element of interest. Only the spectral background is recorded. When a particle of interest is present, its spectral signal is buried in the background spectrum. To overcome this major problem, conditional analysis data acquisition software was implemented into the experimental 
procedure. With this technique, the LIBS signals are analyzed shot by shot, and are recorded only if the desired spectral information is present. Conditional analysis has been shown to greatly improve the signal-to-noise ratio, and sub parts-per-billion (ppb) detection limits of are possible.

Results

Experiments to develop, test, and calibrate the LIBS system using 50 to 200-nm diameter palladium and platinum nanoparticles dispersed in a water flow loop were conducted using conditional analysis. Particulate mass concentrations ranged from 0 parts-per-million (ppm) to $70 \mathrm{ppm}$. The water flowed through a laminar-flow nozzle that produced a thin sheet of water onto which the laser beam was focused. Emission from the resulting high-temperature microplasma was analyzed spectrally for the presence of palladium or platinum. The detection limit for palladium was determined to be about 50 ppb. The detection limit for platinum is about $1 \mathrm{ppm}$.

After calibration of the LIBS signal was completed, reformate water collected from the operating fuel cells was analyzed for the presence of palladium and platinum. Palladium and platinum were both detected. A typical LIBS signal for palladium in the in the reformate water is presented in Figure 93. The maximum concentration of palladium in the reformate water was determined to be about $50 \mathrm{ppm}$. Concentrations of platinum were difficult to quantify because the emission signals were weak. It was also observed that the concentration of palladium in the water fluctuated greatly with values ranging from 0 to $50 \mathrm{ppm}$.

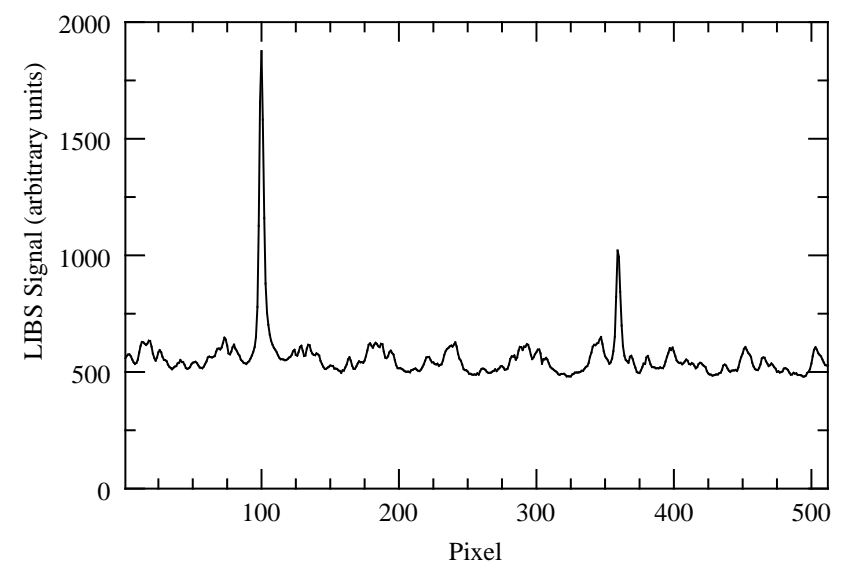

Figure93. The LIBS signal of palladium particles in fuel-cell reformate water. The peaks are prominent palladium emission lines. This data is a clear indication of fuel cell degradation.

\section{Major Conclusions}

- Using conditional analysis, LIBS has been shown to be a very sensitive technique to quantify the mass concentration of palladium particles suspended in water. The technique is less sensitive to platinum.

- Palladium and platinum particles were both detected in the reformate water of PEM fuel cells. This is a strong indication that the cathode catalyst layer is degrading over time. 


\section{Objective}

The project objective is the development of laser-induced breakdown spectroscopy (LIBS) combined with the LabView-based conditional analysis data acquisition technique, as a real time in situ diagnostic technique to characterize platinum-group element (PGE) nanoparticles for process monitoring and control. Conditional analysis records LIBS signals only if the desired PGE spectral information is present, and greatly improves signal-to-noise ratios over conventional LIBS. Initial experiments will be performed to optimize the LIBS single from PGE nanoparticles produced in a custombuilt particle generator based on a published design, and characterize nanoparticle distributions. Final experiments will be conducted to characterize PGE nanoparticles found in the water of proton exchange membrane fuel cells (PEMFC) in support of field trials of operational PEMFCs.

\section{Background}

The overarching objective of the Montana Palladium Research Initiative is to perform scientific research on the properties and uses of palladium in the context of the US DOE Hydrogen, Fuel Cell, and Infrastructure Technologies Program. Long-term field degradation studies of PEMFCs are an important component of this research. A major failure mechanism of PEMFCs is the oxidation of the carbon substrate that supports the platinum or palladium catalyst. Platinum or palladium nanoparticles dissolved from the carbon as it breaks down are carried away by the cathode water. The presence of trace amounts of platinum or palladium in the cathode outlet water is therefore an indication of PEMFC degradation. Monitoring the fuel-cell water at regular intervals for platinum or palladium nanoparticles is an ideal nondestructive method to examine the state of a fuel cell membrane in a way that does not interrupt the PEMFC operation. LIBS is an ideal technology to accomplish this task. LIBS has been extensively applied to liquids, solids, and particulates in general, but its application toPGE particulates, especially nanoparticles in aqueous suspensions, is very limited.

\section{Status}

The project ended on May 31, 2009. It has been previously reported that we have detected the presence of palladium and platinum nanoparticles suspended in the reformate water of fuel cells by LIBS analysis (see Figures 94-95). This is strong evidence of membrane degradation. We have demonstrated that the detection limit for palladium particulate suspensions is about 50 parts-perbillion, and we estimate that this

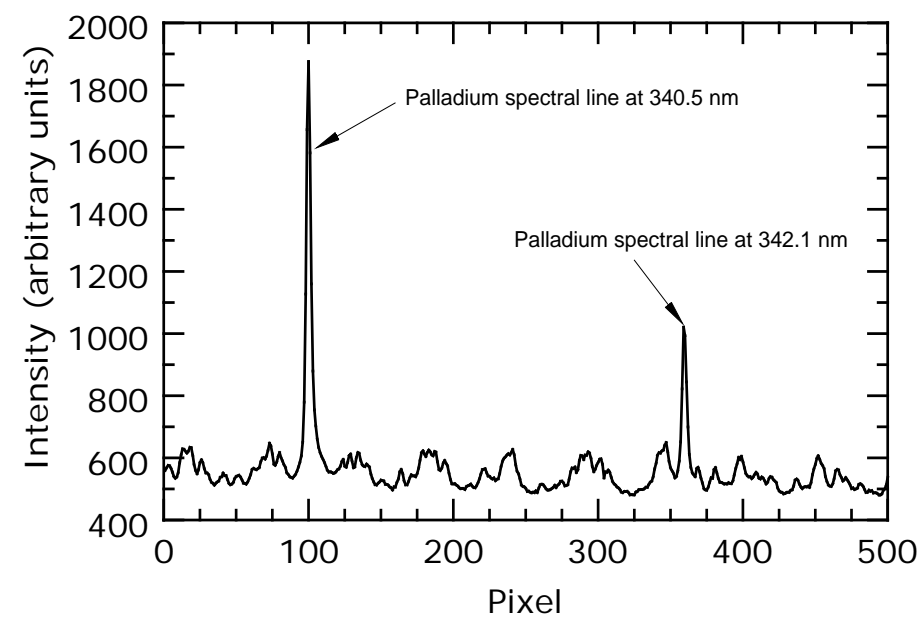

Figure 94.. Average LIBS signal from $\mathrm{Pd}$ Nanoparticles in PEMFC fuel cell water. 
could be improved by a factor of ten. Detection limits for platinum particulates are higher by about a factor of twenty.

Work during the final stage of the project focused on improving the calibration of the LIBS signal against known concentrations of palladium and platinum suspensions. In order to quantify the amount of PGEs in the fuel-cell water, it is necessary to calibrate the LIBS signals against aqueous palladium and platinum nanoparticle suspensions with

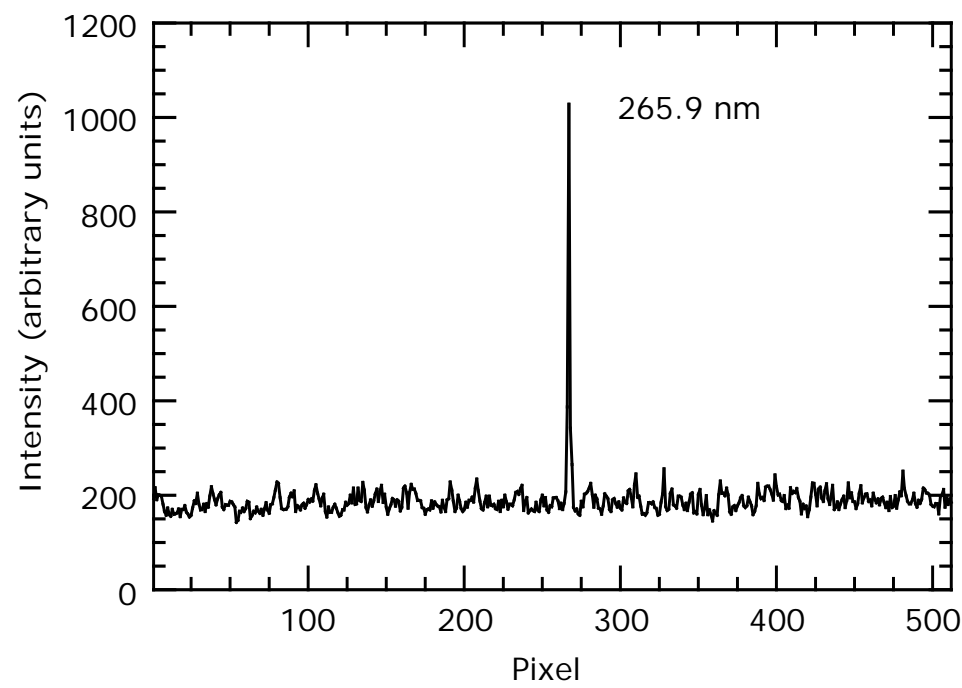
known concentrations and Figure 95. A LIBS spectrum from Pt nanoparticles in PEMFC fuel cell water.

particle size distributions. The relationship between the signal and concentration is expected to be linear. LIBS calibration data of palladium nanoparticle suspensions are nonlinear, as can be seen in Figure 96. The nonlinearity of LIBS signals as a function of concentration is the result of self absorption of the spectral signal by the vaporized species in the microplasma, and becomes significant if species concentrations become too high. To investigate this further, we did extensive measurements using concentrations of palladium chloride dissolved in water. LIBS data were taken as a function of palladium chloride concentrations ranging from $0 \mathrm{ppm}$ to $1000 \mathrm{ppm}$. The results, presented in Figure 97, clearly show a nonlinear relationship. We suspect that reason for this is that the palladium nanoparticles suspended in water tend to clump together and form large particles, as verified by particle-size measurements taken with a scanning electron microscope (see Figure 98). When the large particles are vaporized in the microplasma, the palladium concentration is so high that self

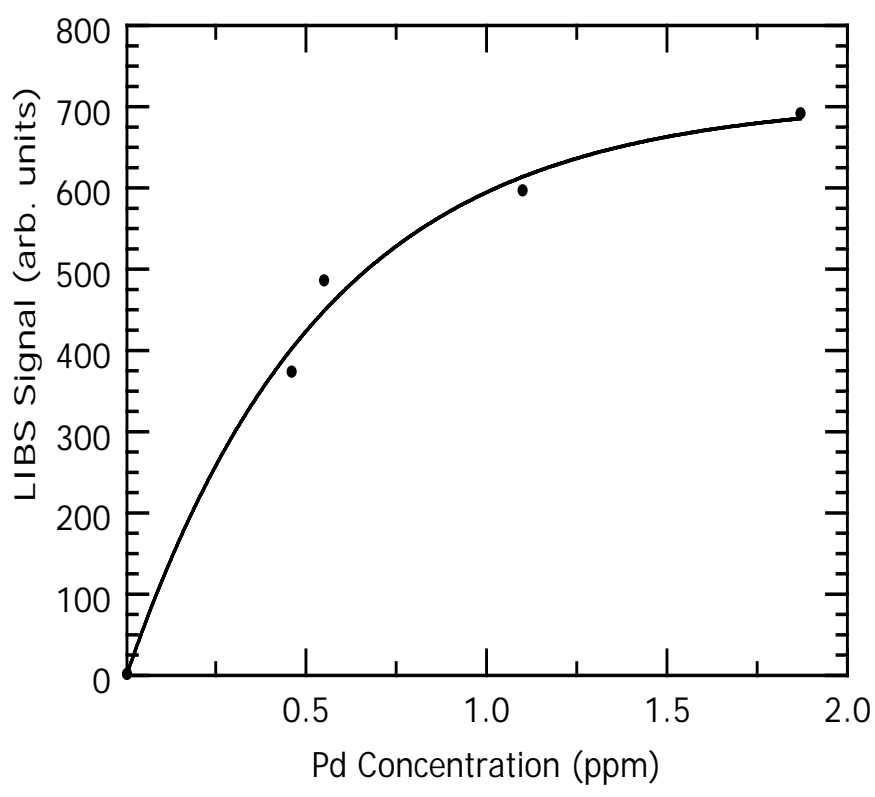

Figure 96. LIBS signal of palladium as a function of palladium particulate concentration in an aqueous suspension. The data indicates self absorption of the LIBS signal. 
absorption occurs, and the calibration curve is nonlinear. We are now confident that the calibration curve of Figure 96 is reasonable, and that self absorption is an important factor in our LIBS data.

We have demonstrated that LIBS using conditional analysis is a powerful technique for sensitive detection of nanoparticles in very dilute aqueous suspensions with a detection limit of around 50 ppb. LIBS is an extremely

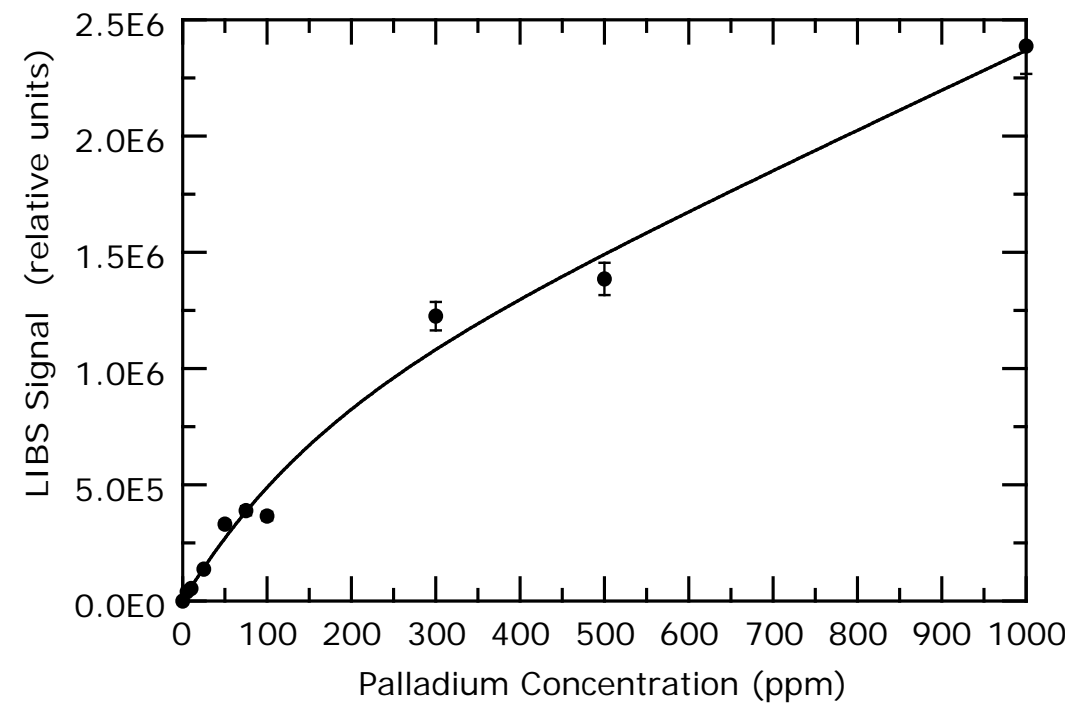
sensitive and valuable tool to study the degradation of PEMFC membranes. As mentioned above, the project has been completed. The eight fuel cell units have been removed from the MSU-Billings campus. A paper reporting the results of this work is being prepared for submission to a peer-reviewed journal.

Figure 97. LIBS signal of palladium as a function of palladium chloride concentration in water. The data indicates self absorption of the LIBS signal.

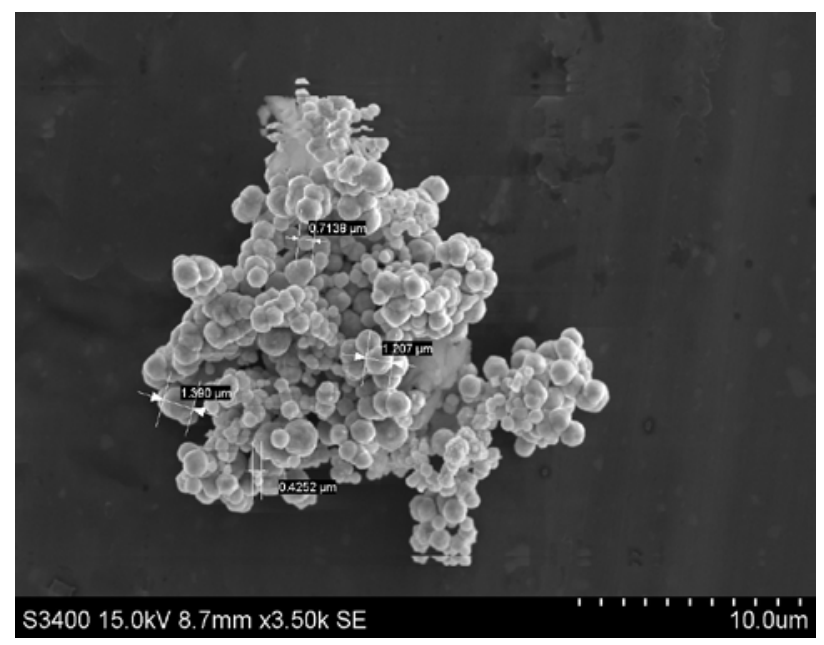

Figure 98. Palladium-particle conglomerate formed in the calibration standard. 


\section{Task 3}

Stuart Snyder, Will Wickun

Publications

S. C. Snyder and W. G. Wickun, "Detection of Trace Platinum Group Element Particulates with Laser Spectroscopy", 2007 Department of Energy Hydrogen Program Review, Washington, D. C., May 15-18, 2007.

W. G. Wickun, S. C. Snyder, "Detection of Trace Platinum Group Element Particulates with Laser Spectroscopy," Montana Academy of Science, Montana Tech, Butte, MT, 12 April 2008.

S. C. Snyder and W. G. Wickun, "Detection of Trace Platinum Group Element Particulates with Laser Spectroscopy", 2008 Department of Energy Hydrogen Program Review, Washington D. C., June 9-13, 2008

\section{Task 4: PEMFC Field Trials}

Report Period: August 1, 2006-June 1, 2010

Date of Report: April 16, 2010

Recipient: Montana State University - Billings (MSU-B)

Award Number: DE-FC36-06-G086060

Working Partners: MSU-B Facility Services, Design 3 Engineering, Ace Electric Cost-Sharing Partners: Montana-Dakota Utilities (MDU), Plug Power Co., MSU-B.

Contact: Mr. Brian Gurney (bgurney@msubillings.edu), Montana State University Billings, 406-657-2906

DOE Managers: DOE Technology Development Manager: Arlene Anderson DOE Project Officer: Katie Randolph

Project Objective: The Cause and Degree of Platinum/Palladium Dissolution and Transport in a Time-Sequenced Regimen

\section{Chronology:}

Site Installation: 1st Half of November 2007

Commissioning: 11/19/2007

Planned Maintenance: Desulf, Filters 6/9/08

PM Service/Upgrades $\quad$ 8/16/08

Fuel Cell Commissioning Ceremony: 8/14/08

1-Year Conclusion: 11/29/08

Data Collection: $\quad 12 / 4 / 08$ 


\section{TASK 4}

\section{Executive Summary}

\section{Background}

Under the umbrella of the Montana Palladium Research Initiative (MPRI), eight (8) Proton Exchange Fuel Cells (PEMFC's) were purchased. Four (4) fuel cells were configured with palladium-based Auto Thermal Reactor (ATR) catalysts and four (4) were configured with platinum-based ATR catalysts. The site was on the campus of Montana State University-Billings and commissioning took place on 19 November 2007. The site was fully operational until 18 November 2008. The goal of the project was to benchmark the performance/degradation of Pd-based ATR's vs. Pt-based ATR's. In order to support the post-project scientific analysis, it was very important that the site maximize unit 'uptime.'

\section{Operational Synopsis}

During the demonstration period there a number of issues that had to be resolved by the site project team. Some issues were fleet-wide, while some issues were unique to a specific fuel cell. For example:

- The circulating DI water in all the units had a negative interaction with the welds in the PROX catalyst vessels. This interaction discolored and released debris into the water subsystem. The result was that all eight units had to be thoroughly flushed and new filters installed.

- All the units suffered from 'condensate line failure' at some point during the demonstration period, especially in the $1^{\text {st }}$ quarter. The fuel cells were ungraded; the condensate line material and all the units were retrofitted with the new materials.

- Another water subsystem problem affected the entire fleet. Specifically, a small, plastic float at the base of a reforming vessel would fill with water and thereby fail to function as a steam trap. The fuel cell company supplied the site team with additional floats, and the design is being reengineered in the next generation product.

- Some units turned in an absolutely stellar performance (i.e. units $3 \& 6$ were over $99.5 \%$ availability during the period), while one unit (unit 8) suffered from electrical issues that the site team was never able to fully address, even with extraordinary support from -the fuel cell supplier's engineers

For the demonstration period, the overall availability/uptime for the fleet was $88.9 \%$ and the fleet generated $168 \mathrm{MW}$-hrs. of electricity. 


\section{$\underline{\text { ATR Post Operational Analysis }}$}

The fuel cell supplier selected four (4) units (2 Pt-based \& $2 \mathrm{Pt} / \mathrm{Pd}$-based) for post operational analysis. Other than PGM content, the other criteria were Run Hours and Stop/Start Cycles. One interesting observation found from the data was that the Pt only ATR catalysts actually increased hydrogen yield and decreased methane slip during the operating period. This would indicate that this particular catalyst type had not degraded during this period of operation, but it also makes predicting the effective catalyst lifetime difficult.
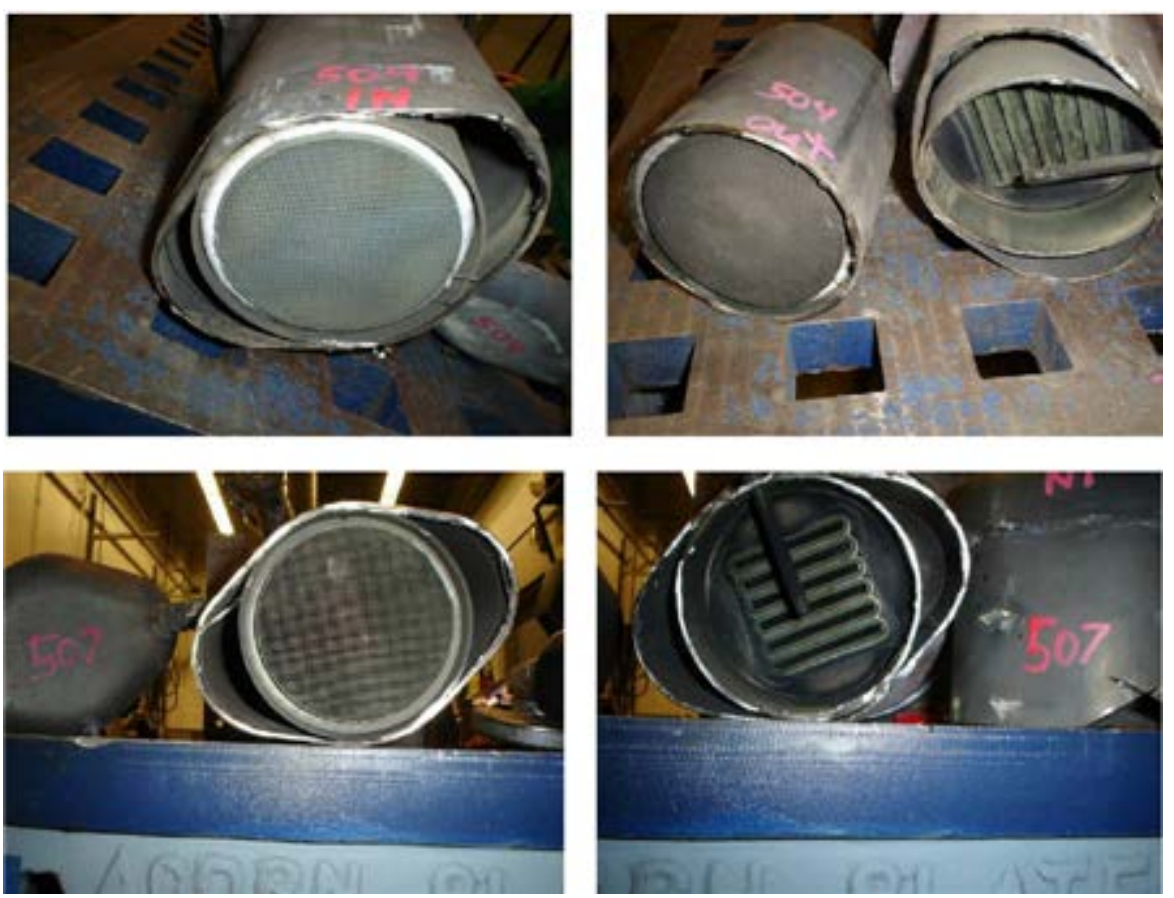

Figure 99. The ATR reactor vessels were cross-sectioned and examined.

It has been concluded that the $P d$-free ATR catalyst performs better than the catalysts which are a blend of $P t$ and $P d$.

\section{Future Research Opportunities}

- Using the data from this project, Plug Power is developing a model that will correlate field data with their accelerated life testing program.

- The site team continues to work with Plug Power and members of its supply chain to integrate and test more Pd loadings in the reforming side of the fuel cell. Four (4) fuel cells are on order with $100 \%$ Pd loadings and are scheduled to be commissioned in the summer of 2010.

- Several design changes have been incorporated in the next generation units, now manufactured in India. We will benchmark and report on the new designs which hopefully lead to a more robust system. 


\section{Palladium vs. Platinum Testing}

Testing Breakdown

- Testing included a comparison of precious metals.

- 4 systems equipped with palladium-based ATR catalysts.

- 4 systems equipped with platinum-based ATR catalysts. Note: ATR = Auto Thermal Reactor

- Testing included shorter / longer run hours.

- 2 systems with $8600+$ run hours.

- 2 systems with $<6500$ run hours.

- Testing included low / high cycles.

- 2 systems with $\sim 75$ startups.

- 2 systems with $<5$ startups.

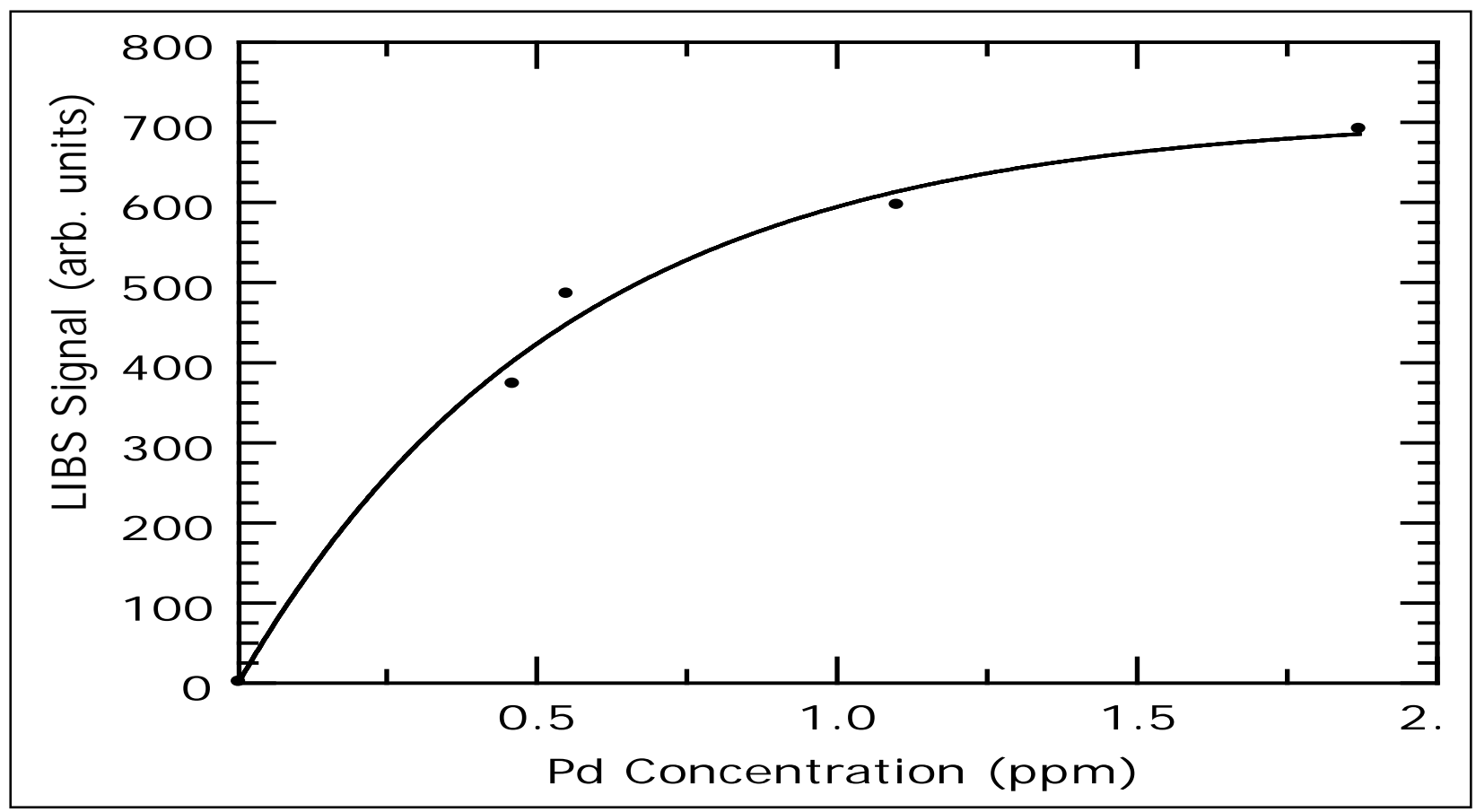




\section{Reliability Metrics}

- Metrics are broken into two groups:

1. Commissioning to End

$(11 / 18 / 07$ to $12 / 04 / 08)$

\begin{tabular}{|c|c|c|c|c|}
\hline \multicolumn{5}{|c|}{ Metrics Since Commissioning (11/18/08 to $12 / 04 / 08)$} \\
\hline System & Total Time & Stack Run Hours & Availability & Stack kW-hr \\
\hline $2 \mathrm{~B} 501$ & 9065.1 & 7554.18 & $83.3 \%$ & 19123.87 \\
\hline $2 \mathrm{~B} 502$ & 9065.5 & 5773.72 & $63.7 \%$ & 17999.98 \\
\hline $2 \mathrm{~B} 503$ & 9111.2 & 9111.17 & $100.0 \%$ & 28332.5 \\
\hline $2 \mathrm{~B} 504$ & 9065.6 & 7690.88 & $84.8 \%$ & 23740.84 \\
\hline $2 \mathrm{~B} 505$ & 9064.5 & 6468.74 & $71.4 \%$ & 19776.84 \\
\hline 2B506 & 9615.2 & 9615.2 & $100.0 \%$ & 29234.72 \\
\hline $2 \mathrm{~B} 507$ & 9064.6 & 8619.66 & $95.1 \%$ & 27037.78 \\
\hline $2 \mathrm{~B} 508$ & 9064.6 & 6411.25 & $70.7 \%$ & 20603.45 \\
\hline Sum & 73116.2 & 61244.8 & $83.8 \%$ & 185849.98 \\
\hline
\end{tabular}

2. Since Flush to End

$(1 / 12 / 08$ to $12 / 04 / 08)$

\begin{tabular}{|c|c|c|c|c|c|c|}
\hline \multicolumn{2}{|c|}{ Metrics Since Flush (1/12/08 to 12/04/08) } \\
\hline System & Total Time & Current Stack Hours & Stack Hrs @ 1/12/08 & Total Stack Hours & Availability & Stack kW-hr \\
\hline 2 B501 & 7845.1 & 7883.65 & 420.87 & 7462.78 & $95.13 \%$ & 22183.21 \\
\hline 28502 & 7845.5 & 5902.01 & 263.77 & 5638.24 & $71.87 \%$ & 17094.11 \\
\hline 28503 & 7845.6 & 9331.13 & 1497.66 & 7833.47 & $99.85 \%$ & 23772.69 \\
\hline 28504 & 7845.6 & 7960.77 & 1549.41 & 6411.36 & $81.72 \%$ & 18731.16 \\
\hline 28505 & 7844.5 & 6580.22 & 259.17 & 6321.05 & $80.58 \%$ & 19054.03 \\
\hline 28506 & 7842.6 & 9830.62 & 1478.01 & 8352.61 & $100.00 \%$ & 24528.38 \\
\hline 28507 & 7844.6 & 8793.58 & 1446.47 & 7347.11 & $93.66 \%$ & 22625.5 \\
\hline 28508 & 7844.6 & 6532.44 & 170.66 & 6361.78 & $81.10 \%$ & 20047.74 \\
\hline Sum & 62758.0 & & & 55728.4 & $88.80 \%$ & 168036.82 \\
\hline
\end{tabular}

Note:

System Flush: 1/8/08 to 1/11/08

(A supplier manufacturing defect prompted the use of remanufactured PROX catalyst assemblies. These assemblies released debris into the water subsystem, which caused operational issues and required a flush for proper fuel cell demonstration.) 


\section{Reliability Issues / Metrics}

(Unique, Isolated Failures)

\begin{tabular}{|c|c|c|c|}
\hline IR & $\begin{array}{c}\text { Serial } \\
\text { Number }\end{array}$ & $\begin{array}{c}\text { Occurrence } \\
\text { Date }\end{array}$ & Failed Part \\
\hline 30374 & 2 B508 & $11 / 27 / 200715: 01$ & PCM Failure \\
\hline 30406 & $2 \mathrm{~B} 505$ & $11 / 28 / 200723: 22$ & UCC Reset (Software Crash) \\
\hline 31013 & $2 \mathrm{~B} 501$ & $1 / 4 / 200810: 21$ & ATR Float Failure \\
\hline 31227 & $2 \mathrm{~B} 501$ & $1 / 16 / 20089: 42$ & Scanner Interface Card Failure \\
\hline 31494 & $2 \mathrm{~B} 504$ & $1 / 30 / 200822: 35$ & Scanner Interface Card Failure \\
\hline 31693 & $2 \mathrm{~B} 505$ & $2 / / / 200815: 40$ & Condensate Line Failure \\
\hline 33631 & $2 \mathrm{~B} 507$ & $5 / 16 / 200815: 26$ & Stack Out Temp High - Loss of Coolant \\
\hline 33698 & $2 \mathrm{~B} 502$ & $5 / 22 / 20080: 57$ & Stack Out Temp High - Loss of Coolant \\
\hline 33701 & $2 \mathrm{~B} 505$ & $5 / 22 / 20081: 02$ & Stack Out Temp High - Loss of Coolant \\
\hline 33703 & $2 \mathrm{~B} 507$ & $5 / 22 / 20081: 05$ & Stack Out Temp High - Loss of Coolant \\
\hline 33906 & $2 \mathrm{~B} 504$ & $6 / 10 / 200810: 09$ & Condensate Line Failure \\
\hline 34139 & $2 \mathrm{~B} 508$ & $6 / 23 / 200822: 23$ & Condensate Line Failure \\
\hline 34140 & $2 \mathrm{~B} 502$ & $6 / 23 / 200822: 32$ & Loss of Water - Exhaust Radiator Assembly \\
\hline 34141 & $2 \mathrm{~B} 506$ & $6 / 23 / 200822: 39$ & Condensate Line Failure \\
\hline 34245 & $2 \mathrm{~B} 505$ & $7 / 1 / 200818: 03$ & Fuel/Air Blower Failure \\
\hline 34367 & $2 \mathrm{~B} 505$ & $7 / 15 / 200810: 08$ & ATR Float Failure \\
\hline 34575 & $2 \mathrm{~B} 501$ & $7 / 31 / 20087: 54$ & ATR Float Valve \\
\hline 34770 & $2 \mathrm{~B} 505$ & $8 / 13 / 200815: 00$ & UCC Failure \\
\hline 35103 & $2 \mathrm{~B} 501$ & $10 / 16 / 200813: 21$ & IOB Failure \\
\hline 34772 & $2 \mathrm{~B} 501$ & $9 / 4 / 20088: 37$ & Loud Exhaust Fan \\
\hline 34950 & $2 \mathrm{~B} 502$ & $10 / 200814: 44$ & Stack Failure \\
\hline 34951 & $2 \mathrm{~B} 504$ & $10 / 2 / 200814: 47$ & Stack Failure \\
\hline 34771 & $2 \mathrm{~B} 505$ & $9 / 4 / 20088: 34$ & UCC Failure \\
\hline 34784 & $2 \mathrm{~B} 507$ & $9 / 4 / 20088: 34$ & TC Failure \\
\hline 34866 & $2 \mathrm{~B} 507$ & $9 / 16 / 200814: 48$ & TCO Failure \\
\hline 34826 & $2 \mathrm{~B} 508$ & $9 / 11 / 200815: 35$ & CTS Failure \\
\hline 36262 & $2 \mathrm{~B} 502$ & $12 / 4 / 200815: 59$ & Undefined Electrical Issues \\
\hline 36263 & $2 \mathrm{~B} 508$ & $12 / 4 / 200816: 00$ & \\
\hline & & & \\
\hline
\end{tabular}




\section{Site Pictures}

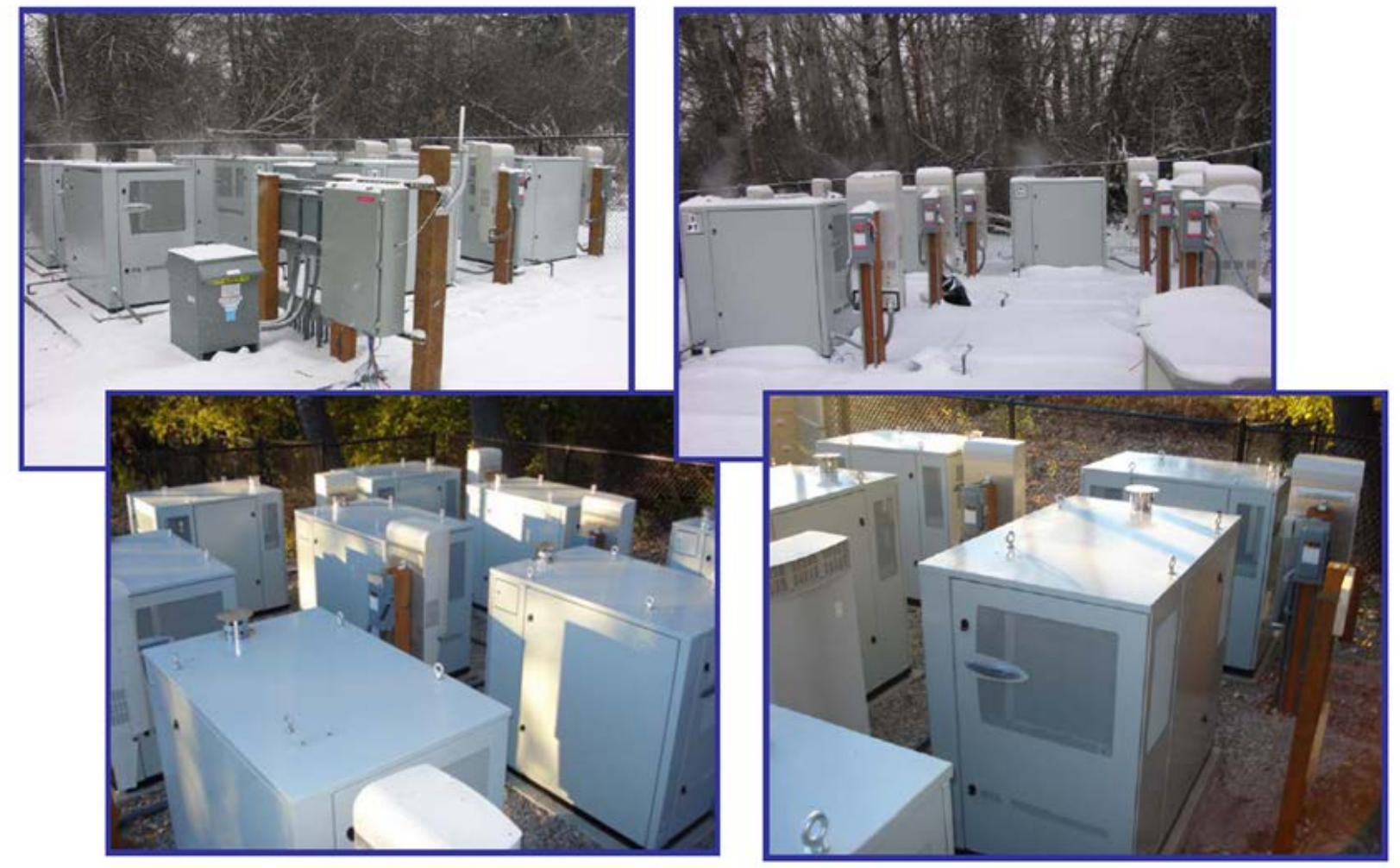

\section{Montana Palladium Research Initiative Ceremony Pictures}

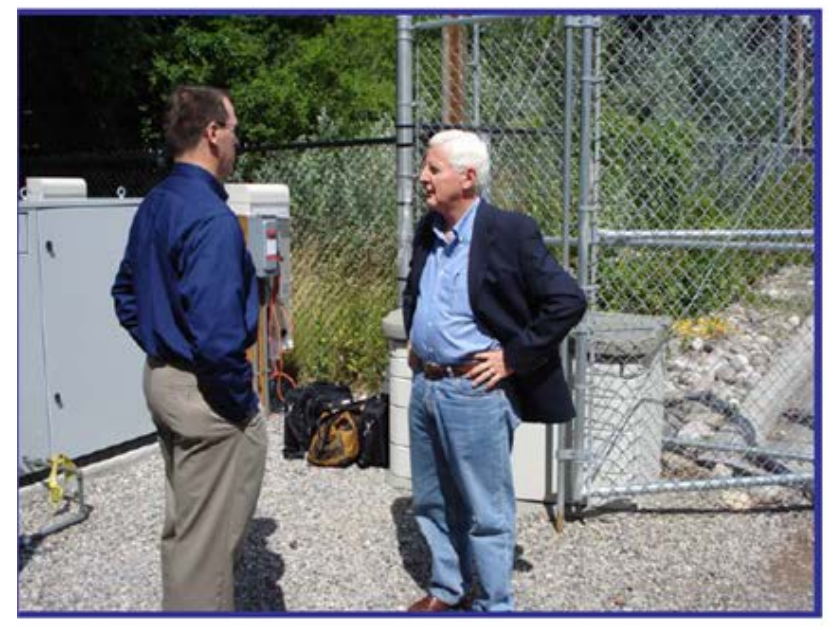

Frank McAllister, President of Stillwater Mining Company
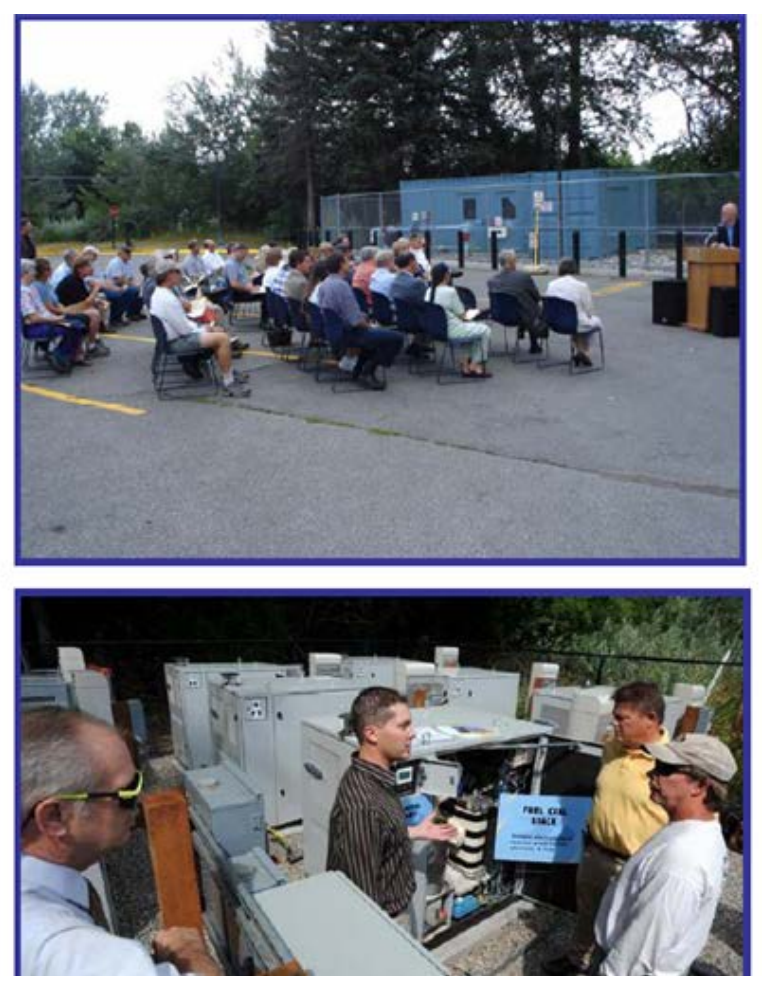


\subsection{Fuel Cell (GenSys) Post Operation Analysis}

The two main factors that affect catalyst activity and heat exchanger effectiveness are the number of start-up and shut-down cycles and the total accumulated run time a reformer experiences. For the eight system fleet at MSUB, we were fortunate to have some systems accumulate several cycles while others accumulated significantly more runtime. For the firwst step of the analysis, we selected the system for each ATR catalyst type that had accumulated the most run hours and the most start-stops for destructive analysis (Table 16). This approach left the machines with less cycles and run hours available for destructive analysis if necessary but able to be operated further in the results from the destructive testing of the most stressed systems proved inconclusive.

\begin{tabular}{|c|c|c|c|}
\hline System & ATR Type & Run Hours & Cycles \\
\hline 2B503 & $\mathrm{Pt}$ & 5638 & 75 \\
\hline 2B504 & $\mathrm{Pt}$ & 6411 & 15 \\
\hline 2B507 & $\mathrm{Pt}, \mathrm{Pd}$ & 7347 & 20 \\
\hline 2B508 & $\mathrm{Pt}, \mathrm{Pd}$ & 6362 & 75 \\
\hline
\end{tabular}

Table 16. Characteristics of units undergoing destructive analysis.

\subsection{Conclusions and Future Planned Activities}

The one-year period of operation and post-operation analysis have provided valuable data to use in determining what steps to take to improve reformer and system design in general, and specifically for the GenSys product. It has been concluded that the palladium free ATR catalyst performs better than the catalysts, which are a blend of platinum and palladium. While most of the catalysts show margin against which design specifications, improvements can be madein both performance and reduction in part to variation for the PrOx and ATO. Based on these results the four remaining systems were returned to Plug Power's Latham facility where they will continue to operate to collect additional runtime. It is currently expected that at least an additional year of operation should be accumulated before further destructive analysis occurs.

Using the dataset from these catalysts, Plug Power will attempt to develop a correlation between accelerated life testing methods and field data. Once proven, these accelerated test protocols can be used to test new catalyst formulations at a faster rate than simply allowing a part to accumulate operating hours at the same rate as calendar time. This would be a huge benefit to program schedules and cost as lifetimes improve to multiple year durations.

\section{Task 4: No publications/presentations}




\section{TABLE OF FIGURES}

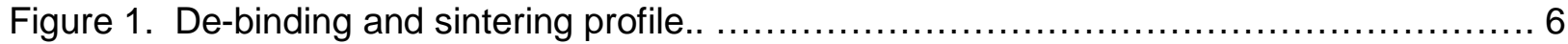

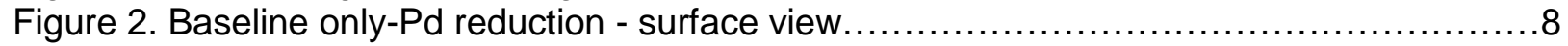

Figure 3. Photomicrograph of the baseline infiltration/sensitization/activation/Pd reduction.......8

Figure 4. SEM/EDX spectra of the baseline infiltration/sensitization/activation/Pd reduction.......9

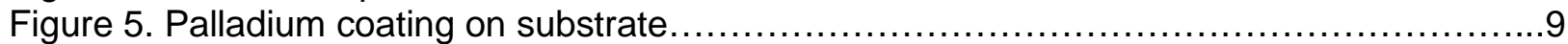

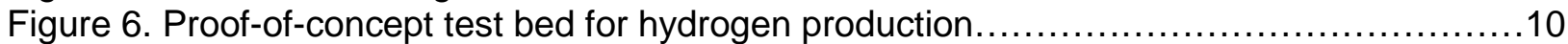

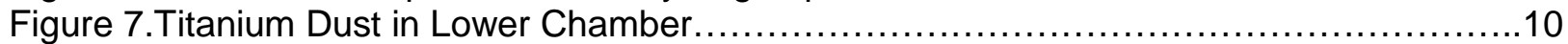

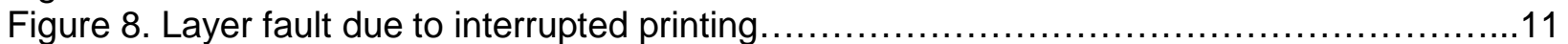

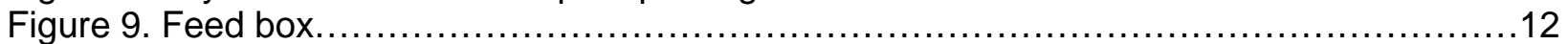

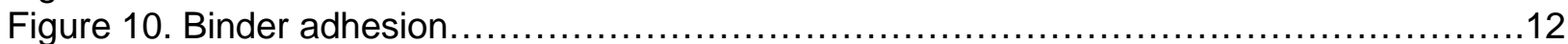

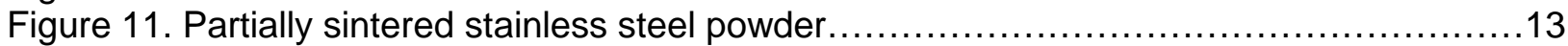

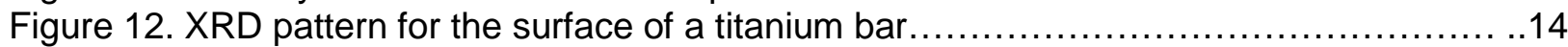

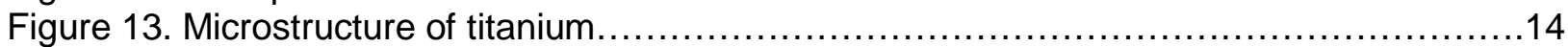

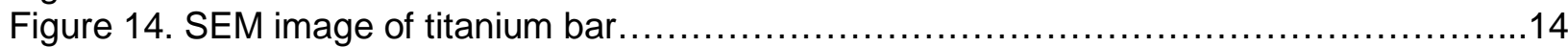

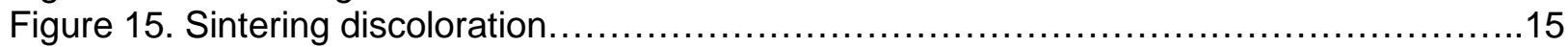

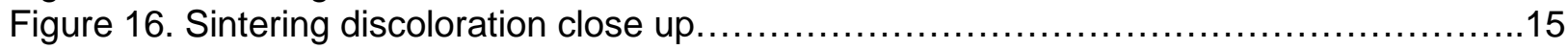

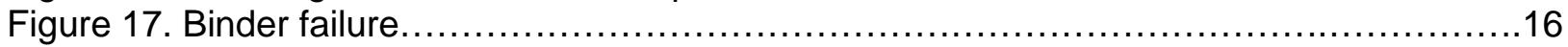

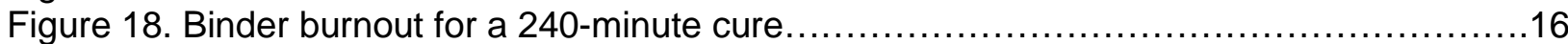

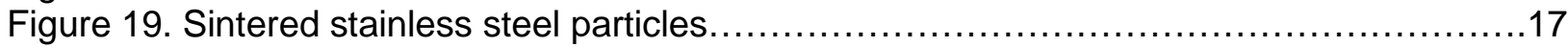

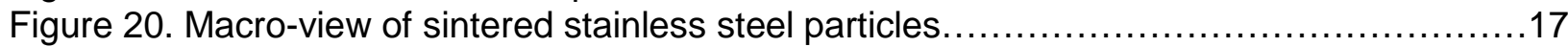

Figure 21. Test shields used to evaluate both the process and the parts......................17

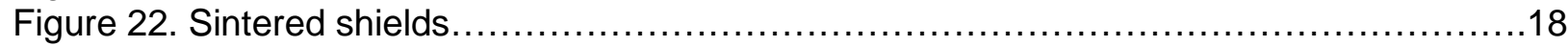

Figure 23. CAD drawing and dimensions of Montana Tech shield $\ldots \ldots \ldots \ldots \ldots \ldots \ldots \ldots \ldots \ldots \ldots$

Figure 24 . Size analysis between CAD drawing and sintered product.......................... 18

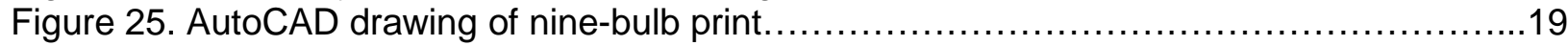

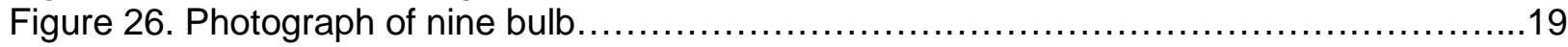

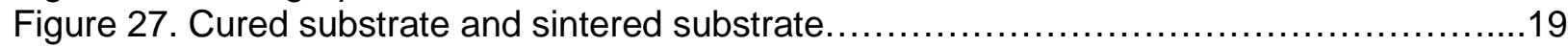

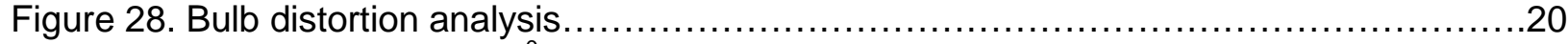

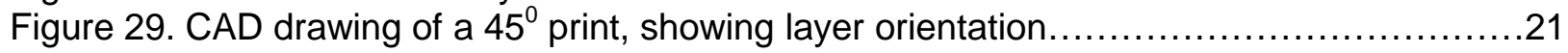

Figure 30. Concept test setup for measuring flexural frequency of specimen...................21

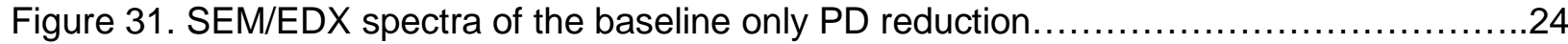

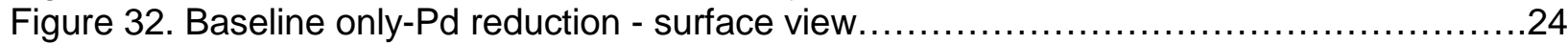

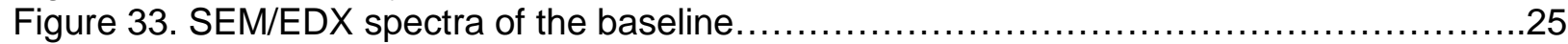

Figure 34: Photomicrograph of the baseline sensitization/activation/Pd reduction..............25

Figure 35: SEM/EDX spectra of the baseline infiltration/sensitization/activation/Pd reduction...25

Figure 36. Photomicrograph of the baseline infiltration/sensitization/activation/Pd reduction....26

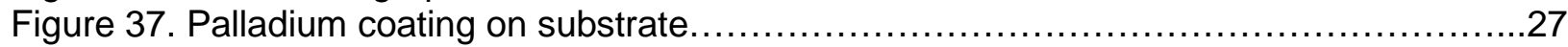

Figure 38: SEM image on stainless steel substrate from matrix testing (no 15) .................28

Figure 39. SEM image of stainless steel substrate from matrix testing (no. 11) .................28

Figure 40. SEM image of stainless steel substrate from matrix testing (no. 17) .................29

Figure 41. SEM image of stainless steel substrate from matrix testing (no. 12) ..................29

Figure 42. SEM image of stainless steel substrate from matrix testing (no. 14) ..................30

Figure 43. $\mathrm{Hg}$ forced under pressure into the Pd-coated substrates...........................30

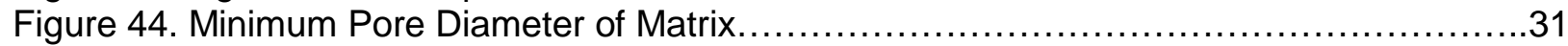

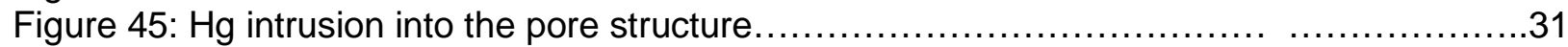

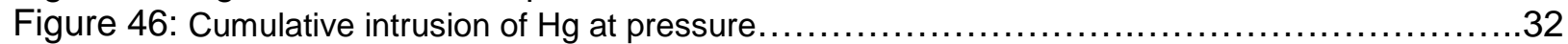

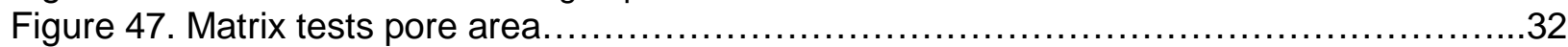

Figure 48. 3-D representation of the influence of variables on " $D$ " response ......................34

Figure 49. 3-D representation of the influence of variables on "E" response.......................34 


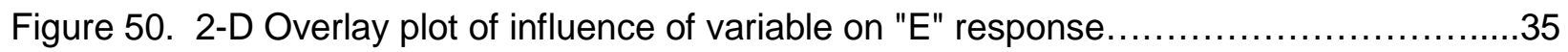

Figure 51. 3-D representation of the influence of variable on "F" response....................35

Figure 52. Contour representation of the influence of variable on "F" response.................36

Figure 53. 3-D representation of the influence of variables on the "H" response................36

Figure 54. Contour representation of the influence of variables on "H" response................37

Figure 55. 3-D representation of the influence of variables on the "l" response.................38

Figure 56. 3-D representation of the influence of variable on the "I" response.................38

Figure 57. 2-D Overlay representation of the influence of variables on "I" response...............39

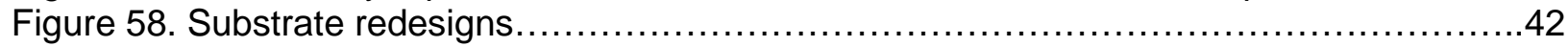

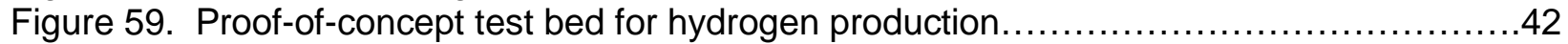

Figure 60. Top view of 15 -minute $\mathrm{Pd}$ reduction reaction on SS substrate $\ldots \ldots \ldots \ldots \ldots \ldots \ldots \ldots . \ldots . \ldots \ldots$

Figure 61 . Bottom view of 15 -minute Pd reduction reaction on SS substrate $\ldots \ldots \ldots \ldots \ldots \ldots \ldots 44$

Figure 62 . Top view of 30 -minute $\mathrm{Pd}$ reduction reaction on SS substrate .....................44

Figure 63: Bottom view of 30-minute Pd reduction reaction on SS substrate $\ldots \ldots \ldots \ldots \ldots \ldots \ldots 44$

Figure 64: Top view of 60 -minute $\mathrm{Pd}$ reduction reaction on SS substrate $\ldots \ldots \ldots \ldots \ldots \ldots \ldots \ldots \ldots \ldots$

Figure 65 . Bottom view of 60 -minute Pd reduction reaction on SS substrate $\ldots \ldots \ldots \ldots \ldots \ldots \ldots . \ldots 45$

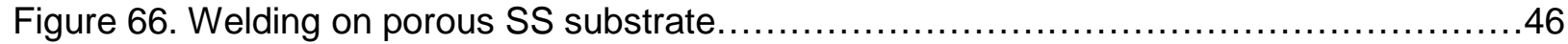

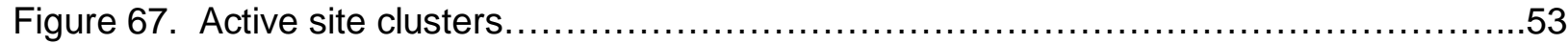

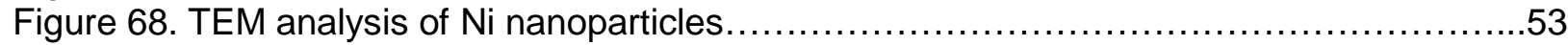

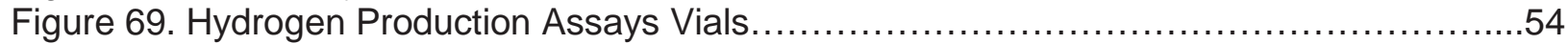

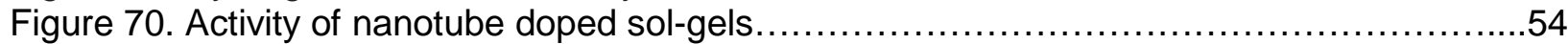

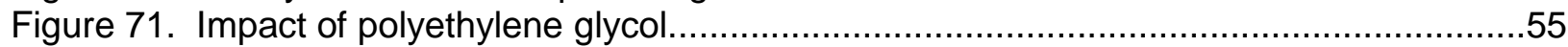

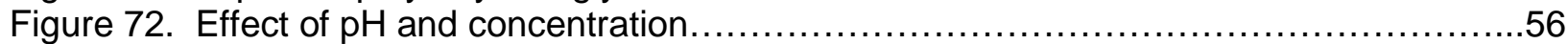

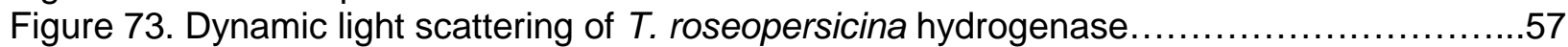

Figure 74 . High resolution structure of $T$. roseopersicina hydrogenase $\ldots \ldots \ldots \ldots \ldots \ldots \ldots \ldots \ldots \ldots$

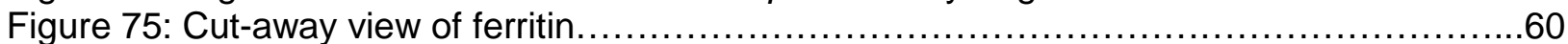

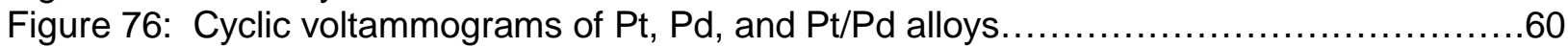

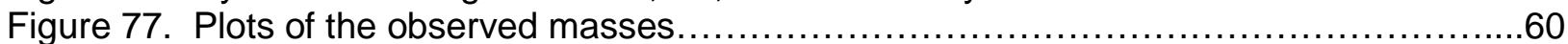

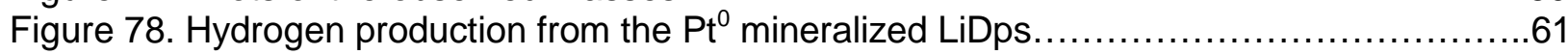

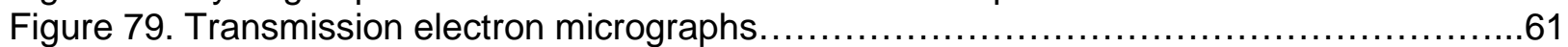

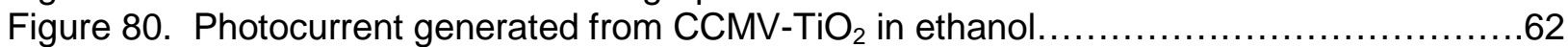

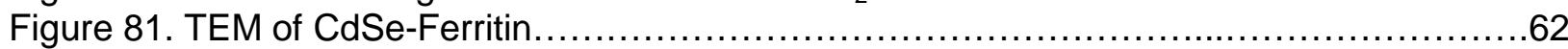

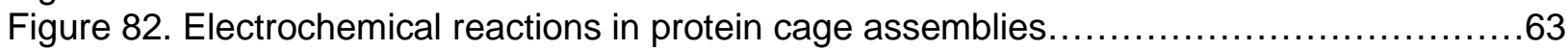

Figure 83. A schematic for the covalent attachment terminal amine on a protein................64

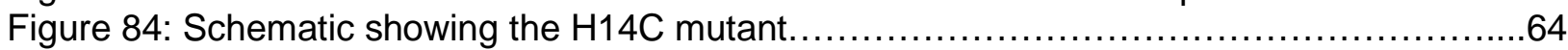

Figure 85. Electron transport from a redox couple conjugated to a protein cage.................65

Figure 86. Electron transport from reduction of protons to hydrogen . .........................66

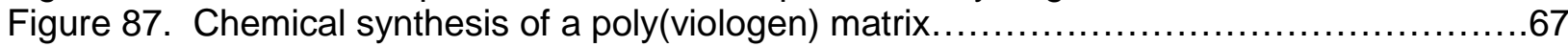

Figure 88. An SEM of the partially crosslinked poly(viologen) matrix .......................68

Figure 89. Schematic of the synthesis of a viologen - azide building bock .....................68

Figure 90. Hexagonally packed, two-dimensional arrays of protein cages....................69

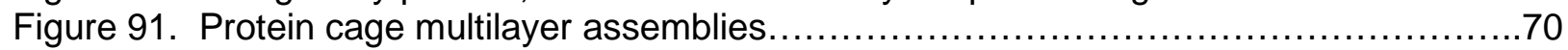

Figure 92. Aschematic of the photocurrent measurement of protein cage semiconductors......71

Figure93. The LIBS signal of palladium particles in fuel-cell reformate water...................75

Figure 94.. Average LIBS signal from Pd Nanoparticles in PEMFC fuel cell water................76

Figure 95. A LIBS spectrum from Pt nanoparticles in PEMFC fuel cell water....................77

Figure 96. LIBS signal of palladium as a function of palladium particulate concentration.........77

Figure 97. LIBS signal of palladium as a function of palladium chloride concentration...........78

Figure 98. Palladium-particle conglomerate formed in the calibration standard .................78

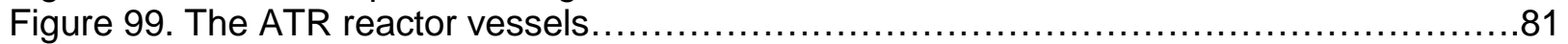




\section{TABLE OF TABLES}

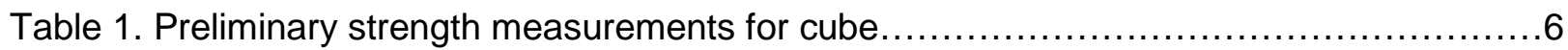

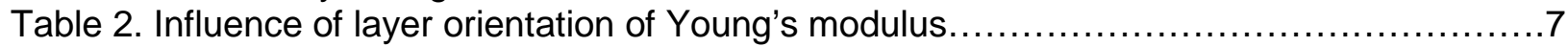

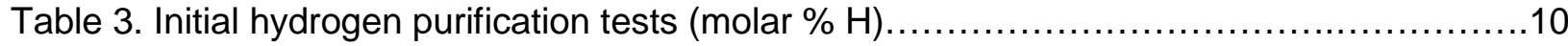

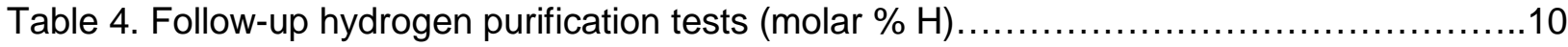

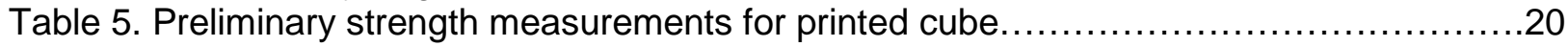

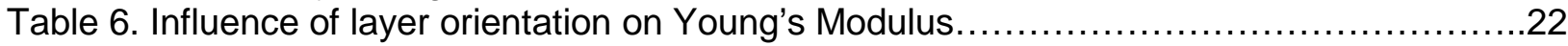

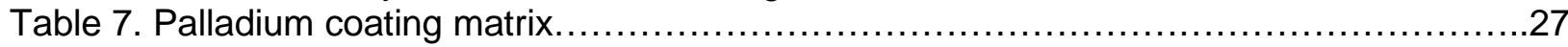

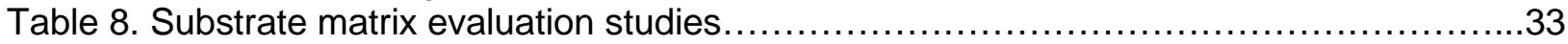

Table 9. Metal powder printing and sintering system capital cost estimate $\ldots \ldots \ldots \ldots \ldots \ldots \ldots \ldots 40$

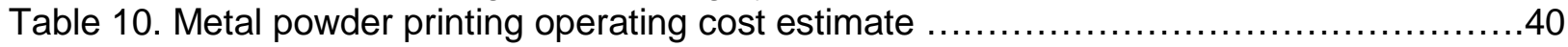

Table 11. Metal powder printing operating cost comparis on, titanium vs. stainless steel........41

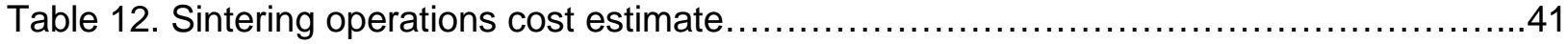

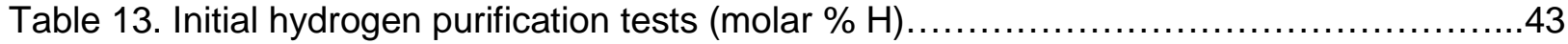

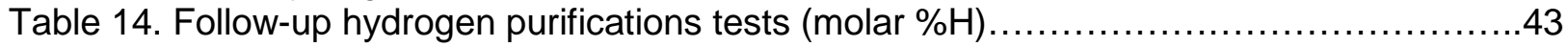

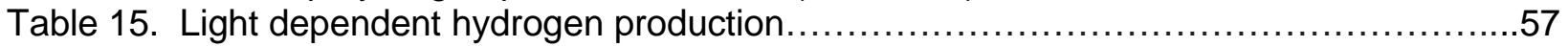

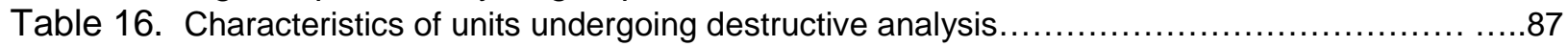

